Luciano Martinez Stefanini

\title{
Efeitos da Camada Limite Térmica na Formação de Gelo em Aerofólios de Uso Aeronáutico
}

\author{
Dissertação apresentada à Escola Po- \\ litécnica da Universidade de São Paulo \\ para obtenção de Título de Mestre em \\ Engenharia Mecânica
}




\title{
Luciano Martinez Stefanini
}

\section{Efeitos da Camada Limite Térmica na Formação de Gelo em Aerofólios de Uso Aeronáutico}

\author{
Dissertação apresentada à Escola Po- \\ litécnica da Universidade de São Paulo \\ para obtenção de Título de Mestre em \\ Engenharia Mecânica \\ Área de Concentração: \\ Engenharia Mecânica \\ Orientador: \\ Prof. Livre Docente Otávio de \\ Mattos Silvares
}




\section{Ficha Catalográfica}

Stefanini, Luciano Martinez

Efeitos da Camada Limite Térmica na Formação de Gelo em Aerofólios de Uso Aeronáutico/ L.M. Stefanini - São Paulo, 2009. 73 p.

Dissertação (Mestrado) - Escola Politécnica da Universidade de São Paulo. Departamento de Engenharia Mecânica.

1.Transferência de Calor 2.Aerodinâmica de Aeronaves 3.Aeronaves I.Universidade de São Paulo. Escola Politécnica. Departamento de Engenharia Mecânica II. t. 
Aos meus pais. 


\section{Agradecimentos}

Ao amigo e orientador Prof. Otávio de Mattos Silvares pela orientação precisa, objetiva, e pelo apoio durante todo o desenvolvimento deste projeto.

Ao amigo Prof. Euryale Jorge Godoy de Jesus Zerbini pelos comentários, sugestões, e pelo apoio na elaboração dos artigos.

Ao amigo Guilherme Araújo Lima da Silva pelo incentivo, motivação, ajuda e sugestões neste projeto e nos artigos.

À Gerência de Sistemas Ambientais da Empresa Brasileira de Aeronáutica, Embraer, pelo apoio durante o início deste projeto.

À Diretoria da Dynamis Engenharia Aplicada, pelo apoio durante os dois últimos anos. 


\section{Resumo}

O modelo de avaliação da camada limite dinâmica e térmica foi implementado, no presente trabalho, em um código numérico para o cálculo do coeficiente de transferência de calor convectivo sobre aerofólios de uso aeronáutico com formação de gelo. Foram considerados, no modelo da camada limite turbulenta, os efeitos da rugosidade equivalente do grão de areia $k_{s}$, e transição entre o regime laminar e turbulento foi avaliada por dois modelos, um abrupto e um suave. Para a transição suave foi utilizada uma função intermitência proposta por (ABUGHANNAM; SHAW, 1980). O código desenvolvido neste trabalho foi acoplado aos módulos do código ONERA com o objetivo de simular as formas de gelo em aerofólios para diversas condições de escoamento do ar com conteúdo de água. As formas de gelo obtidas foram comparadas com dados experimentais de Shin e Bond (1994) e com resultados de simulações dos códigos LEWICE, TRAJICE e ONERA (KIND, 2001). Os resultados das simulações do presente trabalho apresentaram boa semelhança com os resultados dos outros códigos. A simulação da previsão de formas de gelo do tipo Glaze, do presente trabalho e dos outros códigos, resultou em formas de gelo de espessura e volume menores que as formas experimentais. Foi verificado que uma previsão adequada do coeficiente de transferência de calor convectivo afeta a simulação das formas deste tipo de gelo. Um caso de Kind (2001) foi utilizado para avaliar os efeitos dos parâmetros da camada limite dinâmica e térmica na formação de gelo em aerofólios. Verificou-se que a posição do início da transição do regime laminar para o turbulento, o comprimento da transição e o valor da rugosidade afetam a forma, a espessura e o volume do gelo, e que estes parâmetros podem ser utilizados para ajustes dos modelos de camada limite para melhores previsões de formas de gelo do tipo Glaze. 


\section{Abstract}

The model to evaluate the momentum and thermal boundary layer was implemented, in the present work, in a numerical module to calculate the convective heat transfer coefficient over aeronautical airfoils with ice accretion. It was considered, in the turbulent boundary layer model, the effects of the equivalent sand grain roughness $k_{s}$, and the laminar to turbulent transition was evaluated with two models, the abrupt and the smooth one. The smooth transition model used an intermittency function proposed by (ABU-GHANNAM; SHAW, 1980). The module developed in this work was integrated with the modules of the code ONERA in order to simulate the airfoil icing shapes for several air stream with water droplets condition. The ice shapes obtained was compared with experimental data of Shin e Bond (1994) and with simulation results for the codes LEWICE, TRAJICE e ONERA (KIND, 2001). The results of the simulations for the present work showed a good similarity with the other codes results. The Glaze icing shapes simulation, in the present work and in the other codes, resulted in icing shapes with thickness and volumes lesser than the experimental shapes. It was noted that a reasonable prediction of the convective heat transfer coefficient affects the simulation of this type of ice shape. One case of Kind (2001) was used to evaluate the effects of the momentum and thermal boundary layer for the icing accreations in the airfoil. It was noted the onset position, the lenght of the laminar-turbulent transition, and the sand grain roughness value affects the icing shape, thickness and volume and this parameters might be used to adjust the boundary layer models in order to get better predictions of Glaze icing shapes. 


\section{Sumário}

\section{Lista de Figuras}

\section{Lista de Tabelas}

\section{Lista de Abreviaturas e Siglas}

\section{Lista de Símbolos}

1 Introdução 1

1.1 Tipos de Gelo . . . . . . . . . . . . . . . . . 4

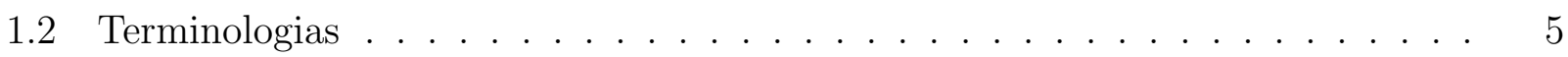

1.2.1 Conteúdo de Água Líquida . . . . . . . . . . . . . . . . . . . . 5

1.2.2 Diâmetro Mediano Volumétrico . . . . . . . . . . . . . . . . . 5

1.2.3 Eficiência de Coleta Local . . . . . . . . . . . . . . . . . 5

1.2.4 Fração de Congelamento . . . . . . . . . . . . . . 6

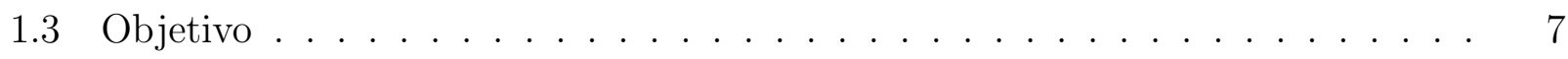

2 Revisão Bibliográfica $\quad 8$

2.1 Referências Básicas . . . . . . . . . . . . . . . . . . 8

2.2 Programas de Simulação de Formação de Gelo . . . . . . . . . . . . . . . . . . 11

2.3 Efeitos Aerodinâmicos da Formação de Gelo . . . . . . . . . . . . . . . . . 15

3 Modelo Matemático $\quad 18$

3.1 Camada Limite Laminar . . . . . . . . . . . . . . . . . . . . 18

3.1.1 Camada Limite da Quantidade de Movimento . . . . . . . . . . . . 18 
3.1 .2 Camada Limite Térmica . . . . . . . . . . . . . . . . . . . 19

3.2 Camada Limite Turbulenta . . . . . . . . . . . . . . . . . . . . . . 20

3.2.1 Camada Limite da Quantidade de Movimento . . . . . . . . . . . . . 20

3.2.2 Camada Limite Térmica Turbulenta sobre uma Superfície Rugosa . . . 21

3.3 Transição Laminar-Turbulenta . . . . . . . . . . . . . . . . . . . . . . . . . . . 23

3.4 Rugosidade Equivalente do Grão de Areia . . . . . . . . . . . . . . . . . . . . 24

4 Implementação do Modelo $\quad 25$

4.1 Pré e Pós Processamento . . . . . . . . . . . . . . . . . . 25

4.2 Implementação do Código de Transferência de Calor . . . . . . . . . . . . . . . 29

4.3 Parâmetros de Similaridade . . . . . . . . . . . . . . . . . . 31

5 Resultados 33

5.1 Formação de Gelo sobre Aerofólios . . . . . . . . . . . . . . . . . . 33

5.2 Efeito Aerodinâmico da Formação de Gelo em Aerofólios de Uso Aeronáutico . 47

$\begin{array}{lll}6 & \text { Discussão } & 53\end{array}$

7 Conclusões e Próximos Trabalhos $\quad 65$

7.1 Conclusões . . . . . . . . . . . . . . . . . . . 65

7.2 Próximos Trabalhos . . . . . . . . . . . . . . . . . 67

$\begin{array}{ll}\text { Referências } & 68\end{array}$ 


\section{Lista de Figuras}

1.1 Efeito de vários tipos de formas de gelo no desempenho aerodinâmico de um

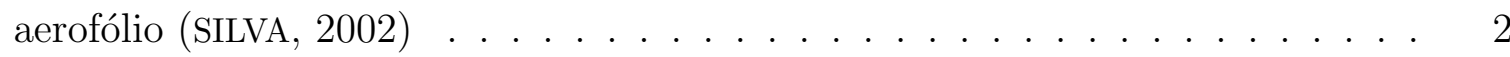

1.2 Superfícies das aeronaves sujeitas à formação de gelo (HEINRICH et al., 1991) 2

1.3 Exemplo de formações de gelo em aerofólios (NASA, 2009) . . . . . . . . . . . 3

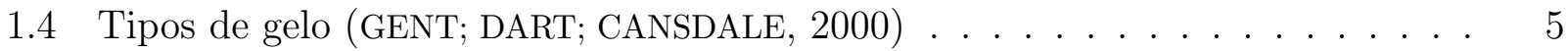

1.5 Definição de Eficiência de Coleta Local $\beta(s) \ldots \ldots$. . . . . . . . . . 6

1.6 Integração do módulo de transferência de calor do presente trabalho com os módulos do código ONERA . . . . . . . . . . . . . . . . . . . . . 7

2.1 Formação de gelo em linha de 22kV em Voss, Noruega (MAKKOnEN, 2000) . 10

4.1 Malha $C$ completa dos escoamento potencial . . . . . . . . . . . . . 26

4.2 Malha computacional ao redor do aerofólio . . . . . . . . . . . . . . . . . 27

4.3 Trajetória de Partículas ao redor do Aerofólio . . . . . . . . . . . . . . . . 28

4.4 Volume de Controle infinitesimal para aplicação da primeira lei da termodinâmica à água acumulada sobre o aerofólio . . . . . . . . . . . . . . . . . . . . . . 29

4.5 Domínios (I, II e III) e sistemas de coordenadas utilizadas no modelo matemático 30

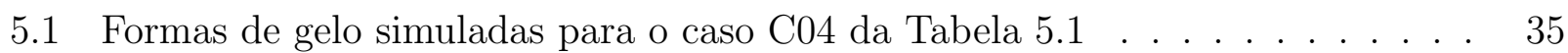

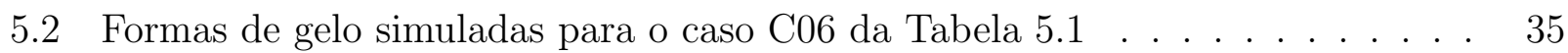

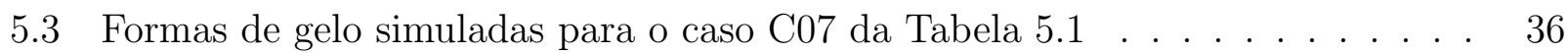

5.4 Formas de gelo simuladas para o caso C13 da Tabela $5.1 \quad \ldots . . . .37$

5.5 Formas de gelo simuladas para o caso C14 da Tabela $5.1 \ldots$. . . . . . . . . . 37

5.6 Formas de gelo simuladas para o caso C17 da Tabela $5.1 \ldots$. . . . . . . . . . 38

5.7 Formas de gelo simuladas para o caso C18 da Tabela 5.1 . . . . . . . . . . . . 39

5.8 Formas de gelo simuladas para o caso F01 da Tabela 5.3 . . . . . . . . . . . 41 
5.8 Formas de gelo simuladas para o caso F01 da Tabela 5.3 (Continuação) . . . . 42

5.9 Formas de gelo simuladas para o caso F02 da Tabela $5.3 \ldots$. . . . . . . . . . . 43

5.9 Formas de gelo simuladas para o caso F02 da Tabela 5.3 (Continuação) . . . . 44

5.10 Formas de gelo simuladas para o caso F03 da Tabela $5.3 \ldots$. . . . . . . . . . 45

5.11 Formas de gelo simuladas para o caso F04 da Tabela $5.3 \ldots$. . . . . . . . . 46

5.11 Formas de gelo simuladas para o caso F04 da Tabela 5.3 (Continuação) . . . 47

5.12 Forma do gelo artificial utilizado por Bragg (1986) e do gelo simulado no presente trabalho para o caso da Tabela $5.5 \ldots$. . . . . . . . . . . . . . . . . . 49

5.13 Coeficiente de Sustentação do Aerofólio Liso $-M_{\infty}=0,125$. . . . . . . . . . . 50

5.14 Coeficiente de Sustentação do Aerofólio Liso - $M_{\infty}=0,165$. . . . . . . . . . . 50

5.15 Coeficiente de Sustentação do Aerofólio com Formação de Gelo - $M_{\infty}=0,125 \quad$. 51

5.16 Coeficiente de Sustentação do Aerofólio com Formação de Gelo - $M_{\infty}=0,165 \quad$. 52

6.1 Parâmetros de similaridade dos casos da Figura $5.8 \ldots \ldots$. . . . . . . . . . 56

6.2 Parâmetros de similaridade dos casos da Figura $5.9 \quad \ldots$. . . . . . . . . . . 57

6.3 Parâmetros de similaridade dos casos da Figura $5.10 \ldots$. . . . . . . . . . . . 58

6.4 Parâmetros de similaridade dos casos da Figura 5.11 . . . . . . . . . . . . . 58

6.5 Efeito da rugosidade equivalente $k_{s}$ na forma de gelo do caso C13 da Tabela 5.160

6.6 Efeito da posição de início da transição Laminar-Turbulenta na forma de gelo do caso C13 da Tabela $5.1 \ldots \ldots$. . . . . . . . . . . . . . . . . . 61

6.7 Efeito do Comprimento da Transição Laminar-Turbulenta na forma de gelo do

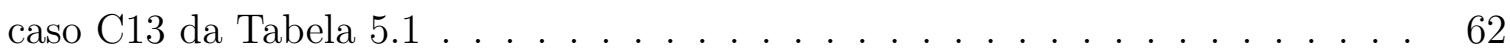

6.8 Comparação dos resultados experimentais e dos modelos implementados com o código ONERA $($ KIND, 2001) f . . . . . . . . . . . . . . . 63

6.9 Comparação do coeficiente de transferência de calor e da função intermitência na transição suave e abrupta . . . . . . . . . . . . . . . . . . . . . . . 


\section{Lista de Tabelas}

2.1 Modelos matemáticos utilizados nos principais códigos de simulação de formação de gelo . . . . . . . . . . . . . . . . . . . . . . 14

5.1 Casos de testes de Kind (2001) simulados no presente trabalho . . . . . . . . . 34

5.2 Parâmetros da camada limite para os casos simulados da Tabela 5.1 . . . . . 39

5.3 Casos de testes de Shin e Bond (1994) simulados no presente trabalho . . . . . 40

5.4 Parâmetros da camada limite para os casos simulados da Tabela 5.3 . . . . . . 48

5.5 Caso de Teste de Bragg (1986) simulado no presente trabalho . . . . . . . . . 48

5.6 Coeficiente de sustentação $C_{l}$ do aerofólio NACA0012 liso . . . . . . . . . . . . 49

5.7 Coeficiente de Sustentação $C_{l}$ do Aerofólio NACA 0012 com Formas de Gelo . 51

6.1 Parâmetros de similaridade dos casos da Figura $5.8 \ldots \ldots$. . . . . . . . . . . 56

6.2 Parâmetros de similaridade dos casos da Figura $5.9 \quad \ldots$. . . . . . . . . . . . 57

6.3 Parâmetros de similaridade dos casos da Figura $5.10 \ldots$. . . . . . . . . . . 57

6.4 Parâmetros de similaridade dos casos da Figura 5.11 . . . . . . . . . . . . . . . 57 


\section{Lista de Abreviaturas e Siglas}

AGARD Advisory Group for Aerospace Research and Development

AIAA American Institute of Aeronautics and Astronautics

AVT Applied Vehicle Technology

CFD Computer Fluid Dynamics

DERA Defense Evaluation ans Research Agency

DOT Departament of Transportation

EUA Estados Unidos da América

FAA Federal Aviation Administration

IRT Icing Research Tunnel

NACA National Advisory Committee for Aeronautics

NASA National Aeronautics and Space Administration

NATO North Atlantic Treaty Organization

NLF Natural Laminar Flow

ONERA Office National D'etudes et de Recherches Aérospatiales

OTAN Organização do Tratado do Atlântico Norte

RTO Research and Technology Organization

SLD Super Large Droplets 


\section{Lista de Símbolos}

$C_{p}$

$c$

$C_{d}$

$C_{f}$

$C_{l}$

$C_{m}$

$C_{p}$

$d$

H

h

$k$

$k_{s}$

$L W C$

$M$

$\dot{m}$

$\dot{m}^{\prime \prime}$

$n_{f}$

$N u$

$P$

$\operatorname{Pr}$

$\mathrm{Pr}_{t}$

$R$

$R e$

$R e_{k}$

$R e_{k s}$

$s$

St

T

$T_{f}$

calor especíico a pressão constante $[\mathrm{J} /(\mathrm{kg} \cdot \mathrm{K})]$

corda do aerofólio, $[m]$

coeficiente de arrasto

coeficiente local de atrito

coeficiente de sustentação

coeficiente de momento

coeficiente de pressão

diâmetro do bordo de ataque $[m]$

fator de forma da camada limite, $\delta_{1} / \delta_{2}$

coeficiente de transferência de calor $\left[W /\left(m^{2} \cdot K\right)\right]$

condutibilidade térmica, $[W /(m \cdot K)]$

rugosidade equivalente do grão de areia $[m]$

conteúdo de água líquida $\left[\mathrm{kg} / \mathrm{m}^{3}\right]$

número de Mach

vazão de água $[\mathrm{kg} / \mathrm{s}]$

vazão de água por unidade de área $\left[\mathrm{kg} /\left(\mathrm{m}^{2} \cdot s\right)\right]$

fração de congelamento

número de Nusselt, $h \cdot s / k$

pressão estática $[P a]$

número de Prandtl, $\mu /(C p \cdot k), \nu / \alpha$

número de Prandtl turbulento

raio de curvatura $\mathrm{R}$ da superfície $[m]$

número de Reynolds baseado na corda do aerofólio, $u \cdot c / \nu$

número de Reynolds rugoso, $\operatorname{Re}_{k}=\left(u_{\tau} \cdot k_{s}\right) / \nu_{a r}$

número de Reynolds baseado na altura da rugosidade, $u \cdot k_{s} / \nu$

coordenada curvilínea na superfície do aerofólio $[m]$

número de Stanton, $h /(u \cdot \rho \cdot C p)$

temperatura estática $[K]$

temperatura de fusão da água $[K]$

tempo $[s]$

velocidade $[\mathrm{m} / \mathrm{s}]$ 


$\begin{array}{ll}u^{+} & \text {velocidade adimensional nas coordenadas da parede } \\ u_{\tau} & \text { velocidade de cisalhamento }[\mathrm{m} / \mathrm{s}] \\ y & \text { distância entre trajetórias }[\mathrm{m}] \\ y^{+} & \text {distância adimensional nas coordenadas da parede }\end{array}$

\section{Símbolos Gregos}

$\alpha$

$\beta$

$\delta$

$\delta_{1}$

$\delta_{2}$

$\delta_{4}$

$\Delta_{4}$

$\mu$

$\nu$

$\rho$

$\sigma$

$\tau_{0}$

ângulo de ataque $\left[^{\circ}\right]$; difusividade térmica $\left[\mathrm{m}^{2} / \mathrm{s}\right]$

eficiência de coleta local

espessura da camada limite da quantidade de movimento $[\mathrm{m}]$

espessura de deslocamento da camada limite da quantidade de movimento $[\mathrm{m}]$

espessura de quantidade de movimento da camada limite $[\mathrm{m}]$

espessura de cisalhamento da camada limite $[m]$

espessura de condução da camada limite térmica, $k / h,[m]$

viscosidade dinâmica $\left[N \cdot s / m^{2}\right]$

viscosidade cinemática $\left[\mathrm{m}^{2} / \mathrm{s}\right]$

densidade $\left[\mathrm{kg} / \mathrm{m}^{3}\right]$

tensão superficial $\left[N / m^{2}\right]$

tensão de cisalhamento avaliada na superfície da parece $\left[\mathrm{N} / \mathrm{m}^{2}\right]$

\section{Subscritos}

$e$

borda da camada limite

estag

estagnação do escoamento

imp

condições no impacto da gota

$\infty$

condições do escoamento ao longe

lam

laminar

tr

transição

turb

turbulento 


\section{Introdução}

A formação de gelo nas superfícies de uma aeronave ocorre quando ela atravessa uma nuvem que contém gotas de água líquida sub-resfriadas e que estão em um estado metaestável. As gotas, ao chocarem-se com as superfícies da aeronave, poderão congelar e formar camadas de gelo. A taxa de congelamento e a quantidade de gelo formado dependerá da forma da superfície, das condições atmosféricas, tais como temperatura, quantidade de gotas e tamanho das gotas, e das condições do vôo, tais como velocidade e ângulo de ataque da aeronave.

O vôo em condições propícias à formação de gelo é considerado pelas autoridades reguladoras nacionais e internacionais, como uma condição de risco para a aeronave. O gelo pode formar-se em diversas superfícies da aeronave, porém os maiores riscos estão associados à formação de gelo nas entradas dos motores e nos aerofólios. Neste último caso o desempenho aerodinâmico é degradado e pode ocorrer uma redução da sustentação, redução da manobrabilidade da aeronave e aumento do arrasto aerodinâmico. A Figura 1.1 mostra os efeitos da rugosidade nas características aerodinâmicas. A Figura 1.1 mostra o coeficiente de sustentação $C_{l}$ em função do ângulo de ataque $\alpha$ de um perfil NACA63A415 sem formação de gelo, que é o perfil limpo, e com vários tipos de formação de gelo. A Figura 1.2 mostra as superfícies de uma aeronave onde pode ocorrer a formação de gelo. A Figura 1.3 mostra exemplos de formação de gelo em túneis e em aeronaves.

O estudo dos fenômenos envolvidos na formação de gelo são de grande importância para a elaboração de modelos que representem o fenômeno. Tais modelos são utilizados na indústria aeronáutica para auxiliar o desenvolvimento dos sistemas de proteção e para auxiliar a certificação da aeronave.

Os sistemas de proteção previnem a formação de gelo em algumas superfícies dos aerofólios, como por exemplo, o bordo de ataque da aeronave. No desenvolvimento dos sistemas de proteção, os modelos são utilizados para determinar a energia térmica necessária que deverá ser transferida para o bordo de ataque e quais superfícies devem ser protegidas. Nesta condições, espera-se que não haja formação de gelo e, portanto, a superfície do bordo de ataque estará quente e com um filme de água. Os sistemas de proteção de formação de gelo podem ser mecânicos ou térmicos e do tipo degelo ou anti-gelo. O sistema de degelo tem funcionamento 


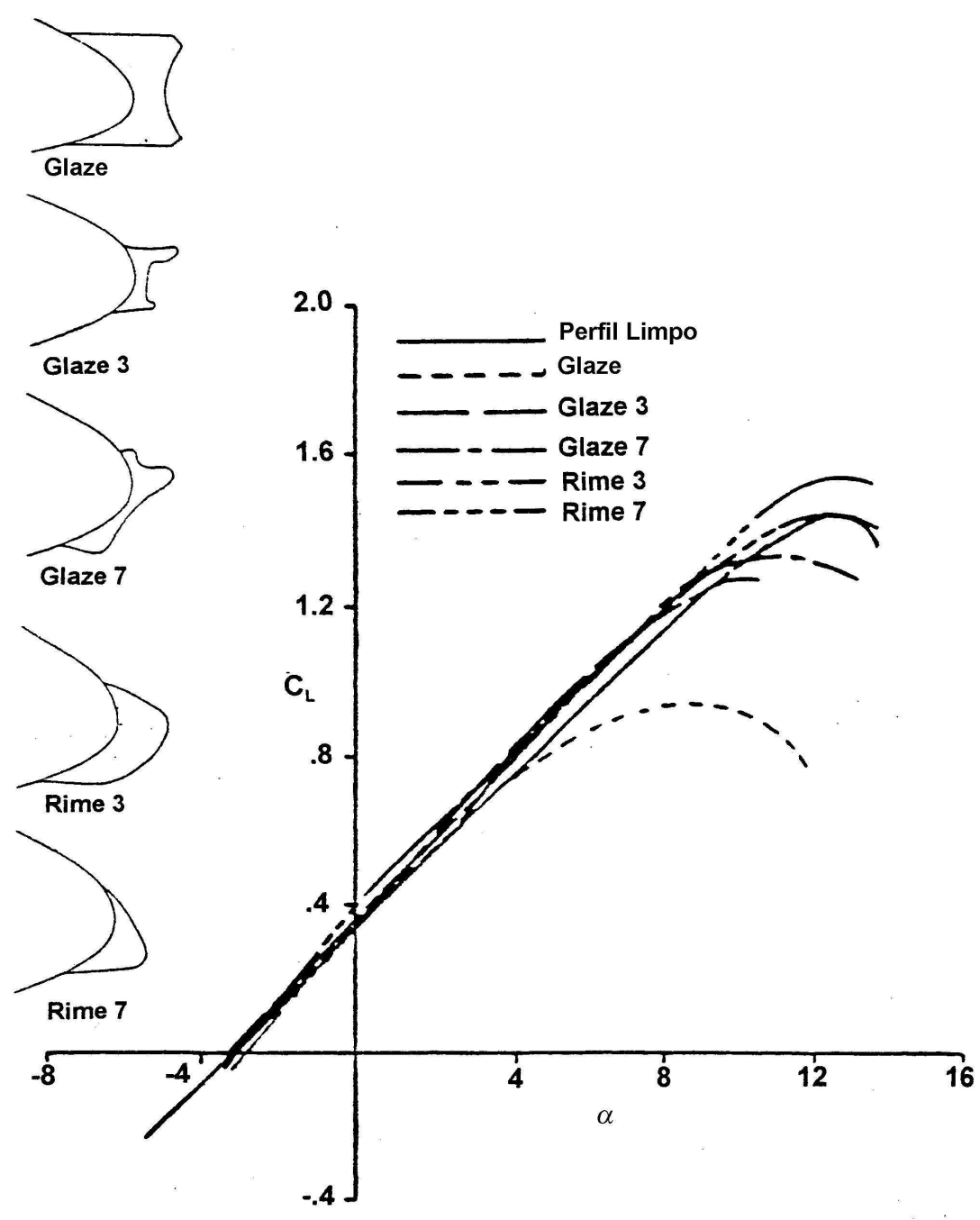

Figura 1.1: Efeito de vários tipos de formas de gelo no desempenho aerodinâmico de um aerofólio (SILVA, 2002)

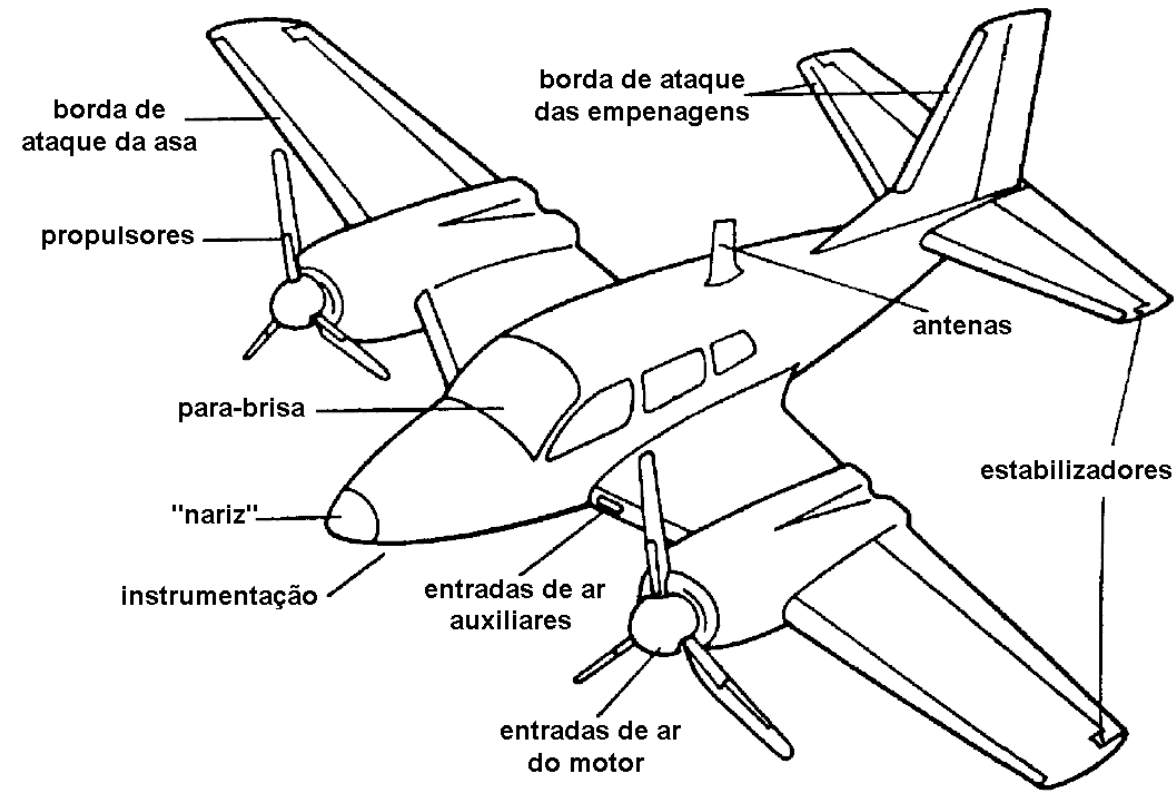

Figura 1.2: Superfícies das aeronaves sujeitas à formação de gelo (HEINRICH et al., 1991) 


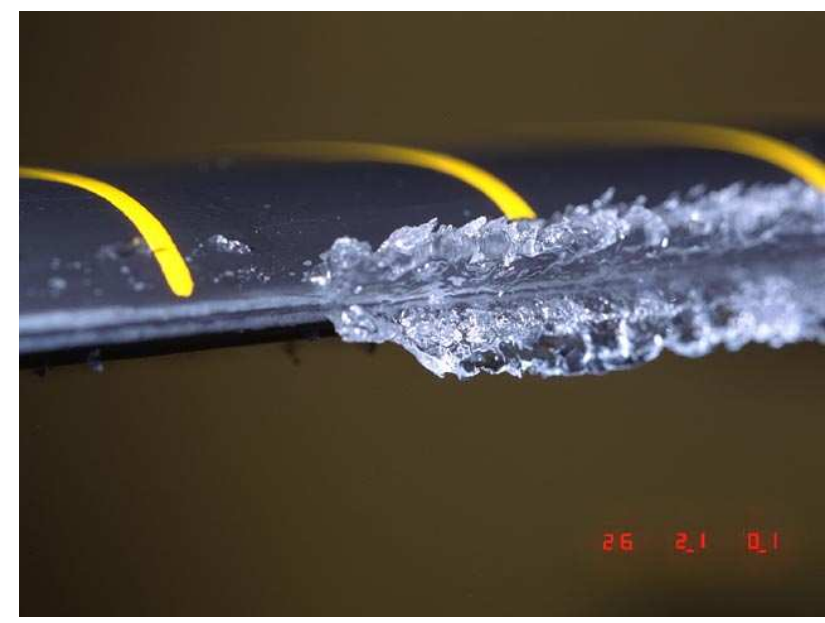

(a) Formação de gelo em túnel

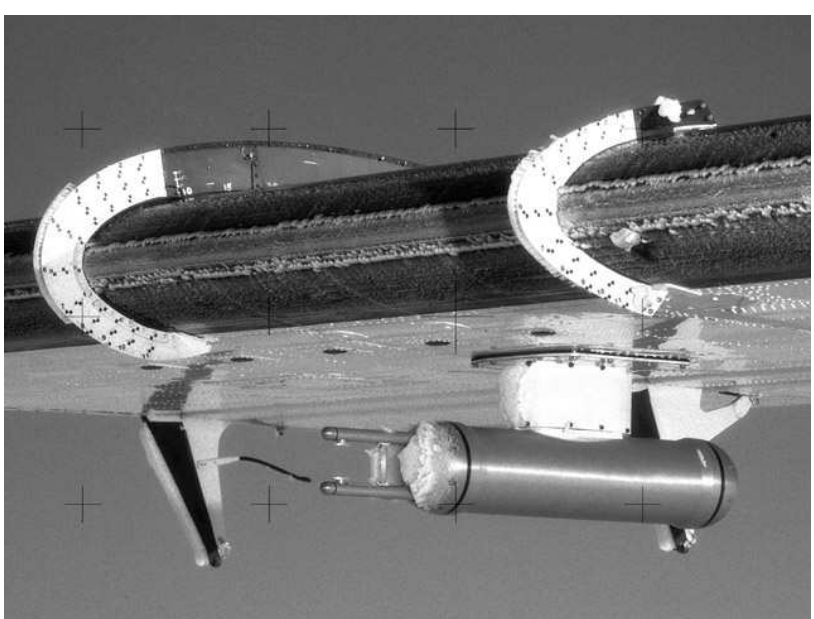

(b) Formação de gelo em asa

Figura 1.3: Exemplo de formações de gelo em aerofólios (NASA, 2009)

intermitente e inicia a operação após a formação de uma pequena forma de gelo no aerofólio. O sistema de anti-gelo tem funcionamento contínuo e evita a formação de gelo. No sistema mecânico o bordo de ataque infla para quebrar o gelo. Nos sistema térmico, ou eletro-térmico o bordo de ataque é aquecido.

No processo de certificação de uma aeronave comercial os códigos de previsão de formação de gelo são utilizados como um meio validação do desempenho da aeronave e das margens de segurança operacional. Os resultados destes códigos, que são as formas de gelo, são utilizados pelas autoridades certificadoras para avaliar a degradação aerodinâmica do aerofólio nos casos de falha dos sistema de proteção e para definir a criticalidade desta falha. Os códigos também são utilizados para as autoridades verificarem os efeitos da formação de gelo em superfícies que não possuem sistemas de proteção.

Ao se utilizar estes códigos, a certificação torna-se mais econômica, pois são poupadas horas de ensaios em vôo, e é possível simular condições de vôo e de formação de gelo que seriam muito difíceis de serem testadas. Nos últimos anos a certificação de uma aeronave tem sido conduzida através de análises e os testes de laboratório e testes em vôo tem sido usados como verificações.

Os principais códigos utilizados pelas indústrias e órgão de pesquisa para a previsão de formas de gelo são LEWICE (MACARTHUR; KELLER; LUERS, 1982), TRAJICE (GENT, 1990) e ONERA (GUFFOND; BRUNET, 1988).

A transferência de calor por convecção é calculada, nos códigos citados, através da análise integral da camada limite sobre uma superfície rugosa. A transição entre o regime laminar e turbulento é realizada de forma abrupta, e cada código adota um critério para o ponto de transição. 
Silva (2002) aponta que a previsão dos parâmetros de transição e os modelos da região de transição afetam o coeficiente de transferência de calor e propõe que novos modelos devem ser estudados. O estudo dos efeitos dos parâmetros da camada limite da transferência de calor, podem auxiliar nas previsões de formação de gelo sobre aerofólios.

\subsection{Tipos de Gelo}

O sub-resfriamento da gotícula de água na atmosfera ocorre durante a formação e a ascensão de uma nuvem. Quando a gotícula está em um estado de sub-resfriamento metaestável, pequenas pertubações mecânicas ou térmicas podem iniciar o seu processo de congelamento. Devido à sensibilidade a fatores externos, não é possível definir a temperatura de início do congelamento, porém, é possível definir a probabilidade de sua ocorrência. Mason (1971) demonstrou que a concentração de cristais cresce com o decréscimo de temperatura. A concentração é máxima quando a temperatura é igual a $-30^{\circ} \mathrm{C}$ e, abaixo de $-40^{\circ} \mathrm{C}$, toda a água presente está na forma de cristais de gelo.

Quando uma superfície da aeronave, tal como o bordo de ataque de uma asa, passa por uma nuvem com gotas sub-resfriadas, estas gotas tenderão a congelar no momento do impacto e transferir a entalpia de solidificação para o bordo de ataque. Os principais mecanismos de transferência da entalpia de solidificação é convectivo e por evaporação da água.

Quando as gotas congelam completamente no impacto com a superfície, há a formação de gelo opaco e com uma forma semelhante ao bordo de ataque, aumentando significativamente a rugosidade da superfície do aerofólio. Este tipo de formação é chamado de Rime Icing (GENT; DART; CANSDALE, 2000) e ocorre quando há uma combinação de baixa temperatura ambiente, baixa velocidade do escoamento e baixa concentração de água. A Figura 1.4(a) mostra a forma típica de um Rime Icing.

Quando as gotas não congelam completamente no impacto com a superfície, forma-se-a um filme de água que escorrerá ao longo do aerofólio no sentido do escoamento, e irá congelar em um ponto a jusante do ponto de impacto. O gelo formado nesta condições é chamado de Glaze Icing (GENT; DART; CANSDALE, 2000) e ocorre quando há a combinação de temperatura ambiente mais, velocidade do escoamento e concentração de água mais altas. A rugosidade desta formação de gelo pode variar de frações de milímetros a alguns milímetros de altura e largura. Este tipo de gelo tende a ser transparente e sua forma assemelha-se a chifres nas faces superior e inferior do aerofólio. A Figura 1.4(b) mostra a forma típica de um Glaze Icing.

Uma terceira forma de gelo, porém menos comum de ser encontrada, ocorre quando a temperatura ambiente está próxima a temperatura de fusão da água ou quando a aeronave 


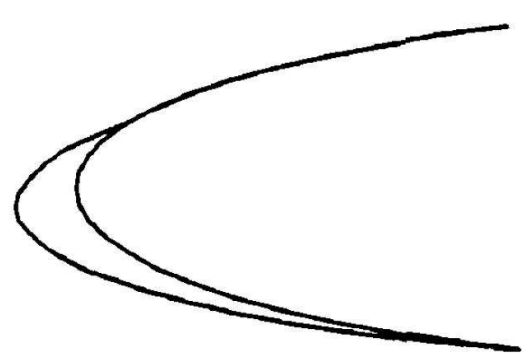

(a) Gelo Rime

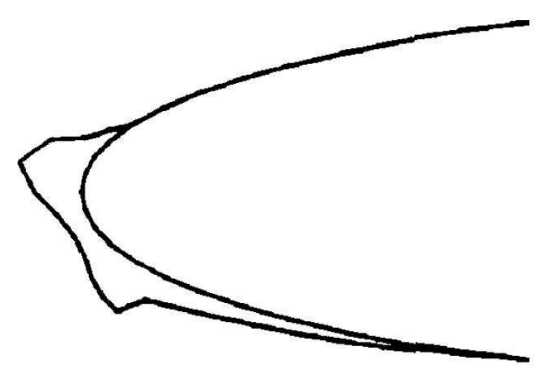

(b) Gelo Glaze

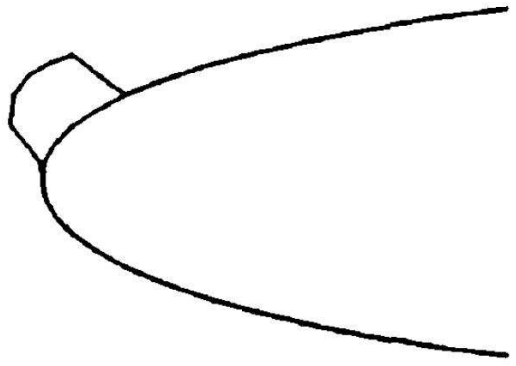

(c) Gelo Beak

Figura 1.4: Tipos de gelo (GENT; DART; CANSDALE, 2000)

voa em altas velocidades. Nesta condição o gelo forma-se na face superior do bordo de ataque e a jusante do ponto de impacto da gota. O filme de água resfria-se devido a aceleração e expansão do ar que escoa em torno do bordo de ataque. Este tipo de formação de gelo é chamada de Beak Icing e é mostrada na Figura 1.4(c) (GENT; DART; CANSDALE, 2000).

\subsection{Terminologias}

Nesta seção são apresentadas as terminologias usualmente utilizadas nos problemas de análise e crescimento de gelo sobre aerofólios.

\subsubsection{Conteúdo de Água Líquida}

O conteúdo de água líquida em uma nuvem, $L W C$ - Liquid Water Content, é definido como a massa de água líquida presente em uma unidade de volume da nuvem. O termo líquido expressa o estado sub-resfriado da gota e a distingue dos cristais de gelo presentes na nuvem.

\subsubsection{Diâmetro Mediano Volumétrico}

O diâmetro das gotas contidas em uma nuvem podem variar e a distribuição das gotas é representado pelo $M V D$ - Median Volumetric Diameter. O MVD é o diâmetro das gotas, que estão presente na distribuição de gotas da nuvem, e cujo soma das massas (ou volumes) representa a metade da massa total de água presente na nuvem.

\subsubsection{Eficiência de Coleta Local}

Considerando-se a definição de $L W C$ apresentada em 1.2.1, a vazão em massa de água máxima que atinge o aerofólio é dada pela Equação 1.1. 


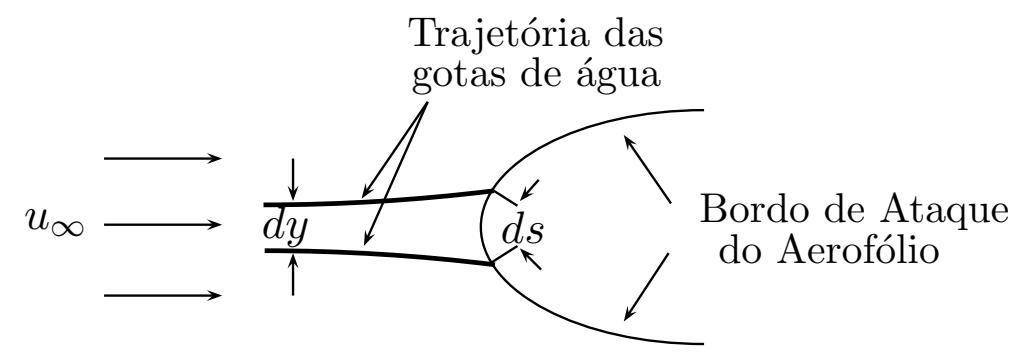

Figura 1.5: Definição de Eficiência de Coleta Local $\beta(s)$

$$
d \dot{m}_{\infty}=L W C \cdot u_{\infty} \cdot(1 \cdot d y)
$$

Onde $d \dot{m}_{\infty}$ é a vazão em massa de água que atravessa uma área $(1 \cdot d y)$, que está compreendida entre duas trajetórias de gotas de água, conforme a Figura 1.5.

Definindo:

$$
d \dot{m}_{i m p}=\dot{m}_{i m p}^{\prime \prime} \cdot(1 \cdot d s)
$$

Onde $(1 \cdot d s)$ é a área da superfície do aerofólio compreendida entre duas trajetórias de gotas de água, $\dot{m}_{i m p}^{\prime \prime}$ é a fluxo de massa de água médio por unidade de área que atinge o aerofólio e $d \dot{m}_{i m p}$ é a vazão de massa de água que atinge o aerofólio.

Aplicando a Equação da Continuidade entre duas trajetórias, $d \dot{m}_{\infty}=d \dot{m}_{i m p}$.

$$
\dot{m}_{i m p}^{\prime \prime}=L W C \cdot u_{\infty} \cdot \frac{d y}{d s}
$$

E assim define-se a eficiência de coleta como:

$$
\beta(s)=\frac{d y}{d s}
$$

Quando o diâmetros das gotículas variam de 30 a $250 \mu \mathrm{m}$ ela são denominadas de $S L D$ Super Larger Droplets. As gotas de grande diâmetros ao chocarem-se com o aerofólio podem ser arremessadas para superfícies a jusante do bordo de ataque. Nestas condições a avaliação da eficiência de coleta com o $L W C$ pode ter grandes imprecisões.

\subsubsection{Fração de Congelamento}

A fração de congelamento $n_{f}$ é a razão entre a massa de água congelada e o total de massa de água incidente em um elemento da superfície. 


\section{$1.3 \quad$ Objetivo}

O objetivo deste trabalho é desenvolver um módulo dedicado à avaliar a camada limite dinâmica e térmica para o cálculo do coeficiente de transferência de calor sobre um aerofólio com formação de gelo. O local da transição entre o regime laminar e turbulento será estimado, e modelos de intermitência serão utilizados para avaliar os parâmetros da camada limite na região de transição.

O módulo implementado neste trabalho será acoplado aos módulos do código ONERA para a simulação de previsão de formas de gelo em aerofólios.

Os módulos deverão prever a forma do gelo formado na superfície do aerofólio e os efeitos da formação de gelo no seu desempenho aerodinâmico.

As formas de gelo simuladas, neste trabalho, serão comparadas com formas de gelos experimentais e com formas de gelo simuladas por outros códigos.

Os parâmetros da camada limite serão variados e será estudado o seus efeitos nas formas de gelo em aerofólios de uso aeronáutico.

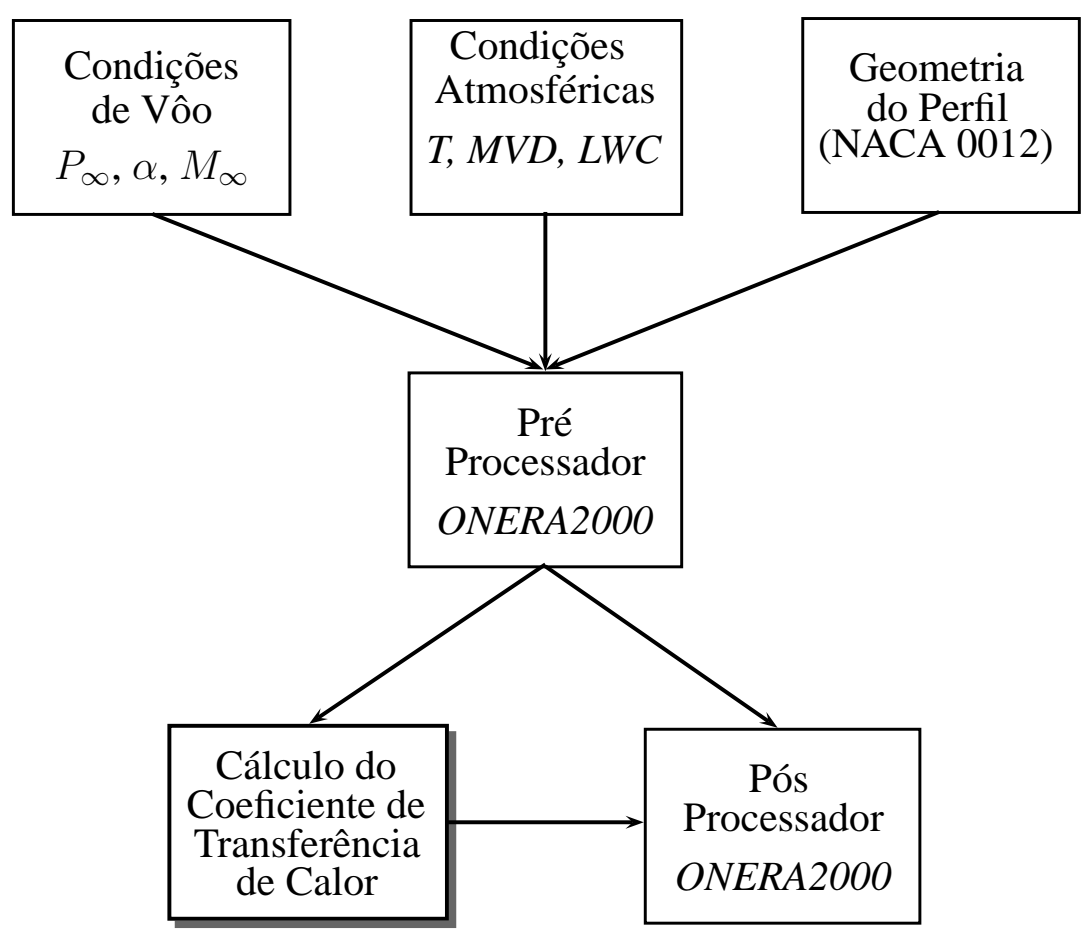

Figura 1.6: Integração do módulo de transferência de calor do presente trabalho com os módulos do código ONERA 


\section{Revisão Bibliográfica}

A formação de gelo nos aerofólios é um problema que tem sido tratado desde os primeiros vôos de aeronaves. Nos anos 40 e 50 vários experimentos e testes em vôo possibilitaram o avanço no projeto de sistemas de proteção. O desenvolvimento dos estudos teóricos, porém, não acompanhou o desenvolvimento dos estudos experimentais e somente avançou na década de 70, com o uso de computadores. Os primeiros trabalhos foram publicados pela extinta agência estadunidense NATIONAL ADVISORY COMMITTEE FOR AERONAUTICS (NACA). Os pesquisadores conseguiram avançar nas simulações de crescimento de gelo e cálculo de trajetórias de gotículas de água sub-resfriada, porém, estavam limitados em formas geométricas que possuíam soluções analíticas, tais como cilindros e esferas, ou em dados experimentais. A partir dos anos 70 a teoria de análise de formação de gelo passa a ser desenvolvida para formas específicas, tais como aerofólios.

\subsection{Referências Básicas}

Os primeiros trabalhos sobre simulação de formação de gelo foram publicado no início da década de 50. Ludlam (1951) mediu o efeito da entalpia de solidificação na formação de gelo em cilindros rotativos. Messinger (1953) desenvolveu o procedimento para o cálculo da temperatura da superfície em um cilindro rotativo de superfície adiabática e em equilíbrio termodinâmico com o escoamento de ar. A fração de congelamento $n_{f}$ foi um resultado de seu trabalho. Os procedimentos de cálculo desenvolvidos pelo autor são utilizados em diversos programas de simulação de formas de gelo.

A primeira modelagem matemática das gotas sub-resfriadas em uma nuvem foi desenvolvida por Langmuir (1961). O primeiro cálculo da trajetória das partículas e da eficiência de coleta local $\beta(s)$, foi desenvolvido por Langmuir e Blodgett (1961). O modelo proposto pelos autores considera somente a força de arraste para o cálculo da trajetória das partículas e não considera a ação das forças gravitacionais. Este modelo é utilizado em diversos programas de simulação de formas de gelo.

A presença de gelo altera a rugosidade da superfície do aerofólio ,e a transferência de calor 
convectiva entre o aerofólio e o escoamento externo.

O histórico trabalho de Nikuradse (1933) relata diversos experimentos para determinação do atrito em tubos rugosos. Os resultados dos experimentos eram baseados na rugosidade produzida por grãos de areia.

Schliting (1937) introduziu o conceito de rugosidade do grão de areia equivalente $k_{s}$, no qual qualquer tipo de rugosidade pode ter $k_{s}$ correspondente às rugosidades de grão de areia testadas por Nikuradse. Com este conceito, foi possível estender os resultados de atrito desenvolvidos por Nikuradse para a camada limite sobre placas. Os principais códigos de análise de crescimento de gelo utilizam $k_{s}$ para os cálculos de transferência de calor sobre o aerofólio.

Dipprey e Sabersky (1963), Owen e Thomson (1963) realizaram experimentos em dutos rugosos e propuseram um modelo com duas camadas para prever a troca de calor. A primeira camada é muito fina, próxima a parede e concentra todos os efeitos causados pelas protuberâncias. A segunda é localizada acima da primeira e comporta-se como uma camada totalmente turbulenta. Para compatibilizar as duas camadas, os autores utilizaram a analogia de Reynolds, o número de Prandtl turbulento $P r_{\text {turb }}$ e a difusividade turbilhonar (eddy diffusity).

Pimenta (1975) estudou o efeito da rugosidade no transporte de calor e quantidade de movimento em um escoamento turbulento. O autor realizou experimentos com escoamento sobre superfícies lisas e rugosas e com e sem transpiração com o objetivo de obter dados confiáveis para validar os códigos de camada limite diferencial. De acordo com a pesquisa bibliográfica de Pimenta (1975) a troca de calor de um escoamento turbulento sobre superfícies rugosas depende das dimensões das formas e da distribuição dos elemntos rugosos.

Baseado em observações experimentais, Pimenta (1975) propôs uma lei de parede e uma lei de turbulência de comprimento de mistura (mixing-length) para serem usadas no código de cálculo da camada limite por diferenças finitas de Crawford e Kays (1976). O autor verificou que, nas estimativas do efeito da rugosidade e transpiração no escoamento turbulento e na transferência de calor, os resultados da teoria do comprimento de mistura eram mais próximos aos dados experimentais que os resultados obtidos por métodos integrais.

Makkonnen (1985) estudou a formação de gelo em linhas de transmissão (Figura 2.1). O autor propôs um procedimento de cálculo para a transferência de calor entre um escoamento de ar com gotas e a superfície rugosa de um clindro com formação de gelo. O procedimento considerava os regimes laminar, turbulento e transicional. O autor implementou a avaliação da espessura de condução da camada limite laminar $\Delta_{4}$ baseado no modelo de Smith e Spalding (1958). O número de Stanton turbulento foi calculado a partit do o coeficiente de atrito $C_{f}$, 


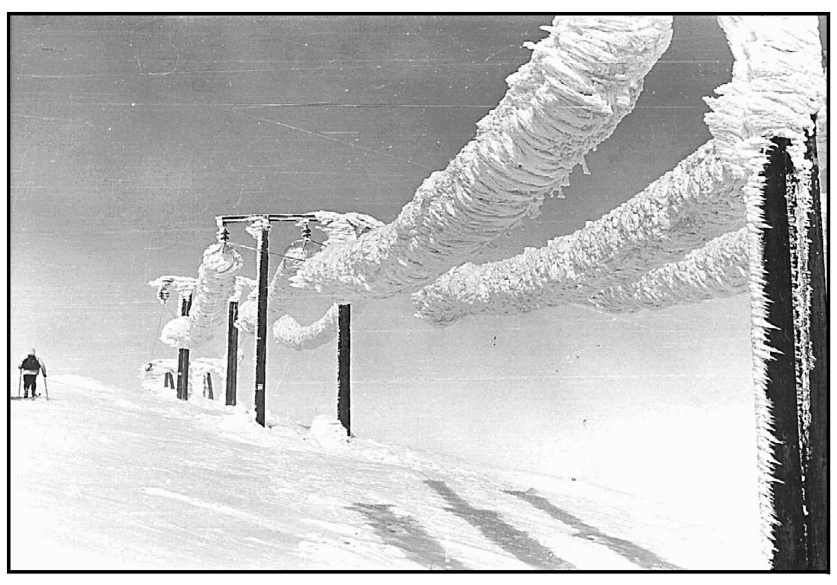

Figura 2.1: Formação de gelo em linha de 22kV em Voss, Noruega (MAKKONEN, 2000)

que é obtido da espessura da quantidade de movimento $\delta_{2, t u r b}$, mais o número de Prandtl turbulento $P r_{\text {turb }}$ e dados experimentais. O coeficiente de transferência de calor turbulento ao redor do cilindro é calculado com a análise integral da camada limite baseada na lei de parede totalmente rugosa, no modelo de duas camadas com ajustes empíricos e na definição de rugosidade equivalente do grão de areia (DIPPREY; SABERSKY, 1963; OWEN; THOMSON, 1963; KAYS; CRAWFORD, 1993). Os coeficientes de transferência de calor laminar e turbulento são calculados através da analogia entre a quantidade de movimento e a transferência de calor e é assumido um escoamento sobre uma superfície isotérmica e sem transferência de massa. Makkonnen (1985) assumiu que a transição abrupta entre o regime laminar e turbulento ocorre quando $R e_{k}=u_{k} \cdot k_{s} / \nu>600$, onde $u_{k}$ é velocidade no topo da rugosidade. A espessura da camada limite da quantidade de movimento não tem descontinuidade no ponto de transição, isto é, $\delta_{2, l a m}=\delta_{2, t u r b}$. O autor também propôs um critério de transição baseado em uma expressão que correlaciona o gradiente de pressão e os efeitos da altura da rugosidade com a estabilidade da camada limite da quantidade de movimento. Para a validação dos resultados, o autor utilizou os dados experimentais de Achenbach (1977), que mediu a transferência de calor ao redor de cilindros com superfícies rugosas e em vários regimes de escoamento.

Cebeci $(1987,1989)$ aplicou seu próprio código de camada limite por diferenças finitas (CEBECI, 1971) para melhorar o cálculo da transferência de calor e de massa sobre aerofólios contaminados com gelo ou com água. O autor utilizou as equações RANS (Reynolds-AveragedNavier-Stokes) e o modelo de turbulência de comprimento de mistura ajustado para o escoamento sobre protuberâncias e rugosidades. O modelo foi validado por Shin, Chen e Cebeci (1992).

Uma comparação do atrito e da previsão de transferência de calor com vários modelos de rugosidade e com dados experimentais foi apresentado por Havugimana et al. (2002), que resolveu o escoamento por diferenças finitas com um modelo de turbulência de comprimento de 
mistura de Cebeci-Smith modificado. O autor considerou o conceito de rugosidade equivalente do grão de areia e o modelo de rugosidade de elementos discretos. Os autores concluíram que os métodos integrais de análise da camada limite superestimam a transferência de calor quando comparados com dados experimentais e resultados de códigos de diferenças finitas.

Newton et al. (1988), Poinsatte (1989), Poinsatte, Van Fossen e De Witt (1990) fizeram testes em vôo e em túnel de vento para medir o coeficiente de transferência de calor local sobre superfícies lisas e rugosas de aerofólios.

Bragg, Kerho e Cummings (1995) testaram a transferência de calor em aerofólios com o bordo de ataque rugoso e compararam os resultados com os de testes de aerofólios lisos. Bragg, Cummings e Henze (1996) mediram o nível de turbulência da camada limite para compreender os efeitos da rugosidade na transição do regime laminar para o regime turbulento e na transferência de calor. Kerho e Bragg (1997) estudaram o desenvolvimento da camada limite sobre uma superfície rugosa para vários estágios de formação de gelo nos bordos de ataque. Os autores mostraram que a rugosidade não causa uma transição abrupta do regime laminar para o turbulento, mas inicia um processo de transição que se desenvolve lentamente a jusante da rugosidade. Esta conclusão conflita com os modelos de camada limite implementados nos códigos de gelo, que utilizam modelos de transição abrupta.

Dukhan, Masiulaniec e De Witt (1999) analisaram os padrões de vários tipos de gelo formados em testes de túnel e definiram um índice que leva em consideração o aumento da área, massa e espaçamento das rugosidades. Os autores fixaram formas de gelo artificiais, baseado nas observações de seus experimentos, e realizaram medições sobre aerofólios aquecidos com o objetivo de criar correlações para o cálculo da transferência de calor.

\subsection{Programas de Simulação de Formação de Gelo}

Wright, Gent e Guffond (1997) publicaram uma revisão abrangente sobre os modelos matemáticos e a capacidade de previsão de gelo dos códigos LEWICE, ONERA2D e TRAJICE2. Os autores selecionaram casos de testes e compararam os resultados das simulações com dados experimentais. Os autores concluíram que os códigos previram razoavelmente bem as formas de gelo, porém indicaram que eram necessários estudos sobre transferência de calor, previsão de altura de rugosidade e sobre os efeitos aerodinâmicos das formações de. Silva (2002) fez uma revisão abrangente dos principais programas de simulação de formação de gelo. O autor apresentou tabelas dos processos de cálculo e dos modelos matemáticos utilizados nos programas.

Cansdale e Gent (1983) desenvolveram, na British Royal Aircraft Establishment, um dos 
primeiros trabalhos sobre o balanço térmico de um aerofólio sem aquecimento e com formação de gelo. Os autores estenderam o trabalho de Messinger (1953) e introduziram o escoamento compressível e a concentração local de vapor de água.

Gent (1990) implementou o código numérico TRAJICE que prevê o gelo bidimensional em aerofólios na Defense Evaluation ans Research Agency (DERA). O programa soluciona o escoamento potencial completo ao redor do aerofólio, considerando os efeitos viscosos da camada limite, com a rotina desenvolvida por Collyer e Lock (1979). Alternativamente, o programa calcula o escoamento pelo método dos painéis de Kennedy e Marsden (1976). O cálculo das trajetórias das gotículas é baseado no método de Langmuir e Blodgett (1961). Para o cálculo da transferência de calor, o autor considerou o bordo de ataque do aerofólio com uma superfície cilíndrica. O autor extrapolou os resultados experimentais de transferência de calor ao redor de um cilindro e desenvolveu uma expressão empírica para avaliar o coeficiente de transferência de calor na superfície do aerofólio. Alternativamente, o autor implementou uma análise integral da camada limite, semelhante a de Makkonnen (1985), para avaliar o coeficiente de transferência de calor sobre uma superfície isotérmica e sem transferência de massa. O autor assumiu que o disparo da transição é uma função do número de Reynolds $R e_{k}$. O balanço termodinâmico na superfície do aerofólio é baseado no procedimento de Messinger (1953) e o cálculo da forma de gelo pode ser realizado em um único ou em múltiplos intervalos de tempo.

O código LEWICE foi desenvolvido por Macarthur, Keller e Luers (1982), Ruff e Berkowitz (1990), Wright $(1995,1999)$ da National Aeronautic and Space Administration - NASA. O código resolve o escoamento potencial ao redor de um aerofólio bidimensional através do método dos painéis (HESS; SMITH, 1967). O cálculo da trajetória das gotas de água considera as forças de arraste e os efeitos da gravidade no cálculo da quantidade de movimento das gotas. O coeficiente convectivo de transferência de calor, é calculado através das equações da camada limite na forma integral a partir do escoamento potencial resultante do método dos painéis. O código calcula o coeficiente de transferência de calor convectivo baseado no procedimento de Makkonnen (1985). O balanço termodinâmico na superfície do aerofólio é baseado no procedimento de Messinger (1953). O cálculo da forma do gelo é realizado em pequenos intervalos de tempo com a solução completa do escoamento e da trajetória das partículas a cada intervalo.

O código ONERA foi desenvolvido por Guffond e Brunet (1988) na Office National D'Études et de Recherches Aérospatiales ONERA. O código resolve o escoamento potencial completo, compressível e isoentrópico, sobre o aerofólio utilizando o método de elementos finitos desenvolvido por Bredif $(1983,1985)$. A trajetória das partículas é calculada pelo método de Langmuir e Blodgett (1961). O código calcula o coeficiente de transferência de calor convec- 
tivo baseado no procedimento de Makkonnen (1985) e com a transição do regime laminar para o turbulento em função de $R e_{k}$. O equilíbrio termodinâmico na superfície do aerofólio é baseado no procedimento de Messinger (1953). O programa utiliza um método similar ao de predição-correção para o cálculo da forma de gelo.

A solução do escoamento em torno de aerofólios é similar entre os programas TRAJICE, , LEWICE e ONERA apesar de empregar modelos distintos em cada um deles. Para formações de gelo com grandes protuberâncias, que são encontradas em gelo do tipo Glaze, a solução do escoamento potencial não é capaz de prever recirculações, que podem aumentar o coeficiente de transferência de calor.

Os programas CANICE (CEBECI; KAFYEKE, 2003), Fortified/LEWICE (CEBECI; CHEN; ALEMDAROGLU, 1991) e FENSAP-ICE (BEAUGENDRE; MORENCY; HABASHI, 2003) introduzem soluções por diferenças finitas para obter soluções mais precisas do escoamento e da transferência de calor.

O programa CANICE e Fortified/LEWICE utilizam uma solução por diferenças finitas para o cálculo da transferência de calor.

O programa FENSAP-ICE acopla a solução de Navier-Stokes na forma tridimensional com um a solução Lagrangiana da trajetória de partículas em um código bidimensional de crescimento de gelo.

A precisão numérica dos códigos é, em geral, bem conhecida e os seus resultados são aceitos pela comunidade aeronáutica. Entre os trabalhos de validação de códigos de gelo, destaca-se o trabalho publicado por Wright e Rutkowski (1999). Neste trabalho, são apresentadas diversas simulações com vários tipos de aerofólio e condições de teste. Os resultados são comparados com dados experimentais obtidos, em grande parte, no túnel IRT.

A mais recente e abrangente coleção de avaliações foi realizada pela Applied Vehicle Technology Panel, Research and Technology Organization, North Atlantic Treaty Organization AVT-NATO-RTO (KIND, 2001), que disponibilizaram dados experimentais de vários túneis e resultados de simulação de formas de gelo da maioria dos códigos utilizados pela indústria e pela academia.

Na Tabela 2.1 é apresentado um resumo dos modelos matemáticos utilizados nos três principais códigos de simulação de formação de gelo, TRAJICE, LEWICE e ONERA. 
Tabela 2.1: Modelos matemáticos utilizados nos principais códigos de simulação de formação de gelo

\begin{tabular}{|c|c|c|c|c|c|}
\hline & \multicolumn{5}{|c|}{ Modelos Matemáticos } \\
\hline $\begin{array}{l}\text { Código (au- } \\
\text { tor) }\end{array}$ & $\begin{array}{ll}\text { Escoamento ao } \\
\text { Longe }\end{array}$ & $\begin{array}{l}\text { Trajetória de } \\
\text { Gotículas de Água }\end{array}$ & $\begin{array}{l}\text { Transferência de } \\
\text { Calor Convectiva }\end{array}$ & $\begin{array}{ll}\text { Equilíbrio } & \text { Termo- } \\
\text { dinâmico } & \\
\end{array}$ & $\begin{array}{l}\text { Crescimento do } \\
\text { Gelo }\end{array}$ \\
\hline $\begin{array}{l}\text { TRAJICE } \\
\text { (GENT, } \\
1990)\end{array}$ & $\begin{array}{l}\text { Escoamento Po- } \\
\text { tencial Completo } \\
\text { (COLLYER; LOCK, } \\
\text { 1979) ou método } \\
\text { dos painéis (KEN- } \\
\text { NEDY; MARSDEN, } \\
\text { 1976) }\end{array}$ & $\begin{array}{l}\text { Efeito das Forças } \\
\text { de Arraste (LANG- } \\
\text { MUIR; BLODGETT, } \\
\text { 1961) }\end{array}$ & $\begin{array}{l}\text { Relações Empírica } \\
\text { para um cilindro } \\
\text { ou Análise Integral } \\
\text { da Camada Limite } \\
\text { (MAKKONNEN, } \\
\text { 1985) }\end{array}$ & $\begin{array}{l}\text { Cálculo da Tempe- } \\
\text { ratura da superfície } \\
\text { adiabáticar do } \\
\text { aerofólio (MESSIN- } \\
\text { GER, 1953) }\end{array}$ & $\begin{array}{l}\text { Cálculo da forma } \\
\text { de gelo em um } \\
\text { único ou múltiplos } \\
\text { intervalos de tempo }\end{array}$ \\
\hline $\begin{array}{l}\text { LEWICE } \\
\text { (MACAR- } \\
\text { THUR; } \\
\text { KELLER; } \\
\text { LUERS, } \\
\text { 1982) }\end{array}$ & $\begin{array}{l}\text { Escoamento Po- } \\
\text { tencial, método } \\
\text { dos painéis (HESS; } \\
\text { SMITH, 1967) }\end{array}$ & $\begin{array}{l}\text { Efeito das Forças } \\
\text { de Arraste e do } \\
\text { Peso }\end{array}$ & $\begin{array}{l}\text { Análise Integral } \\
\text { da Camada Limite } \\
\text { (MAKKONNEN, } \\
1985)\end{array}$ & $\begin{array}{l}\text { Cálculo da Tempe- } \\
\text { ratura da superfície } \\
\text { adiabática do } \\
\text { aerofólio (MESSIN- } \\
\text { GER, 1953) }\end{array}$ & $\begin{array}{lr}\text { Cálculo da } & \text { forma } \\
\text { de gelo em } \\
\text { múltiplos inter- } \\
\text { valos de tempo }\end{array}$ \\
\hline $\begin{array}{l}\text { ONERA } \\
\text { (GUFFOND; } \\
\text { BRUNET, } \\
1988 \text { ) }\end{array}$ & $\begin{array}{l}\text { Escoamento Po- } \\
\text { tencial Completo, } \\
\text { elementos finitos } \\
(\text { BREDIF, 1983) }\end{array}$ & $\begin{array}{l}\text { Efeito das Forças } \\
\text { de Arraste (LANG- } \\
\text { MUIR; BLODGETT, } \\
\text { 1961) }\end{array}$ & $\begin{array}{l}\text { Análise Integral } \\
\text { da Camada Limite } \\
\text { (MAKKONNEN, } \\
1985)\end{array}$ & $\begin{array}{l}\text { Cálculo da Tempe- } \\
\text { ratura da superfície } \\
\text { adiabáticar do } \\
\text { aerofólio (MESSIN- } \\
\text { GER, 1953) }\end{array}$ & $\begin{array}{l}\text { Cálculo da Forma } \\
\text { de Gelo por um } \\
\text { método similar ao } \\
\text { predição-correção }\end{array}$ \\
\hline
\end{tabular}




\subsection{Efeitos Aerodinâmicos da Formação de Gelo}

As primeiras pesquisas dos efeitos aerodinâmicos da formação de gelo tiveram o objetivo de avaliar os coeficientes de sustentação $\left(C_{l}\right)$ e de arraste $\left(C_{d}\right)$. O primeiros trabalhos foram apresentados no fim da década de 20 e identificaram que o maior efeito da formação de gelo era a degradação aerodinâmica dos aerofólios. Neste período estudou-se as condições metereológicas da formação de gelo em ensaios em vôo. O resultado dos trabalhos eram recomendações, aos pilotos, que evitassem as condições estudadas.

Entre 1942 e 1944 foi construído o túnel de vento IRT (LEARY, 2002). Os primeiros ensaios tiveram o objetivo de avaliar as formas de gelo e de testar sistema de proteção. O coeficiente de arraste $\left(C_{d}\right)$ dos aerofólios era estimado através dos efeitos da camada limite na esteira do aerofólio e os coeficientes de sustentação $\left(C_{l}\right)$ e as variações do momento não eram medidos.

O trabalhos mais importantes de investigação dos efeitos da formação de gelo, neste período foram realizado por Gray e Glahn (1958), Gray (1958). Os autores obtiveram dados de sustentação, arraste e momento do aerofólio 65A004. Foram variadas as condições de formação de gelo e estudados os efeitos do tamanho das partículas $(M V D)$, quantidade de água $(L W C)$, temperatura, período de exposição, e ângulo de ataque $(\alpha)$. Os autores correlacioram as condições de teste com as formas de gelo e os coeficientes de sustentação, arraste e com o momento. Em um trabalho posterior, Gray (1964) utilizou dados de outros pesquisadores e expandiu as correlações, obtidas nos trabalhos anteriores, para um aerofólio genérico.

Em 1973 foi formado um grupo de trabalho entre Suécia e Rússia, que resultou em um relatório sobre os efeitos do gelo em aeronaves (INGELMAN; TRUNOV; IVANIKO, 1977). O estudo reportou os resultados de uma série de testes em túnel de vento, onde os efeitos aerodinâmicos da formação de gelo foram medidos. Deste relatório, resultou uma série de observações e recomendações foram feitas para o vôo em condições de gelo.

No fim dos anos 70 e na década de 80 houve um aumento nas pesquisas dos efeitos da formação de gelo e diversos trabalhos experimentais e de simulação por métodos computacionais foram apresentados. Brumby (1979) examinou os efeitos da rugosidade no coeficiente de sustentação máximo. O autor propôs gráficos que estimam a perda de sustentação em função da localização e do valor da rugosidade equivalente $\left(k_{s}\right)$. Bragg (1981) realizou extensos experimentos em um aerofólio NACA0012 e apresentou valores de coeficientes de arraste para formações de gelo rime e glaze. Korkan, Jr. e Cornell (1985) conduziram experimentos para avaliar o efeito do número de Reynolds Re nos coeficiente aerodinâmicos de aerofólios com e sem gelo. Os autores verificaram que a formação de gelo pode ocasionar um aumento do coeficiente de arraste $C_{d}$ de $120-200 \%$. Foi cosntatado que a variação do número de 
Reynolds Re não tem grande influência no desempenho do aerofólio quando há formação de gelo. Flemming e Lednicer (1985) propuseram correlações para a performance de aerofólios baseados em uma série de experimentos com aerofólios de helicópteros.

Apesar da maioria dos trabalhos estudarem a formação de gelos em vôo, houve também necessidade de estudar as condições de decolagem e as condições de início do congelamento. Zierten e Khodadoust (1987), Hengst e Boer (1991) estudaram a performance aerodinâmica de jatos comerciais com formação de gelo na decolagem. Bragg, Heinrich e Valarezo (1994) realizaram testes para estudar o congelamento na superfície inferior do aerofólio e concluíram que o efeito, das formações de gelo estudadas, eram desprezíveis durante a decolagem da aeronave.

Após o ano de 1995, as pesquisas dos efeitos aerodinâmicos concentraram-se nas formações de gelo em condições onde há gotas de água de grande diâmetro SLD (Super Large Droplets. As pesquisas foram motivadas pelo acidente com a aeronave ATR-72, que voava em condições atmosféricas com $S L D$. Uma extensiva revisão bibliográfica dos estudos sobre este tópico foi apresentada por Bragg, Broeren e Blumenthal (2005). Em resumo, em uma condição de operação com $S L D$, a formação de gelo ocorre após a área protegida dos aerofólios e as formas de gelo são semelhantes à cumes ou semi-esferas. O tamanho e a localização das formas variavam com o diâmetro médio $M V D$, ângulo de ataque e temperatura do escoamento. Trabalhos posteriores mostraram que a forma e a posição deste tipo de formação de gelo afetam significativamente o coeficiente de sustentação do aerofólio.

Kim e Bragg (1999) testaram um aerofólio NFL-0414 com formas de gelo Glaze obtidas no túnel IRT. Os pesquisadores constataram que a altura da formação de gelo, que tem um aspecto de chifre, tem uma pequena influência no coeficiente de sustentação da aeronave quando está localizada perpendicularmente ao bordo de ataque e na mesma direção do escoamento. A altura do chifre tem um efeito maior na aerodinâmica do aerofólio quando ele está localizado a jusante do bordo de ataque. Papadakis, Alansatan e Seltmann (1999), Papadakis, Alansatan e Wong (2000) conduziram um estudo similar com formas de gelo simuladas com spoilers. Os autores concluíram que as maiores degradações aerodinâmicas ocorreram quando a posição do spoiler era perpendicular à corda do aerofólio.

Os efeitos da formação de gelo em aerofólios de aeronaves comercias foi estudado por Addy (2000), Addy et al. (2003). Uma importante conclusão deste trabalho foi que o número de Reynolds Re tem pouco efeito no desempenho de aerofólios com formação de gelo.

Wright e Chung (2000) compararam o desempenho aerodinâmico de 20 formas de gelo e desenvolveram correlações entre a geometria das formas e os parâmetros de degradação aerodinâmica do aerofólio. 
Os efeitos das formações de gelo durante a operação de sistemas de degelo foram estudados por Gile-Laflin e Papadakis (2001), Jackson e Bragg (1999). Nos dois estudos os autores observaram uma redução do coeficiente de sustentação do aerofólio de $30 \%$ durante os ciclos do sistema de proteção. Broeren, Addy e Bragg (2002) testaram um aerofólio NACA 23012 com um sistema de degelo pneumático e obtiveram uma degração dos coeficientes aerodinâmicos de 60\%. Similarmente aos resultados de degradação aerodinâmica em aerofólios de aeronaves comerciais, os autores constataram que o número de Reynolds Re não tem influência na performance dos aerofólios durante as operações do sistema degelo.

As publicações, nos últimos anos, sobre efeitos aerodinâmicos concentraram-se nos resultados de análises do escoamento por métodos computacionais em aerofólios com formação de gelo. Os dados experimentais coletados são utilizados para a verificação e ajuste de modelos e, em grande parte, tratam os efeitos aerodinâmicos das formações de gelo em condições de grandes gotas de água $(S L D)$. É reconhecido, pela comunidade científica, que os parâmetros aerodinâmicos são de grande importantes para a avaliação de experimentos e simulações numéricas de crescimento de gelo em aerofólios. 


\section{Modelo Matemático}

Neste capítulo são apresentados os modelos da camada limite da quantidade de movimento e térmica utilizados para a avaliação do coeficiente de transferência de calor sobre aerofólios. São apresentados os critérios de disparo da transição do regime laminar para o turbulento e uma formulação para a previsão da rugosidade equivalente $k_{s}$.

\subsection{Camada Limite Laminar}

\subsubsection{Camada Limite da Quantidade de Movimento}

A camada limite dinâmica laminar é resolvida por meio de uma aproximação desenvolvida por Thwaites (apud KAYS; CRAWFORD, 1993). As principais hipóteses do modelo são:

- regime permanente;

- superfície isotérmica;

- raio de curvatura $\mathrm{R}$ muito grande;

- efeitos de evaporação na camada limite de quantidade de movimento desprezíveis;

- escoamento incompressível.

A equação da camada limite dinâmica é dada por:

$$
\begin{gathered}
\frac{u_{e}}{\nu_{a r}} \cdot \frac{d \delta_{2}}{d s}=F(\lambda) \\
\lambda=\frac{\delta_{2}^{2}}{\nu_{a r}} \cdot \frac{d u_{e}}{d s}
\end{gathered}
$$

Thwaites desenvolveu uma aproximação com base em soluções exatas da Equação 3.1 que é dada por: 


$$
F(\lambda)=0,44-5,68 \cdot \lambda
$$

Utilizando a simplificação de Thwaites a Equação 3.1 é dada por:

$$
d\left(\delta_{2}^{2} \cdot u_{e}^{5,68}\right)=0,44 \cdot \nu_{a r} \cdot u_{\infty} \cdot d s
$$

Sabendo que os valores de $\delta_{2}$ e $u_{\infty}$ são zero no ponto de estagnação, a espessura da quantidade de movimento é dada por:

$$
\delta_{2, l a m}=\frac{0,664 \cdot \nu_{a r}^{1 / 2}}{u_{e}^{2,84}} \cdot\left(\int_{s_{\text {estag }}}^{s_{\text {tr }}} u_{e}^{4,68} d s\right)^{1 / 2}
$$

sendo $s_{\text {estag }}$ a coordenada curvilínea do ponto de estagnação e $s_{t r}$ a coordenada curvilínea do início da transição laminar para turbulenta.

\subsubsection{Camada Limite Térmica}

Kays e Crawford (1993) definiram que a variação da espessura de condução da camada limite térmica $\Delta_{4}$ pode ser expressa pela seguinte forma adimensional:

$$
\frac{u_{e}}{\nu_{a r}} \frac{d \Delta_{4}^{2}}{d s}=f\left(\frac{\Delta_{4}^{2}}{\nu_{a r}} \frac{d u_{e}}{d s}, \operatorname{Pr}\right)
$$

A função $f$, no lado direito da Equação 3.4, é determinada pela solução analítica do escoamento ao redor de cunhas (wedge flow) ${ }^{1}$.

Smith e Spalding (1958) desenvolveram procedimentos para avaliar a camada limite térmica sobre uma superfície lisa e rugosa, com as seguintes considerações.

- Número de Prandtl Pr constante;

- Efeitos da forma e da espessura da camada limite desprezíveis;

- Crescimento da espessura da camada limite depende somente das condições locais.

A partir de aproximações lineares os autores desenvolveram a seguinte expressão para o cálculo da espessura de condução:

\footnotetext{
${ }^{1}$ família de escoamentos de Falkner-Skan para vários gradientes de pressão
} 


$$
\frac{u_{e}}{\nu_{a r}} \cdot \frac{d \Delta_{4}^{2}}{d s}=11,68-2,87 \frac{\Delta_{4}^{2}}{\nu_{a r}} \frac{d u_{e}}{d s}
$$

Integrando a Equação 3.5 obtém-se:

$$
\Delta_{4}^{2}=\frac{11,68 \cdot \nu_{a r}}{u_{e}^{2,87}} \cdot\left(\int_{s_{\text {estag }}}^{s_{\text {tr }}} u_{e}^{1,87} d s\right)
$$

A partir da definição do número de Stanton St a Equação 3.6 resulta em:

$$
S t=0,418 \cdot \frac{\mu_{a r} \cdot G_{e}^{0,435}}{\left(\int_{s_{e s t a g}}^{s_{t r}} G_{e}^{1,87} d s\right)}
$$

em que $G_{e}=\rho_{e} \cdot u_{e}$ e $S t=h /\left(G_{e} \cdot C_{p, a r}\right)$

A espessura de condução no ponto de estagnação $\left(s \rightarrow s_{\text {estag }}\right)$ é avaliada por:

$$
\left(\frac{\Delta_{4}}{c}\right)^{2}\left(\frac{V_{\infty}}{\nu_{a r}}\right)=4,07\left[\frac{d\left(u_{e} / V_{\infty}\right)}{d(s / c)}\right]_{s-s_{e s t a g}}^{-1}
$$

Partindo da equação 3.8, Spalding (1958) desenvolveu a seguinte expressão para o cálculo da espessura de entalpia:

$$
u_{e} \cdot \Delta_{2}=\left[0,7 \cdot \frac{k_{a r}}{\rho_{a r} \cdot C_{p, a r}} \int_{s_{\text {estag }}}^{s_{t r}}\left(\frac{u_{e}}{\delta_{4}}\right)^{0,5} d s\right]
$$

\subsection{Camada Limite Turbulenta}

\subsubsection{Camada Limite da Quantidade de Movimento}

Kays e Crawford (1993) desenvolveram a equação da quantidade de movimento na forma integral para a camada limite dinâmica turbulenta, admitindo as seguintes hipóteses simplificadoras:

- regime permanente;

- $u^{+}=8,75 \cdot\left(y^{+}\right)^{1 / 7}$ é utilizada para toda espessura da camada limite, e consequentemente $\delta_{1} / \delta_{2}=1,29=H$

- efeito da formação da esteira desprezível; 
- efeito do gradiente de pressão desprezível;

- raio de curvatura $\mathrm{R}$ da superfície muito grande;

- efeito da evaporação desprezível;

- escoamento incompressível.

Utilizando estas hipóteses os autores definiram que a tensão de cisalhamento $\tau_{o}$ pode ser definida como:

$$
\tau_{0}=0,0125 \cdot \rho_{a r} \cdot u_{e}\left(\frac{\delta_{2} \cdot u_{e}}{\nu_{a r}}\right)^{-0,25}
$$

A equação integral da quantidade de movimento é expressa em função da espessura de quantidade de movimento $\delta_{2}$ na seguinte forma adimensional (KAYS; CRAWFORD, 1993).

$$
\frac{C_{f}}{2}=\frac{d \delta_{2}}{d s}+\delta_{2} \cdot\left[\left(2+\frac{\delta_{1}}{\delta_{2}}\right) \cdot \frac{1}{u_{e}} \cdot \frac{d u_{e}}{d s}\right]
$$

em que $C_{f}=\tau_{0} /\left(0,5 \cdot \rho_{e} \cdot u_{e}^{2}\right)$.

Substituindo a Equação 3.10 na Equação 3.11, utilizando as hipóteses simplificadoras e integrando a Equação 3.11, os autores obtiveram a seguinte expressão:

$$
\delta_{2, t u r b}=\frac{0,036 \cdot \nu_{a r}^{0,2}}{u_{e}^{3,29}} \cdot\left(\int_{s}^{0} u_{e}^{3,86} d s\right)^{0,8}
$$

Na condição que há a transição entre o regime laminar para o turbulento, admite-se que a função $\delta_{2}$ é contínua, ou seja, $\delta_{2, t r}=\delta_{2, l a m, t r}=\delta_{2, t u r b, t r}$. A Equação 3.3 fornece a condição inicial de integração da Equação 3.12, que tem a seguinte forma:

$$
\delta_{2, t u r b}=\frac{0,036 \cdot \nu_{a r}^{0,2}}{u_{e}^{3,29}} \cdot\left(\int_{s_{t r}}^{s} u_{e}^{3,86} d s\right)^{0,8}+\delta_{2, l a m, t r}
$$

\subsubsection{Camada Limite Térmica Turbulenta sobre uma Superfície Rugosa}

Kays e Crawford (1993) desenvolveram um modelo matemático para prever o número de Stanton no regime turbulento que é dado pela seguinte equação.

$$
\mathrm{St}_{\text {turb }}=\frac{C_{f, \text { turb }} / 2}{\operatorname{Pr}_{\text {turb }}+\left(C_{f, t u r b} / 2\right)^{0,5} / \mathrm{St}_{k}}
$$


Sendo $S t_{k}$ o número de Stanton baseado na altura da rugosidade, que é definido por:

$$
\mathrm{St}_{k}=C \cdot \operatorname{Re}_{k}^{a} \cdot \operatorname{Pr}^{b}
$$

sendo $R e_{k}$ o número de Reynolds rugoso dado pela seguinte equação.

$$
\begin{aligned}
& \operatorname{Re}_{k}=\left(u_{\tau} \cdot k_{s}\right) / \nu_{a r} \\
& u_{\tau}^{2}=\frac{c_{f} \cdot u_{e}^{2}}{2}=\frac{\tau_{0}}{\rho_{a r}}
\end{aligned}
$$

Dipprey e Sabersky (1963) definiram $a=-0,2$ e $b=-0,44$ com base em dados experimentais em esferas densamente empacotadas. Para uma condiçãode rugosidade semelhante, Pimenta, Moffat e Kays (1975) definiram $C=0,8$ quando utiliza-se $P r_{t}=0,9$.

Owen e Thomson (1963) definiram $a=-0,45$ e $b=-0,8$ com base em dados experimentais em rugosidades densas e igualmente espaçadas. De acordo com os autores, o valor de $C=1,92$ é uma boa aproximação quando a forma e a distribuição da rugosidade é desconhecida. Esta é a formulação utilizada nos programas LEWICE e ONERA, e foi utilizada na implementação do código deste trabalho com $P r_{t}=0,9$.

Com o uso das leis de parede para superfícies totalmente turbulentas e fazendo ajustes empíricos, Kays e Crawford (1993) definiram o coeficiente de atrito turbulento pela Equação 3.17, que foi utilizada na implementação do código do presente trabalho.

$$
\frac{C_{f, t u r b}}{2}=\frac{0,168}{\left[\ln \left(864 \cdot \delta_{2, \text { turb }} / k_{s}\right)\right]^{2}}
$$

Wright (1995) avaliou o $C_{f, t u r b}$ por:

$$
\frac{C_{f, \text { turb }}}{2}=\frac{0,168}{\left[\ln \left(864 \cdot \delta_{2, \text { turb }} / k_{s}+2,568\right)\right]^{2}}
$$

Makkonnen (1985) avaliou o coeficiente de atrito considerando uma superfície lisa e virtualmente localizada no topo da rugosidade, conforme a Equação 3.19.

$$
C_{f, t u r b}=0,025 \cdot \operatorname{Re}_{\delta_{2}}^{-1 / 4}
$$




\subsection{Transição Laminar-Turbulenta}

Os códigos clássicos assumem que a transição ocorre abrutamente na posição $s_{t r}$. Na transição abrupta o escoamento é laminar na célula a montante do local de transição e totalmente turbulento na célula onde o critério para a transição é atingido.

O código LEWICE adota um critério empírico clássico, que foi originalmente definido por Doenhoff e Horton (1956) para escoamento ao redor de aerofólio rugoso. A transição ocorre para $R e_{k}$ dado por:

$$
R e_{k s}=\frac{u_{k} \cdot k_{s}}{\nu} \sim 600
$$

em que $u_{k}$ é a velocidade no topo da provável rugosidade de máxima altura , e é calculada pela aproximação polinomial de Pohlhausen (WHITE, 2000).

$$
\frac{u_{k}}{u_{e}}=2\left(\frac{k_{s}}{\delta_{l a m}}\right)-2\left(\frac{k_{s}}{\delta_{l a m}}\right)^{3}+\left(\frac{k_{s}}{\delta_{l a m}}\right)^{4}+\frac{\lambda}{6}\left(\frac{k_{s}}{\delta_{\text {lam }}}\right)\left(1-\frac{k}{\delta_{l a m}}\right)^{3}
$$

Onde $\lambda$ é dado pela Equação $3.1 b$ e $\delta_{\text {lam }}$ é a espessura da camada limite da quantidade de movimento.

Os códigos ONERA e TRAJICE utilizam o critério da Equação 3.20, porém, os autores utilizam a velocidade na fronteira superior da camada limite $u_{e}$ para a avaliação do número de Reynolds. As duas formulações fornecem resultados equivalentes pois a altura da rugosidade é semelhante à altura da camada limite (PIMENTA, 1975). Foi utilizada neste trabalho, a formulação da Equação 3.22 .

$$
R e_{k s}=\frac{u_{e} \cdot k_{s}}{\nu} \sim 600
$$

O número de Stanton na região de transição é avaliado pela combinação linear de $S t_{\text {lam }}$ e $S t_{\text {turb }}$, que são ponderados pela função intermitência $\gamma(s)$. Esta combinação linear pode também ser aplicado ao cálculo do coeficiente de atrito $C_{f}$.

$$
\operatorname{St}(s)=[1-\gamma(s)] \cdot S t_{\text {lam }}+\gamma(s) \cdot S t_{\text {turb }}
$$

A função intermitência $\gamma(s)$ é definida como a fração de tempo que o escoamento é turbulento em certa posição $s$. Este valor é zero $\gamma=0$ na região a montante do ponto de transição; e é unitária $\gamma=1,0$ na posição de fim da transição,onde o escoamento torna-se totalmente turbulento. Baseado no conceito de intermitência e em uma abrangente coleção de dados 
experimentais, Abu-Ghannam e Shaw (1980) definiram a função intermitência $\gamma(s)$ como:

$$
\gamma(s)=1-\exp \left[-5 \cdot\left(\frac{s-s_{t r}}{s_{f}-s_{t r}}\right)^{3}\right]
$$

sendo $s_{t r}$ é a posição de início da transição em relação ao ponto de estagnação e $s_{f}$ é a posição final da região de transição. A diferença $\left(s_{f}-s_{t r}\right)$ fornece o comprimento da transição.

\subsection{Rugosidade Equivalente do Grão de Areia}

A Equação 3.25 foi obtida com dados experimentais para o cálculo da rugosidade $k_{s}$ equivalente de formas de gelo em aerofólios. Esta qquação é utilizada no código LEWICE (RUFF; BERKOWITZ, 1990) e no presente trabalho.

$$
\begin{gathered}
k_{s}=\left[\frac{k_{s} / c}{\left(k_{s} / c\right)_{\text {base }}}\right]_{u_{\infty}} \cdot\left[\frac{k_{s} / c}{\left(k_{s} / c\right)_{\text {base }}}\right]_{L W C} \cdot\left[\frac{k_{s} / c}{\left(k_{s} / c\right)_{\text {base }}}\right]_{T_{s}} \cdot\left(k_{s} / c\right)_{\text {base }} \cdot c \\
{\left[\frac{k_{s} / c}{\left(k_{s} / c\right)_{\text {base }}}\right]_{L W C}=0.5714+0.2457 \cdot L W C+1.2571 \cdot L W C^{2}} \\
{\left[\frac{k_{s} / c}{\left(k_{s} / c\right)_{\text {base }}}\right]_{T_{\infty}}=46.8384 \cdot \frac{T_{\infty}}{1000}-11.2037} \\
{\left[\frac{k_{s} / c}{\left(k_{s} / c\right)_{\text {base }}}\right]_{u_{\infty}}=0,4286+0,0044139 \cdot u_{\infty}}
\end{gathered}
$$

O código ONERA utiliza o valor fixo de $k_{s} / c=0,001$ para todos as simulações cuja corda do aerofólio esteja no intervalo entre 0.2 e $1.5 \mathrm{~m}$. Versões mais recentes do código LEWICE (WRIGHT; GENT; GUFFOND, 1997) utilizam a Equação 3.26.

$$
k_{s}=\left(\frac{4 \cdot \sigma \cdot \mu_{\text {agua }}^{2}}{\rho_{\text {agua }} \cdot n_{f} \cdot \tau}\right)^{1 / 3}
$$

sendo $\sigma$ a tensão superficial e $\tau$ a tensão de cisalhamento na superfície do aerofólio. 


\section{Implementação do Modelo}

O modelo matemático mostrado no Capítulo 3 foi desenvolvido em um código numérico utilizando a linguagem Fortran77. O código numérico foi acoplado aos módulos de solução do escoamento, da trajetória de gotículas e crescimento de gelo do código ONERA.

\subsection{Pré e Pós Processamento}

Foram utilizados os módulos do código ONERA para o pré e o pós processamento do módulo implementado neste trabalho, conforme foi mostrado na Figura 1.6. O código ONERA é composto por quatro módulos, que realizam os seguintes cálculos:

- Módulo CHAMP: solução do escoamento totalmente potencial em torno do aerofólio;

- Módulo TRAJ: solução das trajetórias das gotas e cálculo da eficiência de coleta $(\beta(s))$;

- Módulo ECHAN: cálculo do coeficiente de transferência de calor convectivo através da análise integral da camada limite térmica;

- Módulo CAPT: balanço térmico e cálculo do crescimento de gelo.

Os resultados do código ONERA são considerados apropriados para a aplicação proposta pois são reconhecidos por autoridades homologadoras de vários países e foram publicados por Wright, Gent e Guffond (1997).

O cálculo do escoamento, realizada pelo módulo CHAMP, utiliza uma malha do tipo 'C' Esta malha é assim designada devido a sua semelhança com a letra 'C' do alfabeto, como é mostrado na Figuras 4.1 e 4.2. A mesma malha é utilizada para o cálculo do escoamento, independente do ângulo de ataque. Silva (2002) verificou que simulações com ângulos de ataque próximos a $\alpha=4^{o}$ podem apresentar dificuldades de convergência e desvios significativos em relação a dados experimentais. 


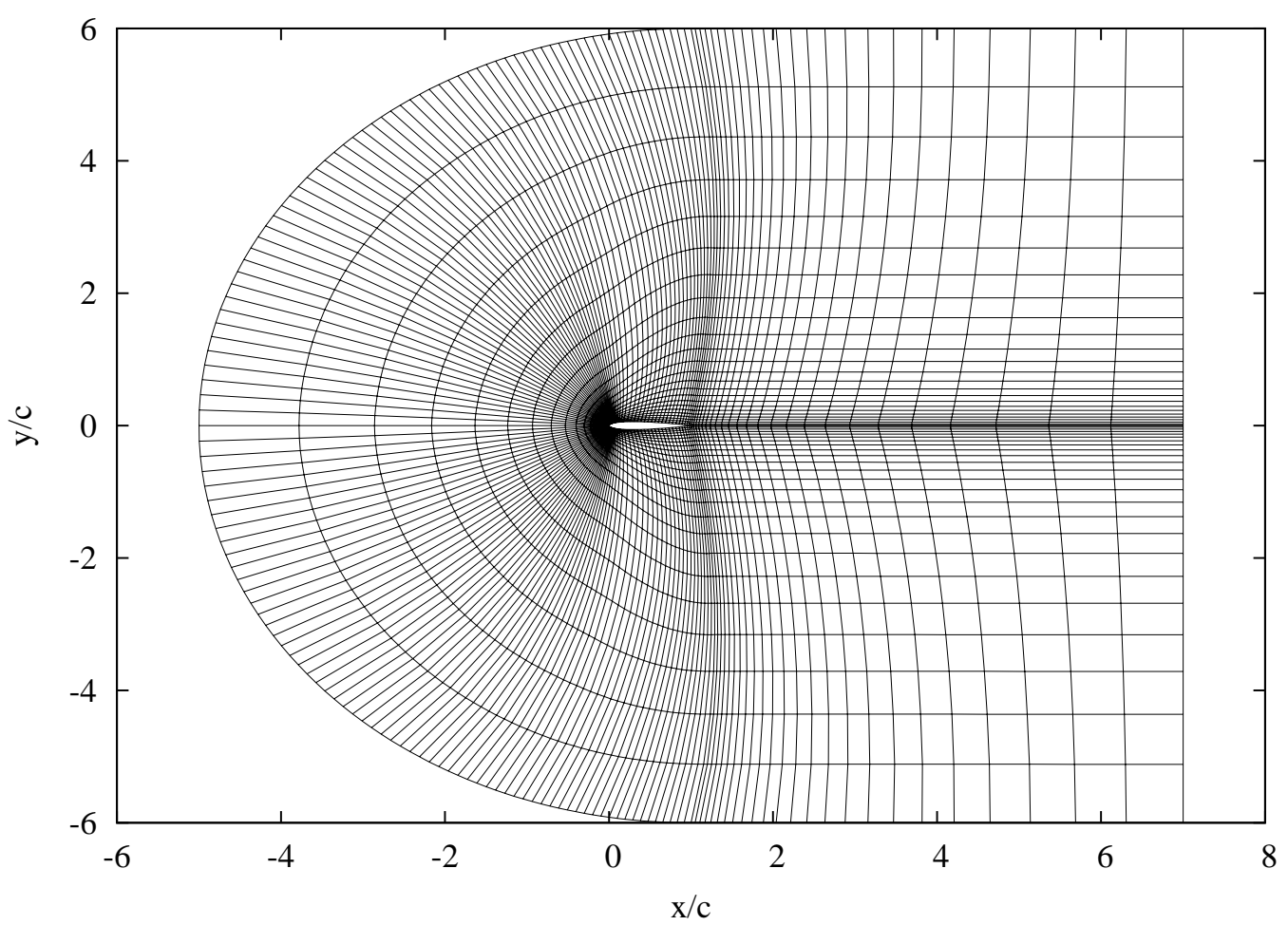

Figura 4.1: Malha $C$ completa dos escoamento potencial

O módulo CHAMP resolve o campo do escoamento potencial compressível e isoentrópico em torno do aerofólio, que é denominado escoamento potencial completo. O módulo foi desenvolvido originalmente por Bredif (1983) e depois incluído no ONERA por Guffond e Brunet (1988). A validação do solucionador do escoamento foi demonstrada por Bredif (1985) para condições experimentais até números de Mach $M_{\infty}=0,84$ e ângulos de ataque $\alpha=0^{\circ}$ até $\alpha=3,06^{\circ}$.

O módulo TRAJ foi implementado por Guffond e Brunet (1988). Este módulo calcula as trajetórias das partículas a partir de um referencial lagrangiano e o coeficiente de coleta $\beta(s)$. O módulo considera somente as forças de inércia e de arrasto na Equação da Conservação da Quantidade de Movimento.

$$
m_{\text {goticula }} \cdot \frac{d^{2} s_{g}}{d t^{2}}=\frac{1}{2} \cdot \rho_{a r} \cdot V_{r}^{2} \cdot A_{g} \cdot C_{d, g}
$$

Sendo que $C_{d}=f\left(R e_{g}\right)$ que é dado por:

$$
R e_{g}=\frac{D_{g} \cdot \rho_{a r} \cdot V_{r}}{\mu_{a} r}
$$

$V_{r}$ é a velocidade relativa entre a partícula e o escoamento, $C_{d, g}$ é o coeficiente de arraste da gotícula esférica, $A_{g}$ é a área da seção transversal da gotícula, $\rho_{a r}$ é a densidade do ar, $\mu_{a r}$ 


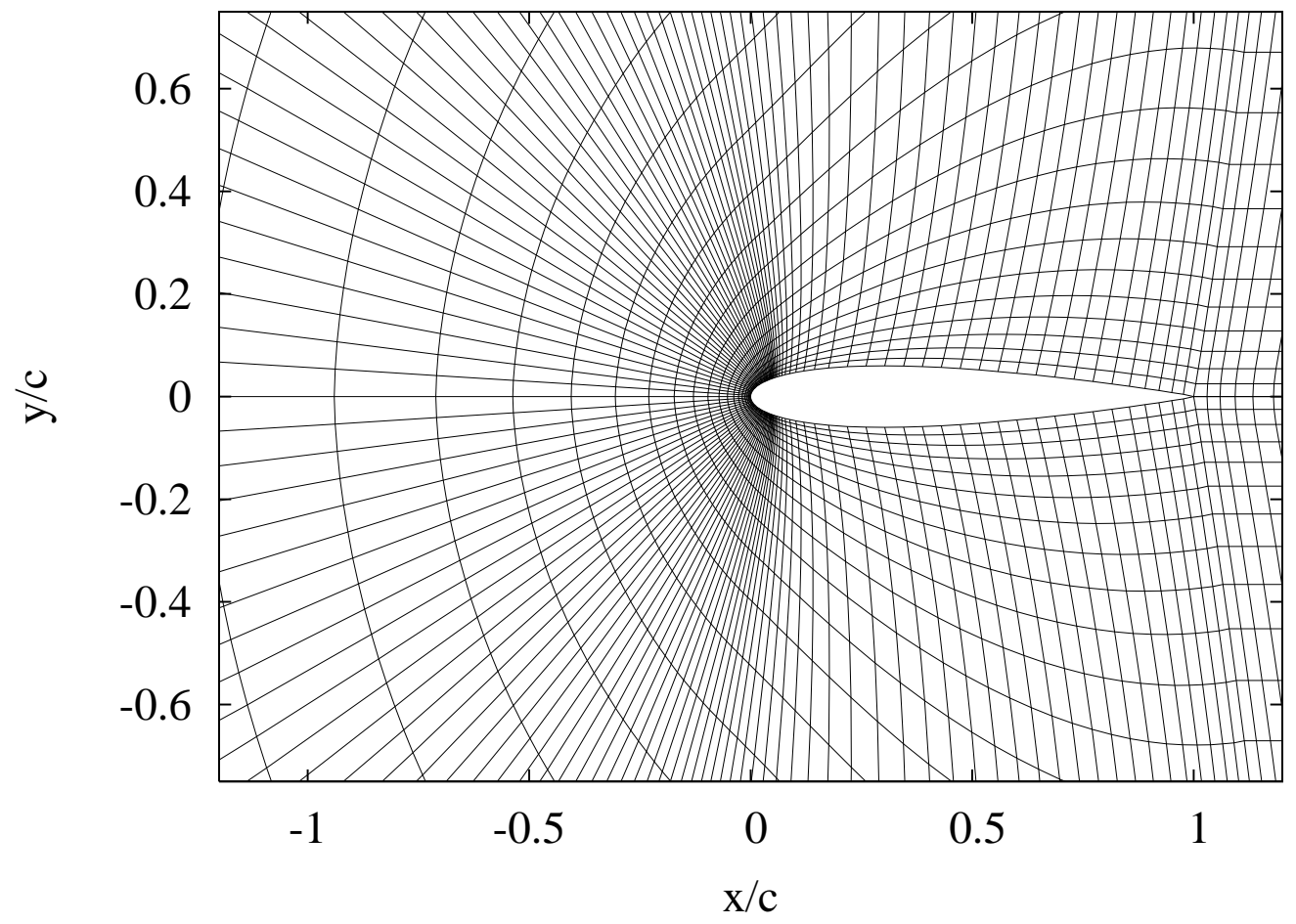

Figura 4.2: Malha computacional ao redor do aerofólio

é a viscosidade dinâmica do ar, $m_{\text {goticula }}$ é a massa da gotícula, $D_{g}$ é o diâmetro da gotícula e $s_{g}$ é o deslocamento da gotícula.

Guffond e Brunet (1988) validaram o cálculo do coeficiente de coleta local com dados experimentais em diferentes geometrias e compararam os resultados com os obtidos pelos códigos LEWICE e TRAJICE (WRIGHT; GENT; GUFFOND, 1997). Um exemplo do resultado do cálculo das trajetórias é mostrado na Figura 4.3.

O módulo ECHAN calcula o coeficiente de transferência de calor sobre o filme de líquido utilizando a avalição da camada limite térmica, de forma similar ao modelo que foi implementado neste trabalho. O módulo ECHAN não é utilizado nas simulações, e foi substituído pelo módulo implementado neste trabalho.

No módulo CAPT é calculado o crescimento do gelo. O modelo implementado é baseado no trabalho de Messinger (1953), o qual, aplica a Primeira Lei da Termodinâmica em uma superfície isotérmica e na temperatura de congelamento $T_{f}$.

A aplicação da Primeira Lei da Termodinâmica considera os seguintes efeitos:

- transferência de calor entre a superfície e o escoamento externo $\left(d \dot{q}_{\text {agua }}\right)$;

- fluxo de entalpia do vapor de água $\left(d \dot{m}_{\text {evap }} \cdot h_{\text {vapor }}\right)$

- fluxo da entalpia total da água impingida $\left(d \dot{m}_{i m p} \cdot h_{t o t a l}\right)$ 


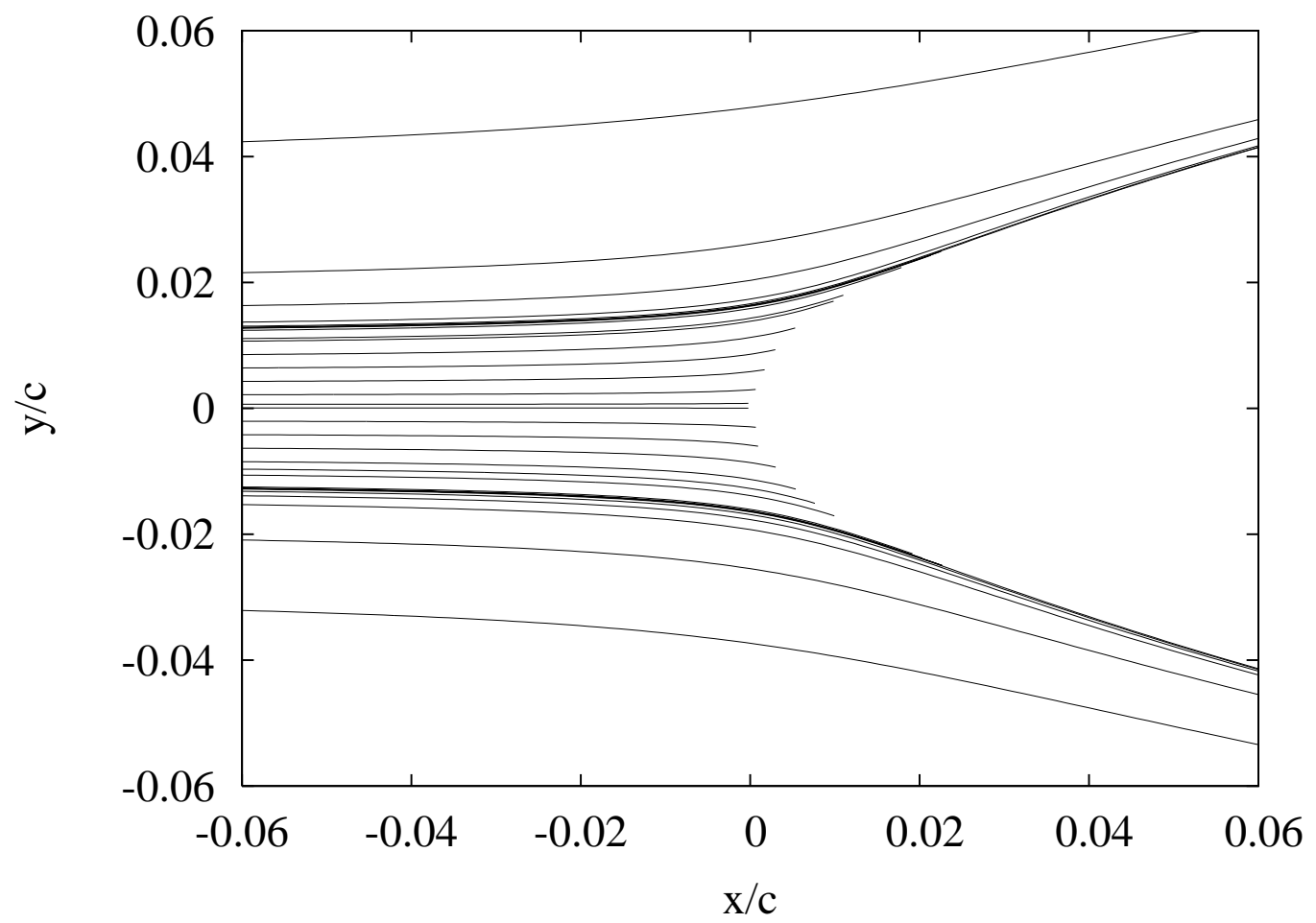

Figura 4.3: Trajetória de Partículas ao redor do Aerofólio

- fluxo de entalpia do elemento a montante $\left(d \dot{m}_{s} \cdot h_{s}\right)$

- fluxo do entalpia para o elemento a jusante $\left(d \dot{m}_{(s+d s)} \cdot h_{(s+d s)}\right)$

- entalpia de solidificação da água $\left(d \dot{m}_{g e l o} \cdot h_{l s}\right)$

A formulação básica da Primeira Lei da Termodinâmica para volumes finitos discretizados na água acumulada resulta em:

$$
-d \dot{q}_{\text {agua }}-d \dot{m}_{\text {evap }} \cdot h_{\text {vapor }}+d \dot{m}_{i m p} \cdot h_{\text {total }}+d \dot{m}_{s} \cdot h_{s}-d \dot{m}_{(s+d s)} \cdot h_{(s+d s)}+d \dot{m}_{\text {gelo }} \cdot h_{l s}=0
$$

A aplicação da Conservação de Massa resulta em:

$$
-d \dot{m}_{\text {evap }}+d \dot{m}_{i m p}+d \dot{m}_{s}-d \dot{m}_{(s+d s)}+d \dot{m}_{\text {gelo }}=0
$$

O código ONERA2D utiliza o procedimento de predição-correção para calcular a forma de gelo final. Neste procedimento os módulos são executados duas vezes. No primeiro cálculo, o programa estima uma forma de gelo utilizando a solução do escoamento e o cálculo da trajetória das partículas e do coeficiente de transferência de calor convectivo do aerofólio liso. No segundo cálculo, o programa soluciona o escoamento em torno da forma de gelo estimada 


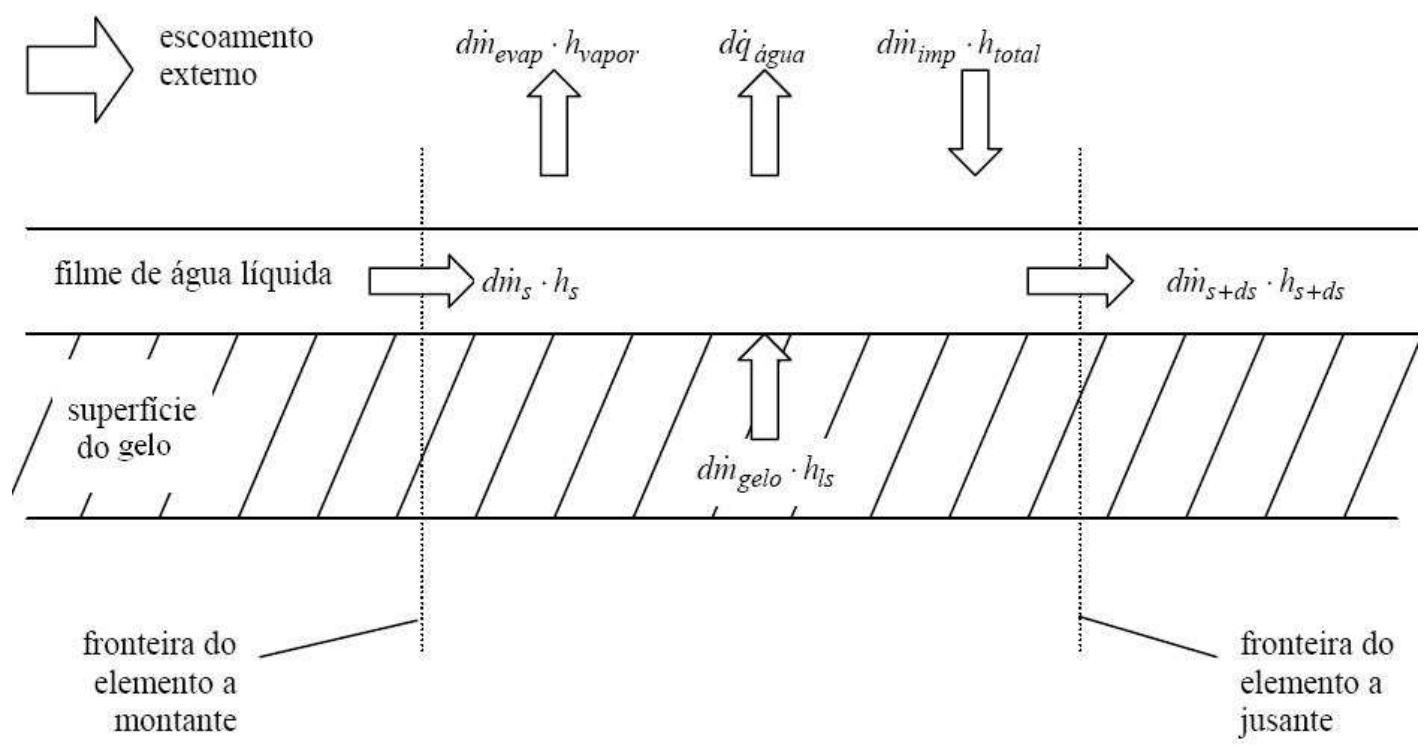

Figura 4.4: Volume de Controle infinitesimal para aplicação da primeira lei da termodinâmica à água acumulada sobre o aerofólio

e recalcula a trajetória das partículas e o coeficiente de transferência de calor convectivo. O programa faz uma interpolação linear dos valores de eficiência de coleta $\beta(s)$ e do coeficiente de transferência de calor do aerofólio liso e do aerofólio com a forma de gelo estimada, e usa os valores interpolados das variáveis no cálculo da forma de gelo final do aerofólio. Este método é bastante ágil, pois requer somente duas soluções do escoamento, porém pode ter grandes erros quando o tempo de crescimento do gelo for suficientemente grande para invalidar a hipótese de linearidade entre as soluções de predição, que é o aerofólio liso, e correção, que é o aerofólio com a forma de gelo estimada.

\subsection{Implementação do Código de Transferência de Ca- lor}

O código de transferência de calor foi implementado, por conveniência, na malha gerada pelo código ONERA. O primeiro elemento da malha tem índice $(i=1)$ é esta no bordo de fuga do aerofólio. O incremento dos índices é feito no sentido anti-horário. A célula que contém o ponto de estagnação tem índice $\left(i=i_{\text {stag }}\right)$ e a última célula da malha tem índice $\left(i=i_{n b p}\right)$.

Para a implementação do código de avaliação da camada limite foram considerados os domínios e o sistema de coordenadas mostrados na Figura 4.5. A coordenada $s$ é igual a zero no elemento da estagnação do escoamento, ou seja, na célula com índice $i_{\text {stag }}$. Esta coordenada é positiva no extradorso do aerofólio e negativa no intradorso, como mostra a figura.

As propriedades do ar são avaliadas no centro das células da malha e na temperatura 


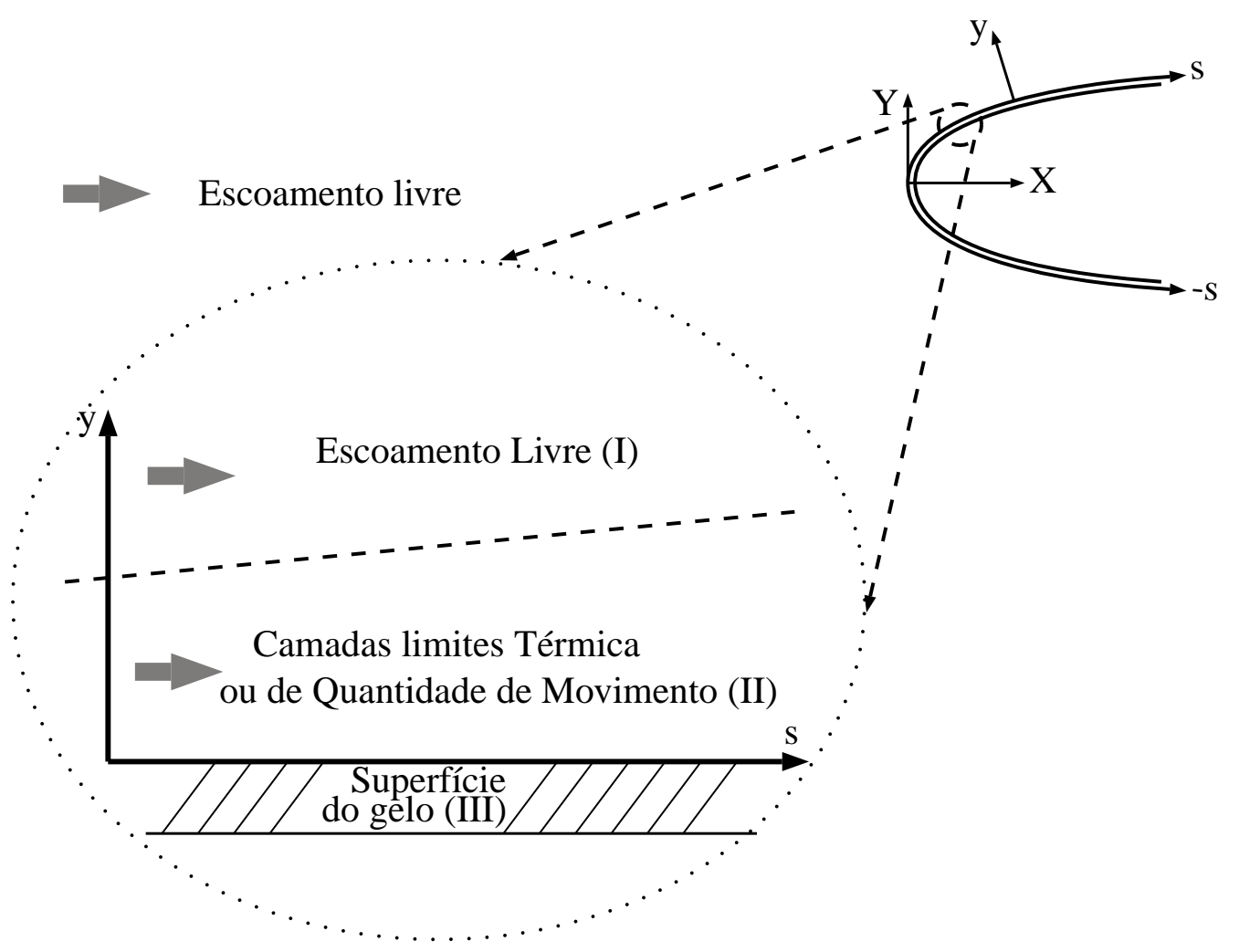

Figura 4.5: Domínios (I, II e III) e sistemas de coordenadas utilizadas no modelo matemático

temperatura da borda da camada limite $T_{e}$.

As equações integrais da camada limite dinâmica e térmica são resolvidas a partir do ponto de estagnação do aerofólio $\left(i_{\text {stag }}\right)$ até o bordo de fuga, na direção da coordenada $s$ mostrada na Figura 4.5. A solução é realizada em duas etapas, a primeira para o extradorso e a segunda para o intradorso do aerofólio.

O método dos trapézios é utilizado para a avaliação das integrais. Os intervalos de integração corresponde ao comprimento da célula da malha computacional e não são igualmente espaçados. O cálculo dos parâmetros da camada limite dinâmica e térmica requer a avaliação da derivada da velocidade na borda da camada limite $\left(\partial u_{e} / \partial s\right)$.

A transição é disparada quando o critério estabelecido na Equação 3.22 é atingido. Caso a transição ocorra abruptamente, considera-se que a célula da malha computacional onde o critério de disparo foi atingido, está no regime turbulento. Caso a transição seja suavizada, utiliza-se a função de intermitência para a avaliação da região de transição. Quando a transição é disparada, considera-se que o regime é turbulento da região de transição até o bordo de fuga do aerofólio. 


\subsection{Parâmetros de Similaridade}

Os parâmetros de similaridade são usados para determinar as condições de um teste de tunel que será realizado com um aerofólio que tem uma escala, em geral, menor que aerofólio real. São utilizados diversos parâmetros de similaridade, que são escolhidos em função das condições do teste e do tipo do aerofólio. Uma discussão ampla sobre os parâmetros de similaridade é apresentada por Anderson (2004).

Neste trabalho os parâmetros de similaridade foram utilizados para a verificar em quais condições de teste os resultados das simulações de previsão de gelo correspondem aos dados experimentais. Foram selecionados parâmetros publicados por Anderson (2004) que caracterizem as condições do escoamento, quantidade de água coletada, e transferência de calor.

\subsubsection{Similaridade do Escoamento}

O parâmetro adimensional que define a similaridade do escoamento é o número de Reynolds baseado no diâmetro do bordo de ataque do aerofólio $(d)$, que é definido como o dobro do raio do bordo de ataque.

$$
R e_{d}=\frac{u_{\infty} \cdot \rho_{\infty, a r} \cdot d}{\mu_{\infty, a r}}
$$

\subsubsection{Similaridade da Quantidade de Água}

Para levar em consideração a quantidade de água coletada pelo aerofólio é utilizado um número adimensional chamado de fator de acumulação que é definido na Equação 4.6.

$$
A_{c}=\frac{L W C \cdot u_{\infty} \cdot t}{\rho_{\text {gelo }} \cdot d}
$$

\subsubsection{Similaridade da Transferência de Calor}

Para a similaridade da troca de calor no aerofólio é utilizado o parâmetro definido na Equação 4.7 que é expresso na unidade de temperatura $[K]$.

$$
\phi=T_{f}-T_{\infty}-\frac{u_{\infty}^{2}}{2 \cdot C_{p, \text { agua }}}
$$

O trabalho de Anderson (2004) apresenta outros parâmetros de similaridade que se relacio- 
nam, por exemplo, com a trajetória das gotículas de água e com o escoamento do filme de água sobre o aerofólio. Foram selecionados, para este trabalho, os parâmetros estão relacionados com as variáveis que afetam a formação de gelo do tipo 'Rime' ou 'Glaze', que são a velocidade do escoamento ao longe $u_{\infty}$, a quantidade de água no escoamento $L W C$ e a temperatura do escoamento $T_{\infty}$. 


\section{Resultados}

A apresentação dos resultados, obtidos no presente trabalho, está dividida em duas seções. Na primeira seção são apresentados os resultados obtidos nas simulações da formação de gelo sobre aerofólios. Os resultados são comparados com resultados experimentais e com o resultado das simulações dos códigos ONERA, LEWICE e TRAJICE. Na segunda seção são apresentados alguns efeitos da formação de gelo no desempenho de aerofólios de uso aeronáutico.

\subsection{Formação de Gelo sobre Aerofólios}

Foram pesquisados na literatura casos de testes conhecidos pela comunidade aeronáutica e que são relevantes devido a sua abrangência e por sua validação. Foram selecionados os trabalhos apresentados de Kind (2001) e Shin e Bond (1994) como referências para comparação e validação dos resultados.

O trabalho publicado por Kind (2001) foi patrocinado pela NATO. O seu objetivo era avaliar o desempenho dos programas de simulação de previsão de formas de gelo disponíveis. Foram selecionados casos de teste que possuíam dados experimentais que foram obtidos com boa precisão em túneis. Foi dada preferência aos casos de formação de gelo do tipo Glaze, que são os mais difíceis de se preverem com simuladores numéricos. Foram selecionados um total de 31 casos. Na primeira etapa os pesquisadores e usuários dos programas receberam a descrição dos casos, e sem ter os resultados experimentais, obtiveram as formas de gelo simuladas. Na segunda etapa do trabalho, os resultados experimentais foram divulgados e os pesquisadores e usuários puderam rever suas simulações.

O trabalho publicado por Shin e Bond (1994) teve o objetivo de avaliar a repetibilidade dos resultados experimentais de formação de gelo. Os testes foram realizados no túnel IRT-Icing Research Tunnel da NASA e utilizaram um perfil de aerofólio NACA0012. Foram avaliadas as formas de gelo em cinco condições de operação, e foram variadas a temperatura estática ao longe $T_{\infty}$ e a quantidade de água $L W C$ do escoamento. Shin e Bond (1994) concluíram que há repetibilidade das formas de gelo nos experimentos realizados no IRT. As formas de gelo experimentais obtidas pelos autores foram consideradas de boa precisão e foram utilizadas 
Tabela 5.1: Casos de testes de Kind (2001) simulados no presente trabalho

\begin{tabular}{cccccccccc}
\hline Caso & Túnel & Aerofólio & $\begin{array}{c}\mathrm{c} \\
(\mathrm{m})\end{array}$ & $\begin{array}{c}u_{\infty} \\
(\mathrm{m} / \mathrm{s})\end{array}$ & $\begin{array}{c}\alpha \\
(\text { graus })\end{array}$ & $\begin{array}{c}T_{\infty} \\
(\mathrm{K})\end{array}$ & $\begin{array}{c}\text { LWC } \\
\left(\mathrm{g} / \mathrm{m}^{3}\right)\end{array}$ & $\begin{array}{c}\text { MVD } \\
(\mu \mathrm{m})\end{array}$ & $\begin{array}{c}\mathrm{t} \\
(\mathrm{s})\end{array}$ \\
\hline C04 & DERA & NACA0012 & 0,45 & 77,2 & 0,0 & 270,5 & 0,32 & 18,0 & 300,0 \\
\hline C06 & IRT & GLC305 & 0,91 & 69,9 & 0,0 & 257,4 & 1,16 & 50,0 & 258,6 \\
\hline C07 & IRT & GLC305 & 0,91 & 69,9 & 0,0 & 257,4 & 1,16 & 50,0 & 517,1 \\
\hline C13 & IRT & NACA0012 & 0,53 & 67,0 & 0,0 & 264,4 & 0,65 & 40,0 & 672,0 \\
\hline C14 & IRT & NACA0012 & 0,27 & 57,0 & 0,0 & 267,6 & 1,04 & 27,73 & 247,2 \\
\hline C17 & Boeing & NACA0012 & 0,91 & 67,0 & 3,0 & 266,0 & 1,00 & 24,8 & 1200,0 \\
\hline C18 & Boeing & NACA0012 & 0,91 & 67,0 & 3,0 & 266,0 & 1,00 & 38,8 & 1200,0 \\
\hline
\end{tabular}

para a avaliação das formas de gelo calculadas no presente trabalho.

Na Tabela 5.3 são mostrados os dados dos casos simulados neste trabalho. Não foram simulados, neste trabalho, os casos de aerofólios complexos, multi-corpo, cilindros e condições de presença de SLD. O aerofólio NACA0012 é utilizado na maior parte dos casos. Os casos C06 e C07 utilizam o aerofólio GLC305, que é semelhante aos aerofólios de pequenas aeronaves.

Foram selecionados alguns resultados de outros códigos, que foram publicados no relatório de Kind (2001), para serem comparados com os resultados obtidos no presente trabalho. O critério de seleção utilizado foi a relevância do programa para a comunidade aeronáutica e científica e que os resultados tivessem sido gerados pelo desenvolvedor do código. Foram selecionados os resultados dos programas ONERA, TRAJICE e LEWICE.

As Figuras 5.1 a 5.7 mostram as formas de gelo calculadas pelo código implementado neste trabalho, as formas de gelo obtidas experimentalmente e as formas de gelo dos programas ONERA, TRAJICE e LEWICE.

Todas as simulações utilizaram os mesmos parâmetros da camada limite para o cálculo do coeficiente de transferência de calor. Foi considerado que a transição entre os regimes laminar e turbulento ocorre de forma abrupta, e é disparada com o critério da Equação 3.22. O valor da rugosidade equivalente $k_{s}$ foi calculado com a formulação da Equação 3.25.

A simulação do caso C04, obtida neste trabalho e mostrada na Figura 5.1, apresenta uma grande semelhança com os resultados obtidos pelo código ONERA, o que evidencia que o valor do coeficiente de transferência de calor e da rugosidade dos dois programas são próximos.

A figura mostra que todos os códigos apresentaram deficiências na previsão da forma do gelo, como já apontara Gent (KIND, 2001). O relatório da NATO destaca que as formas de gelo simuladas tendem a ficar diferentes das formas experimentais conforme a temperatura $T_{\infty}$ e a quantidade de água $L W C$ aumentam. 


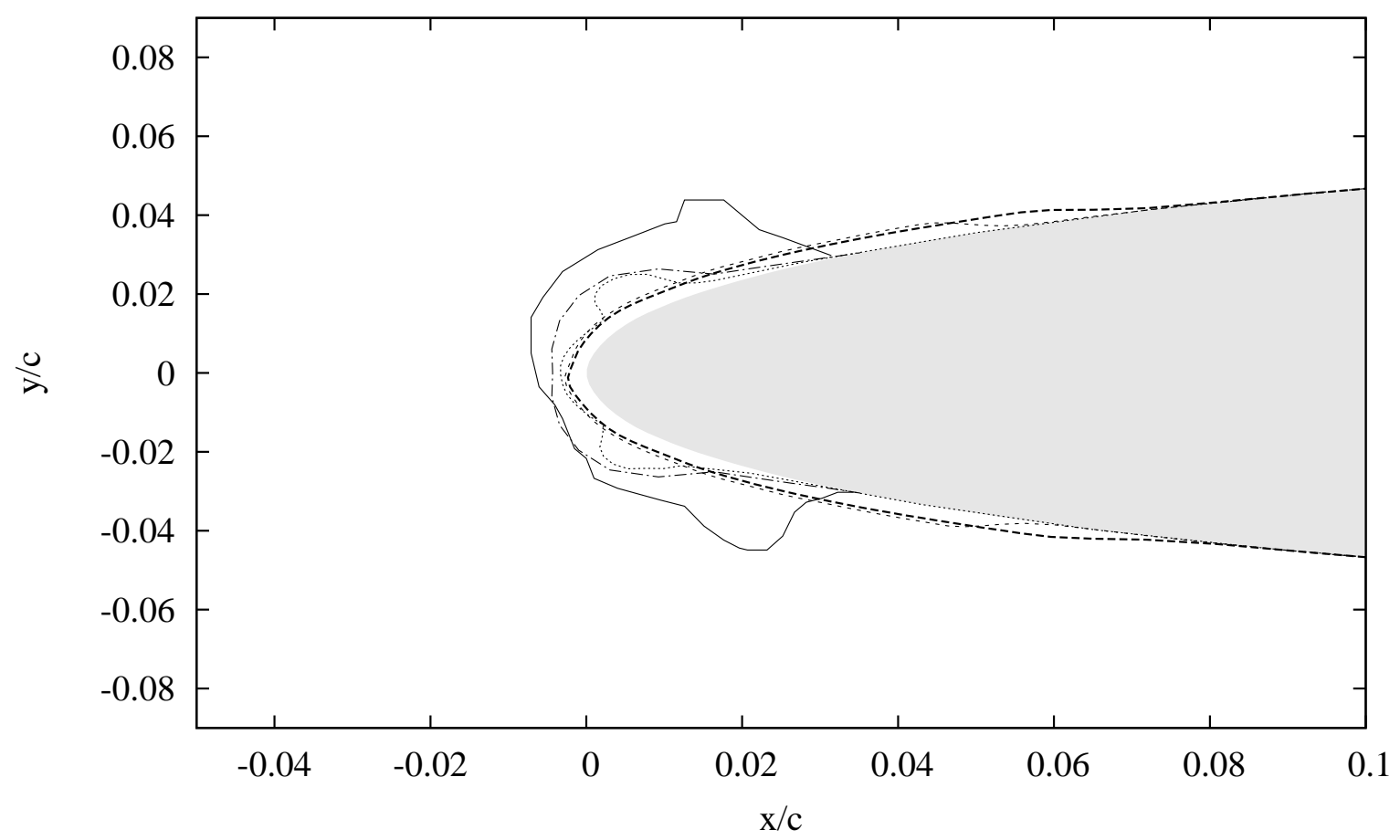

Experimental

LEWICE

Presente Trabalho

TRAJICE

ONERA

Figura 5.1: Formas de gelo simuladas para o caso C04 da Tabela 5.1

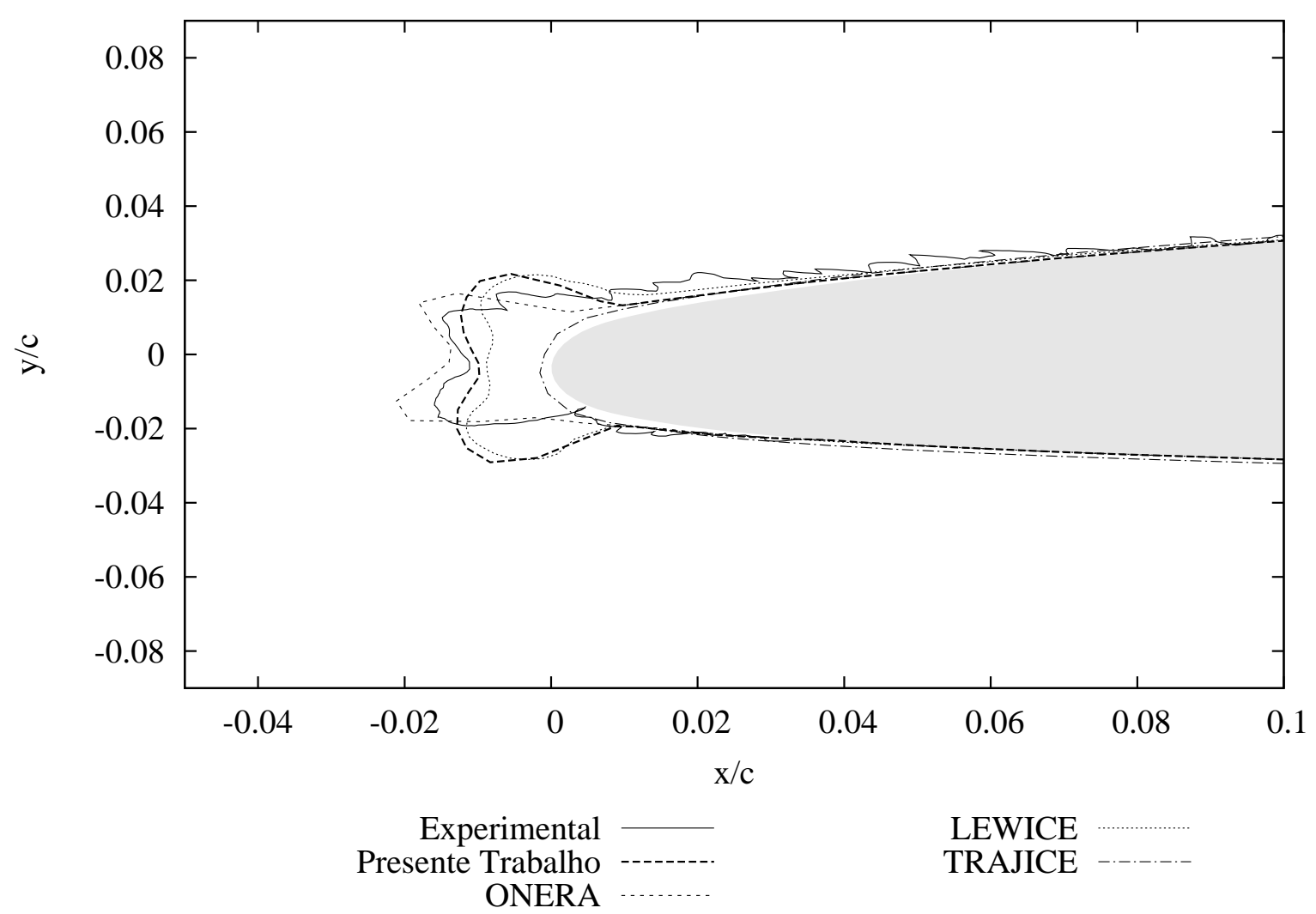

Figura 5.2: Formas de gelo simuladas para o caso C06 da Tabela 5.1 


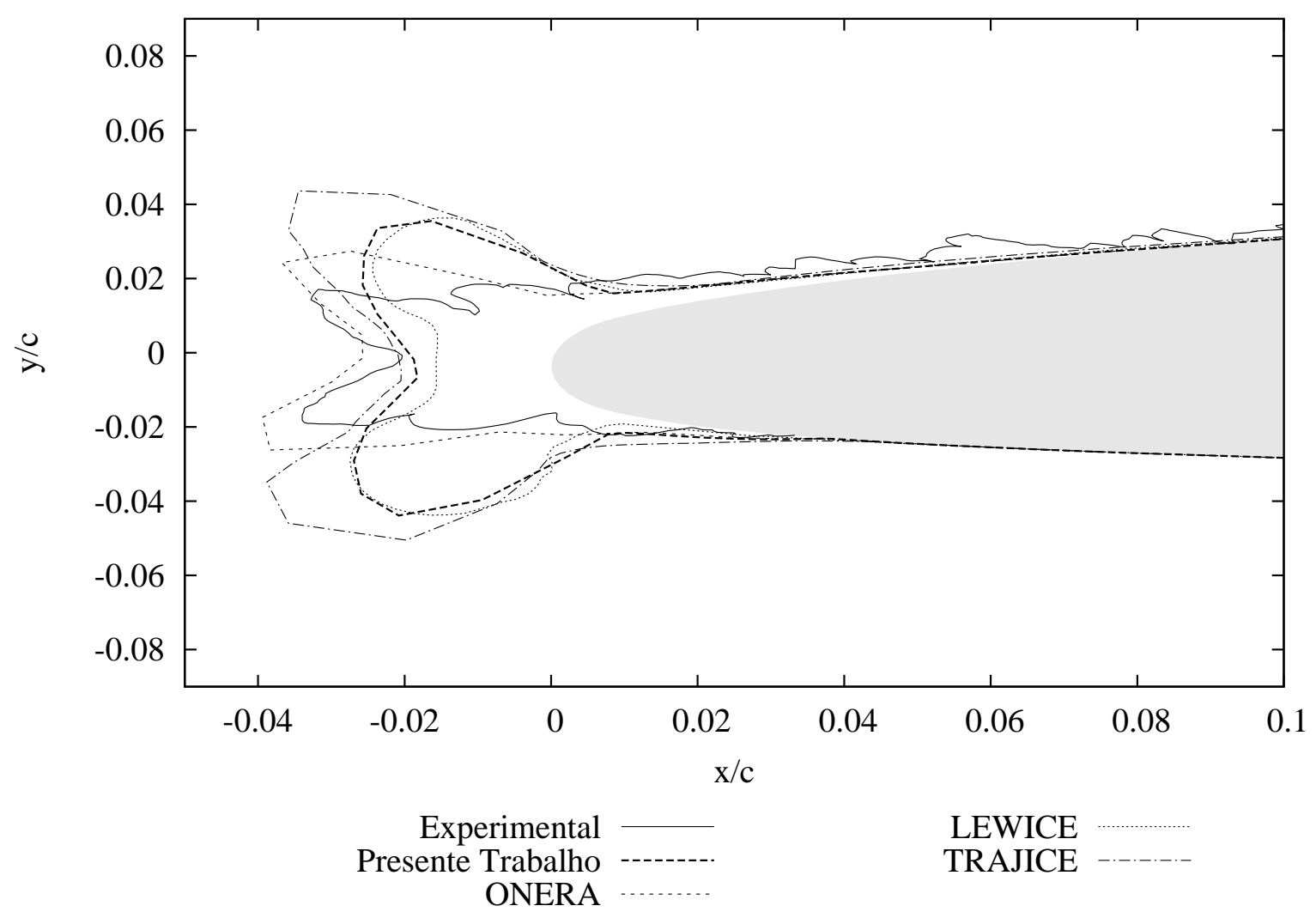

Figura 5.3: Formas de gelo simuladas para o caso C07 da Tabela 5.1

Os casos C06 e C07, apresentados nas Figuras 5.2 e 5.3, têm as mesmas condições atmosféricas, porém com tempo de crescimento do gelo diferentes. As formas de gelo experimentais são semelhantes e diferem na espessura do gelo, como é esperado. As formas de gelo calculadas neste trabalho aproximam-se dos resultados do código LEWICE. Os resultados do código ONERA foram os que apresentaram maior semelhança em relação ao perfil experimental. A comparação dos resultados deste trabalho para os casos C06 e C07, mostra que, com o aumento do tempo de exposição, há um aumento da divergência da forma de gelo simulada em relação ao perfil experimental. Considerando que os módulos de transferência de calor, de cálculo do escoamento e da trajetória de gotículas são independentes do tempo de exposição, pode-se atribuir ao módulo de crescimento do gelo, a piora da previsão das formas de gelo. Os métodos de previsão-correção apresentam erros maiores para tempos de maiores de exposição.

As simulações das formas de gelo para o caso C13, apresentado na Figura 5.4, geraram resultados bastante variados em relação aos dados experimentais. O programa ONERA e o programa TRAJICE tiveram resultados mais próximos aos dados experimentais. Na Tabela 5.2 mostra-se que este é caso cuja transição ocorre mais distante da estagnação do escoamento, e portanto, esta condição afeta a forma de gelo.

Os resultados da simulação do presente trabalho para o caso C14, apresentado na Figura 

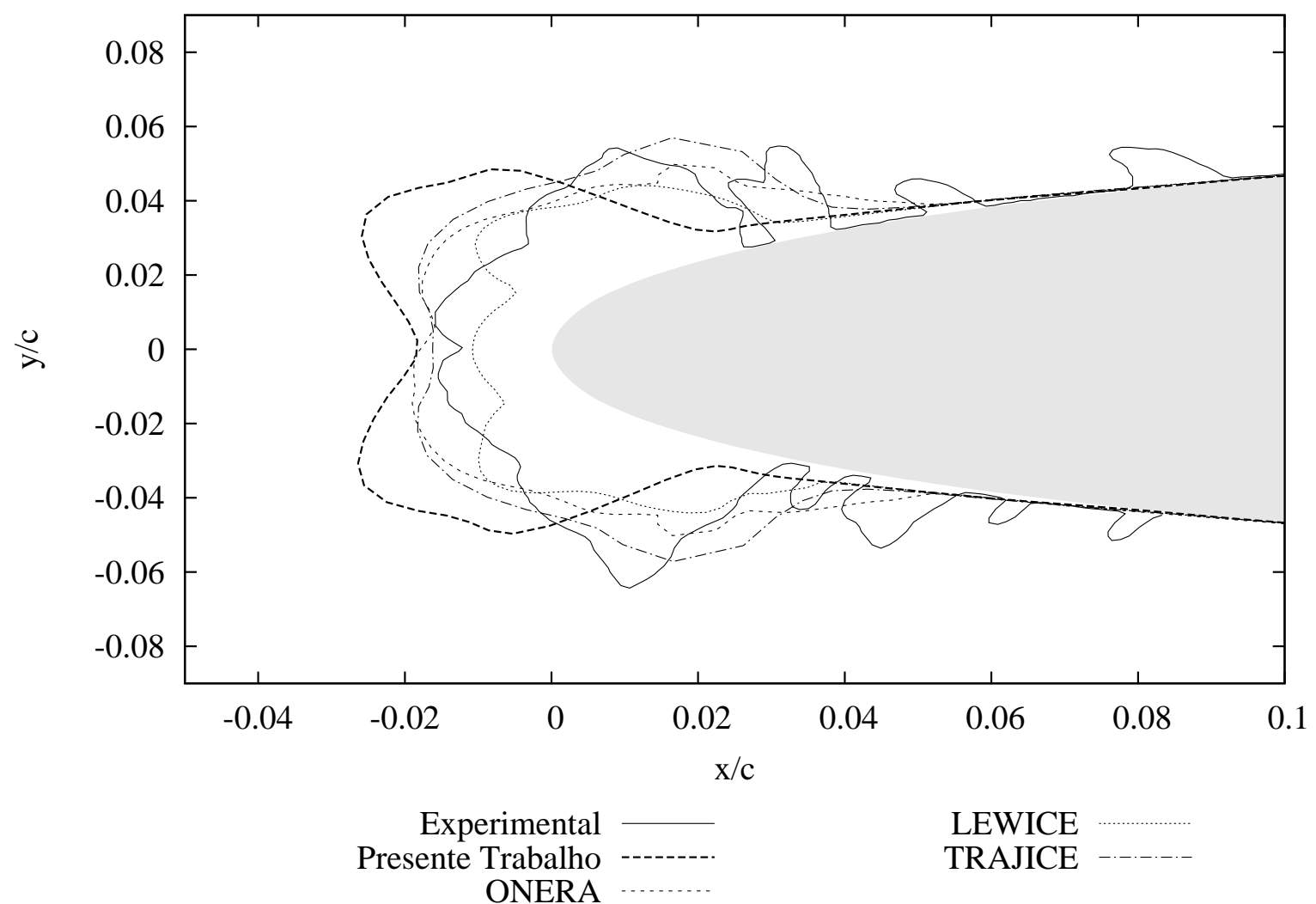

Figura 5.4: Formas de gelo simuladas para o caso C13 da Tabela 5.1

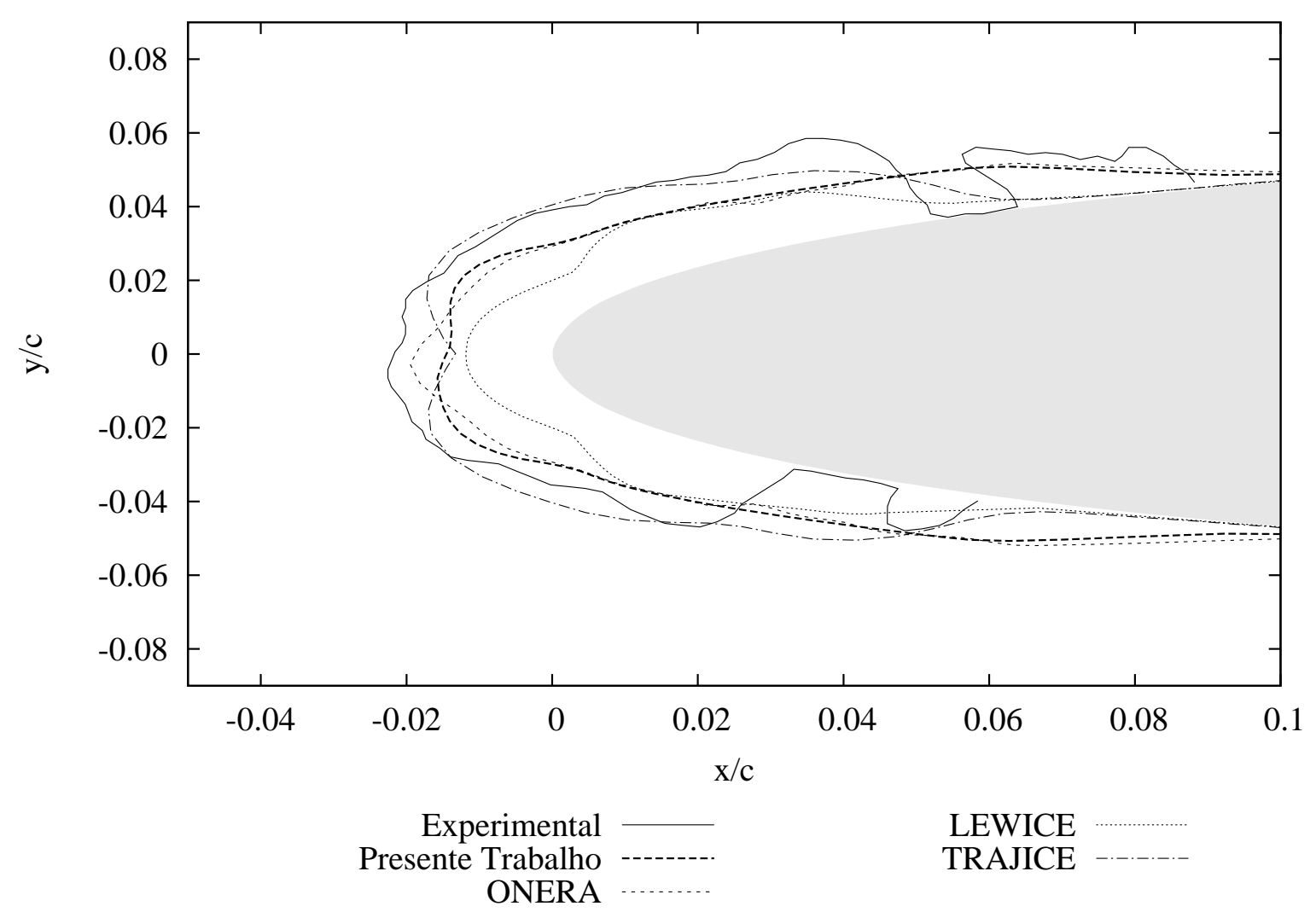

Figura 5.5: Formas de gelo simuladas para o caso C14 da Tabela 5.1 


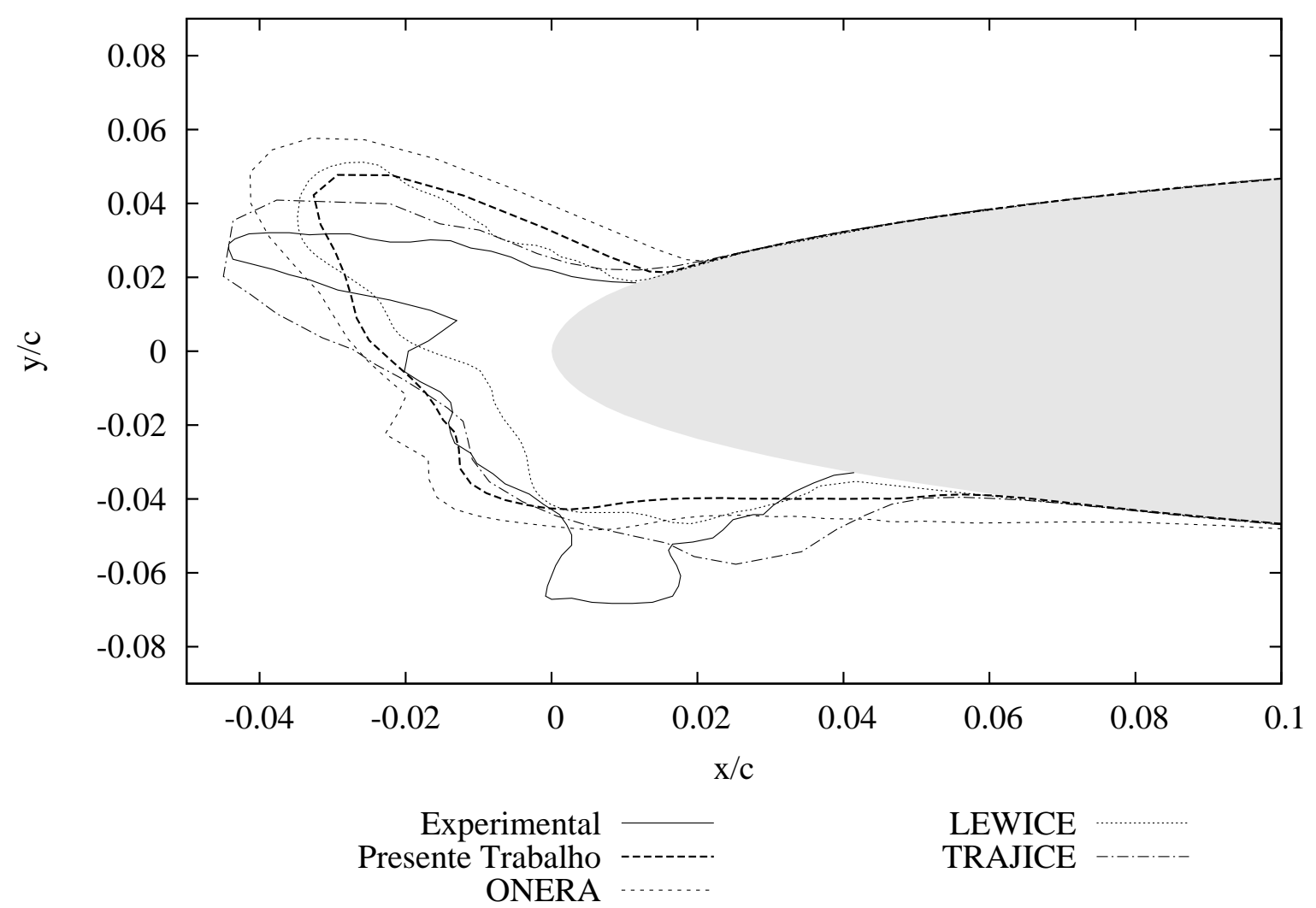

Figura 5.6: Formas de gelo simuladas para o caso C17 da Tabela 5.1

5.5, são muito próximos dos resultados do código ONERA, o que evidencia que as duas simulações utilizam valores de rugosidades equivalentes semelhantes. A posição da transição, como no caso C13, influi na forma do gelo pois ela ocorre a jusante do ponto de estagnação.

Os casos $\mathrm{C} 17$ e C18, apresentados nas Figuras 5.6 e 5.7, tem somente o parâmetro $M V D$ diferente. Estes casos tem um tempo de exposição maior que os casos anteriores e foram simulados com ângulo de ataque $\alpha=3^{\circ}$. Quanto maiores os ângulos de ataque, maiores são os erros esperados no cálculo do coeficiente de transferência de calor, pois a imprecisão da solução potencial do escoamento aumenta com o aumento do ângulo. Os resultados são razoáveis e próximos dos resultados experimentais. Os tamanhos e o ângulo dos chifres foram semelhantes nas simulações de todos códigos.

A tabela 5.2 mostra os valores da rugosidade equivalente $k_{s}$ calculada para cada caso e as posições onde ocorre a transição do regime laminar para o turbulento. O local do início da transição é apresentado como a posição na coordenada curvilínea normalizada pela corda $s / c$ e como o índice da malha relativo à mesma coordenada. Na maior parte das simulações, a transição do regime laminar para o turbulento ocorre nos primeiros elementos da malha a poucos milímetros do ponto de estagnação do escoamento, que é representada pelo índice $i_{\text {stag }}$.

As condições dos testes realizados por Shin e Bond (1994) no IRT são resumidos na 


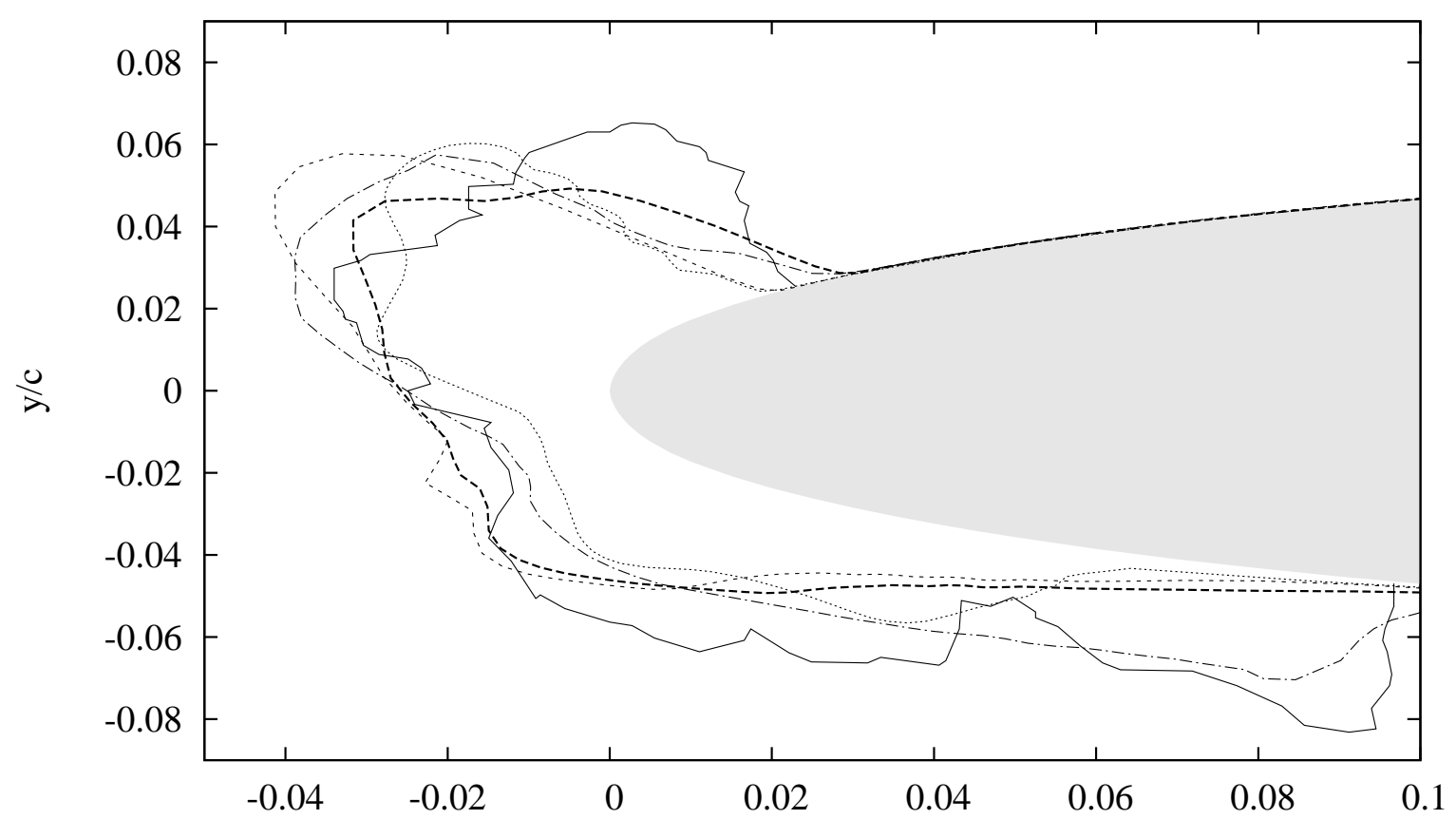

Experimental

Presente Trabalho

TRAJICE

ONERA

Figura 5.7: Formas de gelo simuladas para o caso C18 da Tabela 5.1

Tabela 5.2: Parâmetros da camada limite para os casos simulados da Tabela 5.1

\begin{tabular}{ccccccc}
\hline Caso & $k_{s}$ & \multicolumn{2}{c}{$(s / c)_{t r}\left[\mathrm{x} 10^{-3}\right]$} & $i_{\text {stag }}$ & \multicolumn{2}{c}{$i_{\text {trans }}$} \\
& $(\mathrm{mm})$ & intradorso & extradorso & & intradorso & extradorso \\
\hline C04 & 0,46 & $-5,12$ & 3,07 & 66 & 63 & 67 \\
\hline C06 & 1,63 & $-5,20$ & 3,12 & 67 & 64 & 68 \\
\hline C07 & 1,63 & $-7,47$ & 5,35 & 67 & 63 & 69 \\
\hline C13 & 0,67 & $-11,76$ & 11,81 & 66 & 60 & 71 \\
\hline C14 & 0,62 & $-7,30$ & 7,33 & 66 & 62 & 69 \\
\hline C17 & 2,01 & $-1,06$ & 3,21 & 63 & 62 & 64 \\
\hline C18 & 2,01 & $-3,17$ & 3,20 & 63 & 61 & 64 \\
\hline
\end{tabular}


Tabela 5.3: Casos de testes de Shin e Bond (1994) simulados no presente trabalho

\begin{tabular}{ccccccc}
\hline Caso & $\begin{array}{c}u_{\infty} \\
(\mathrm{m} / \mathrm{s})\end{array}$ & $\begin{array}{c}\alpha \\
\text { graus })\end{array}$ & $\begin{array}{c}T_{\infty} \\
(\mathrm{K})\end{array}$ & $\begin{array}{c}\text { LWC } \\
\mathrm{g} / \mathrm{m}^{3}\end{array}$ & $\begin{array}{c}\text { MVD } \\
\mu \mathrm{m}\end{array}$ & $\begin{array}{c}\mathrm{t} \\
(\mathrm{s})\end{array}$ \\
\hline F01 & 67,1 & 4,0 & Variável & 1,00 & 20,0 & 360,0 \\
\hline F02 & 102,8 & 4,0 & Variável & 0,55 & 20,0 & 420,0 \\
\hline F03 & 67,1 & 4,0 & Variável & 1,00 & 20,0 & 720,0 \\
\hline F04 & 102,8 & 4,0 & 267,7 & Variável & 30,0 & 360,0 \\
\hline
\end{tabular}

Tabela 5.3. O aerofólio utilizado nos testes foi um NACA0012 de corda igual a 0,533m. Foram realizados quatro casos de testes. Nos três primeiros casos, a temperatura estática $T_{\infty}$ foi variada para simular situações de gelo do tipo 'Glaze' e do tipo 'Rime'. No último caso, foi variada a quantidade de água $L W C$. Todas as simulações foram realizadas com $\alpha=4,0^{0}$, o que introduz incertezas provenientes da solução do escoamento potencial. Os testes foram repetidos ao menos três vezes. Como houve uma repetibilidade das formas de gelo, foi selecionada uma forma de gelo, para ser comparada com os resultados das simulações no presente trabalho.

Da análise da Figura 5.8 é possível concluir que as simulações do caso F01 tendem a fornecer resultados mais semelhantes às formas de gelo à medida que a temperatura estática $T_{\infty}$ diminui. Esta é uma conclusão válida, porém pode estar associada a outras variáveis, tais como quantidade de água $L W C$ e velocidade do escoamento $u_{\infty}$. O caso C04, apresentado na Figura 5.1, possui temperatura estática também próxima a temperatura de congelamento da água. Para este caso todos os códigos apresentaram resultados insatisfatórios e semelhanças entre eles.

O caso F02, mostrado na Figura 5.9, apresentou a mesma tendência de resultados que o caso F01. Pode-se considerar que com o aumento da velocidade e do tempo de exposição, aumentaram as divergências entre as formas de gelo.

O caso F03, mostrado na Figura 5.10, difere do caso F01 somente no intervalo de tempo de exposição ao escoamento. Os resultados são inferiores ao do caso F01 e, à semelhança da análise feita para os casos C06 e C07, atribui-se os desvios ao método de previsão-correção.

No caso F04 foi avaliado o efeito da quantidade de água $L W C$ na forma de gelo. Nota-se que com a aumento do $L W C$, as formas de gelo experimentais tendem a ter chifre maiores e mais pontudos qando comparadas com as formas simuladas no presente trabalho. $\mathrm{O}$ aumento do $L W C$ proporciona maiores taxas de água não congelada ao longo do aerofólio, que torna os cálculos de crescimento mais dependentes de bons modelos de simulação de escoamentos de filmes de água e de transferência de calor. 


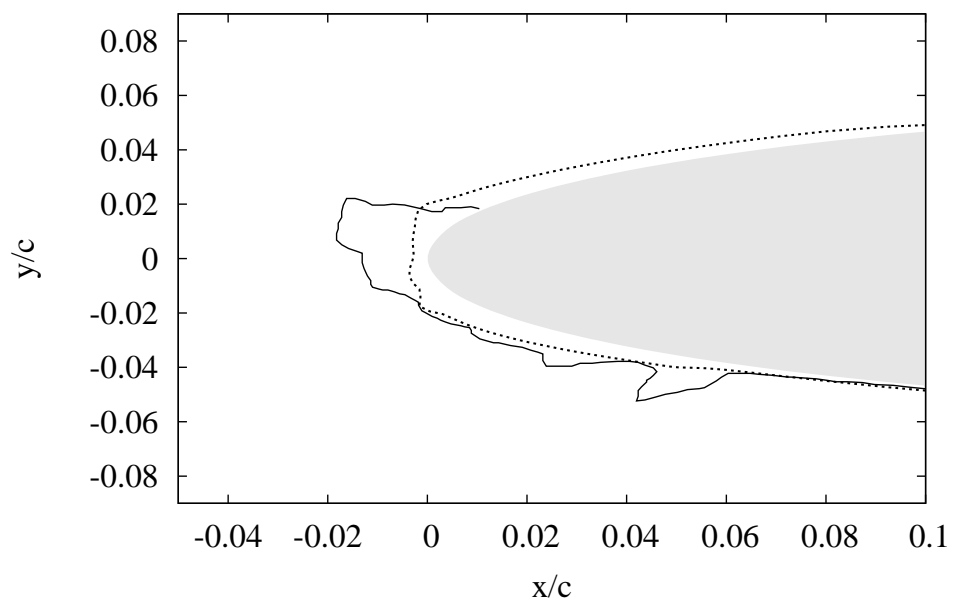

Experimental — Presente Trabalho

(a) $T_{\infty}=270,9 \mathrm{~K}$

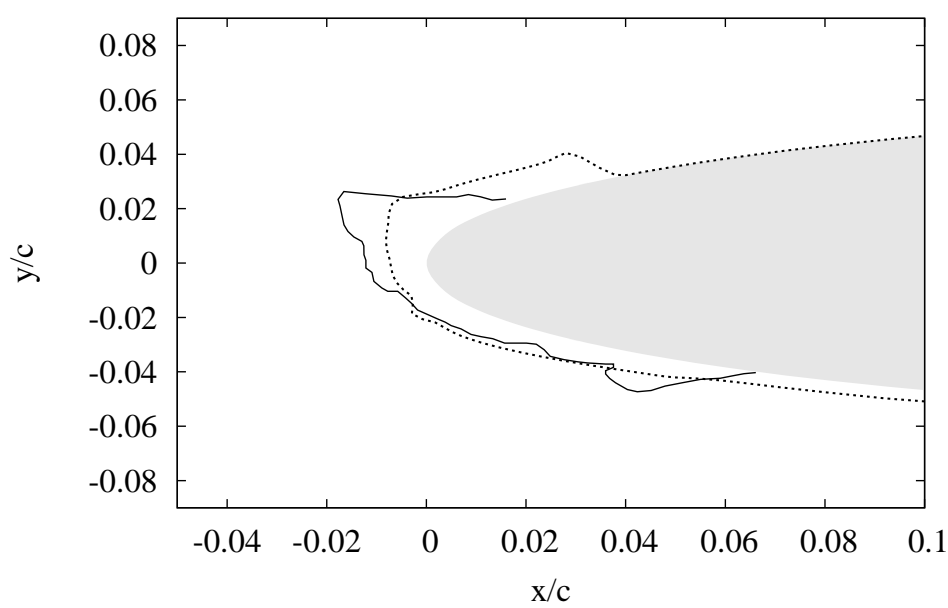

Experimental — Presente Trabalho

(b) $T_{\infty}=269,3 \mathrm{~K}$

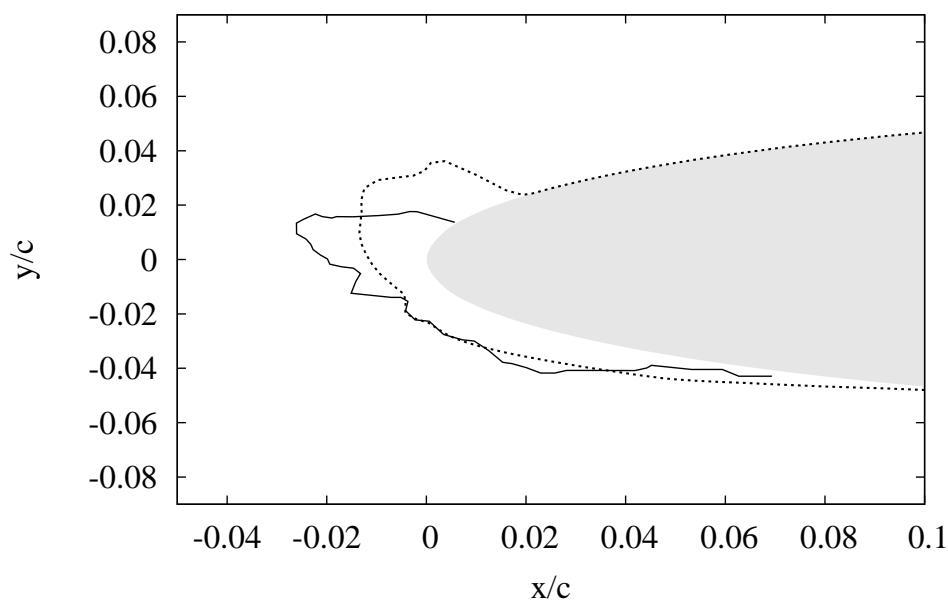

Experimental — Presente Trabalho

(c) $T_{\infty}=267,6 \mathrm{~K}$

Figura 5.8: Formas de gelo simuladas para o caso F01 da Tabela 5.3 


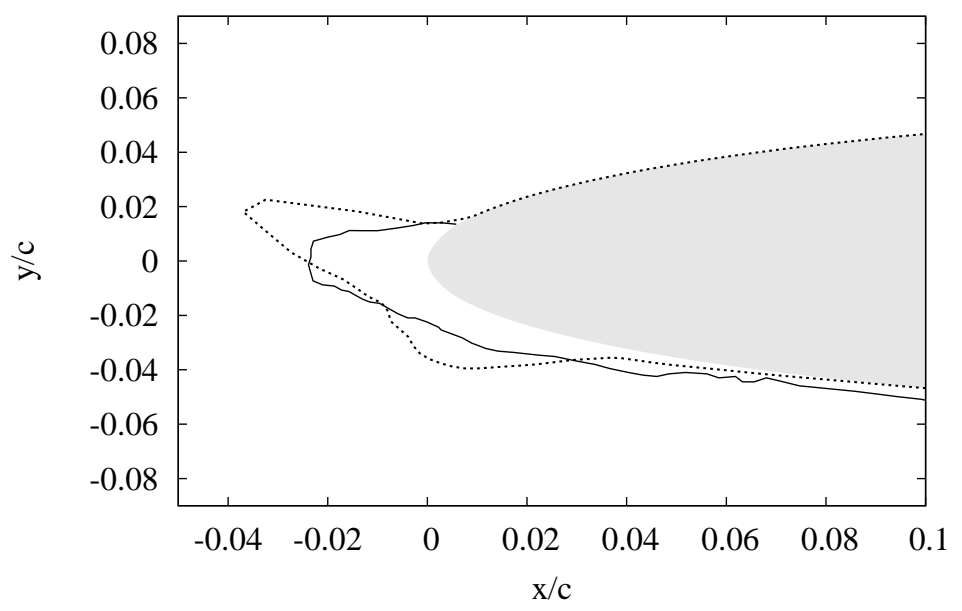

Experimental — Presente Trabalho

(d) $T_{\infty}=262,1 \mathrm{~K}$

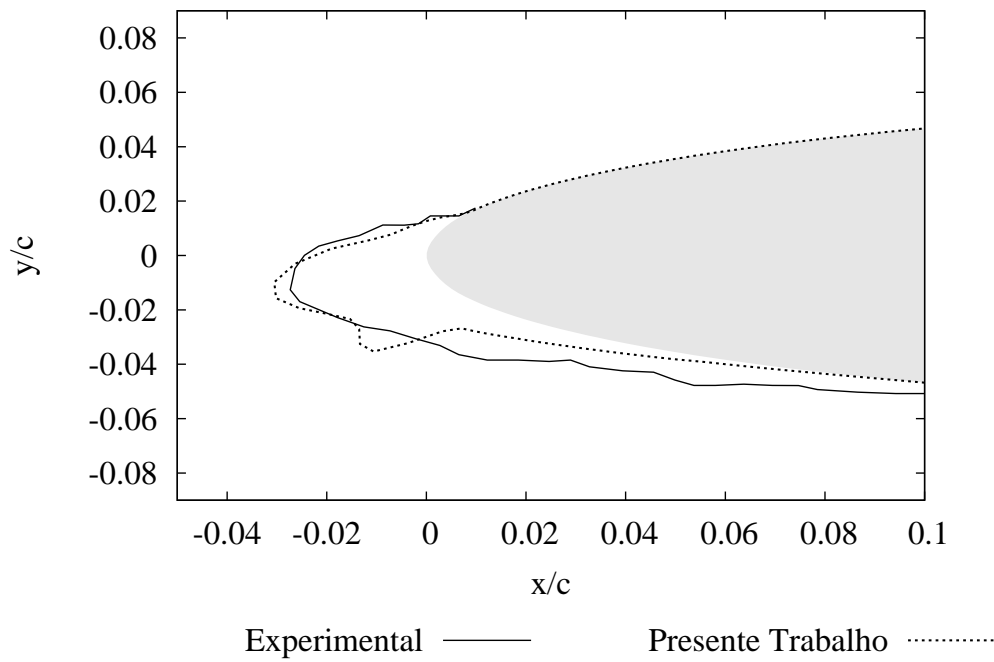

(e) $T_{\infty}=247,3 \mathrm{~K}$

Figura 5.8: Formas de gelo simuladas para o caso F01 da Tabela 5.3 (Continuação) 


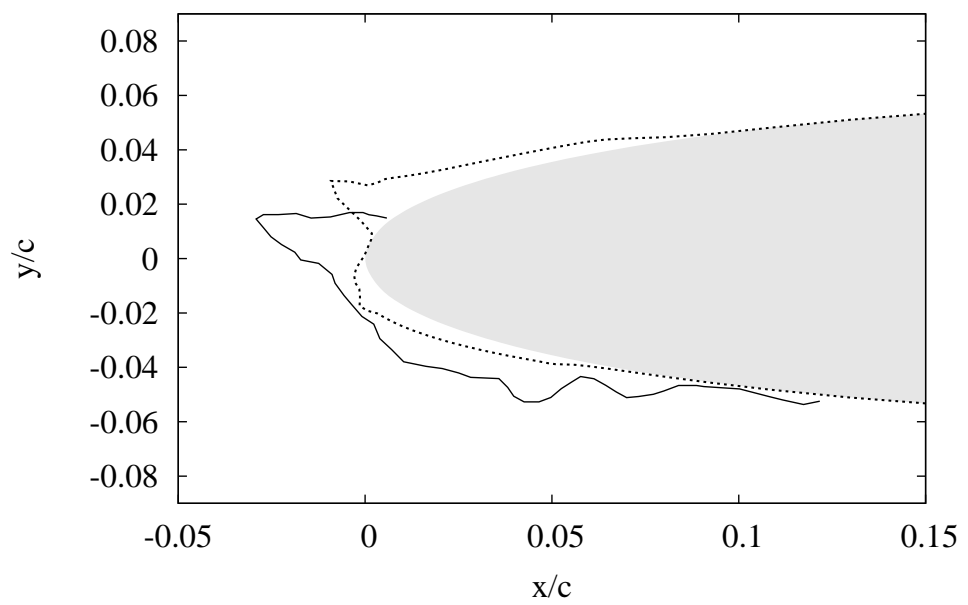

Experimental — Presente Trabalho

(a) $T_{\infty}=271,0 \mathrm{~K}$

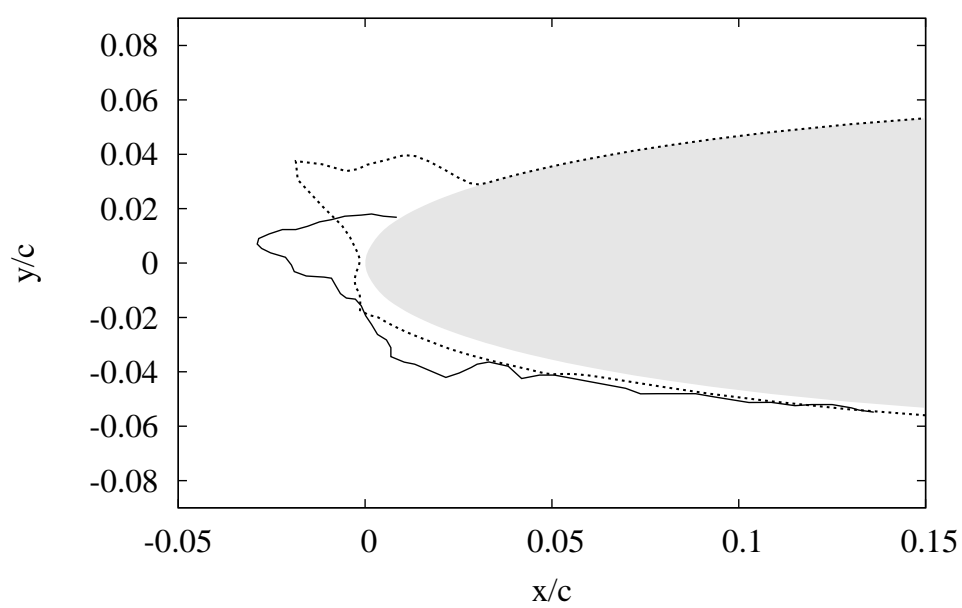

Experimental — Presente Trabalho

(b) $T_{\infty}=269,3 \mathrm{~K}$

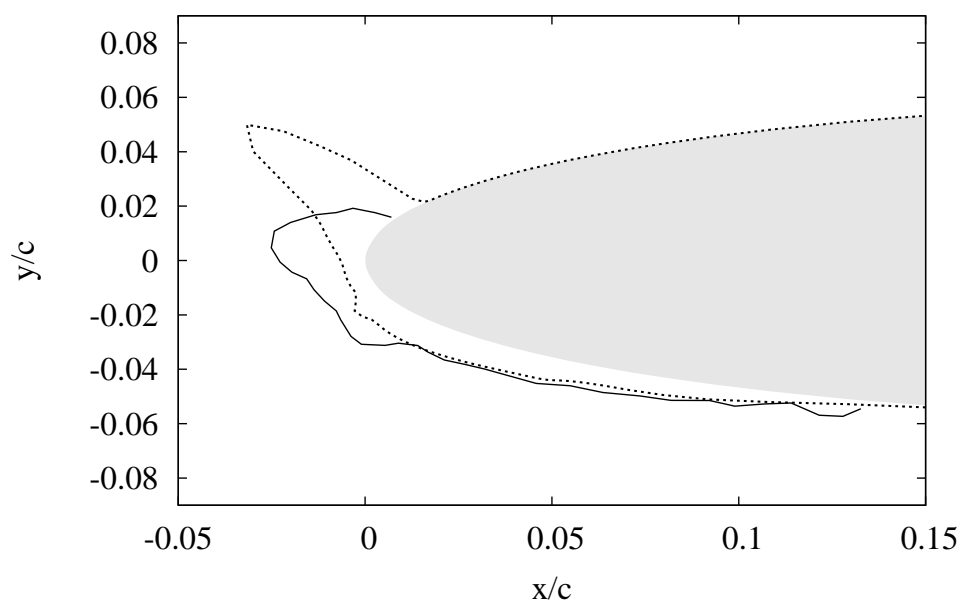

Experimental — Presente Trabalho

(c) $T_{\infty}=267,7 \mathrm{~K}$

Figura 5.9: Formas de gelo simuladas para o caso F02 da Tabela 5.3 


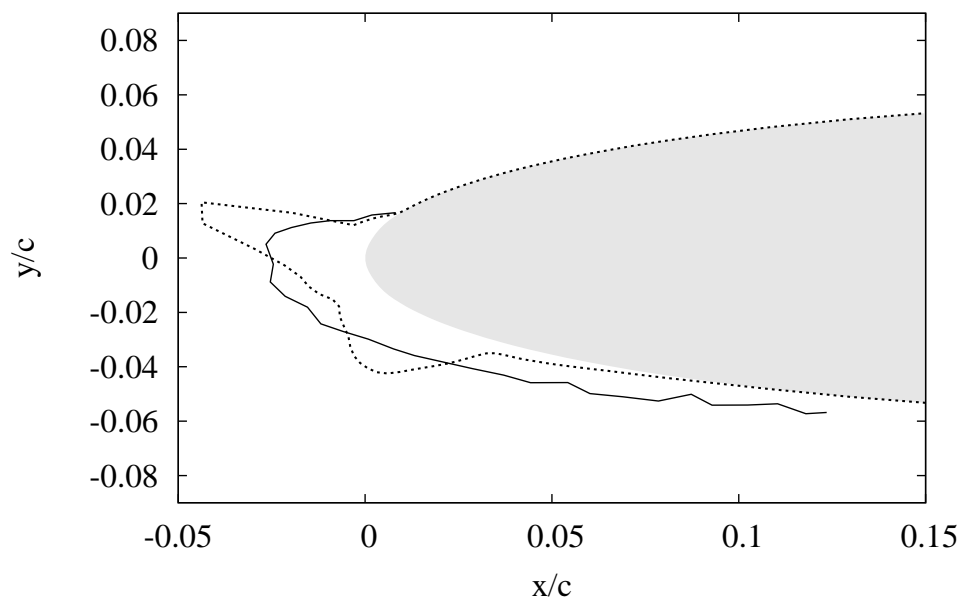

Experimental — Presente Trabalho

(d) $T_{\infty}=262,3 \mathrm{~K}$

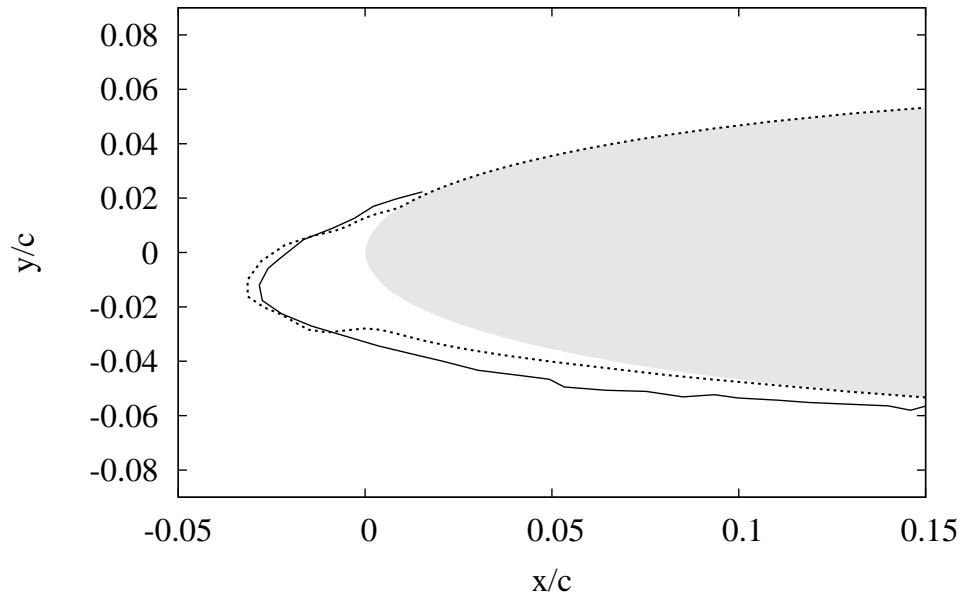

Experimental $-\quad$ Presente Trabalho …….....

(e) $T_{\infty}=247,6 \mathrm{~K}$

Figura 5.9: Formas de gelo simuladas para o caso F02 da Tabela 5.3 (Continuação) 


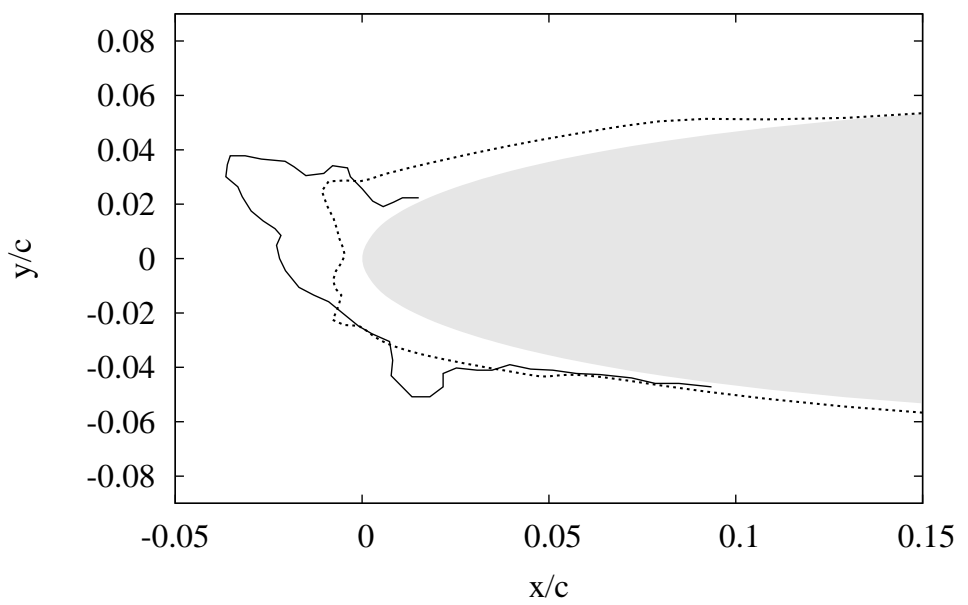

Experimental $-\quad$ Presente Trabalho

(a) $T_{\infty}=270,9 \mathrm{~K}$

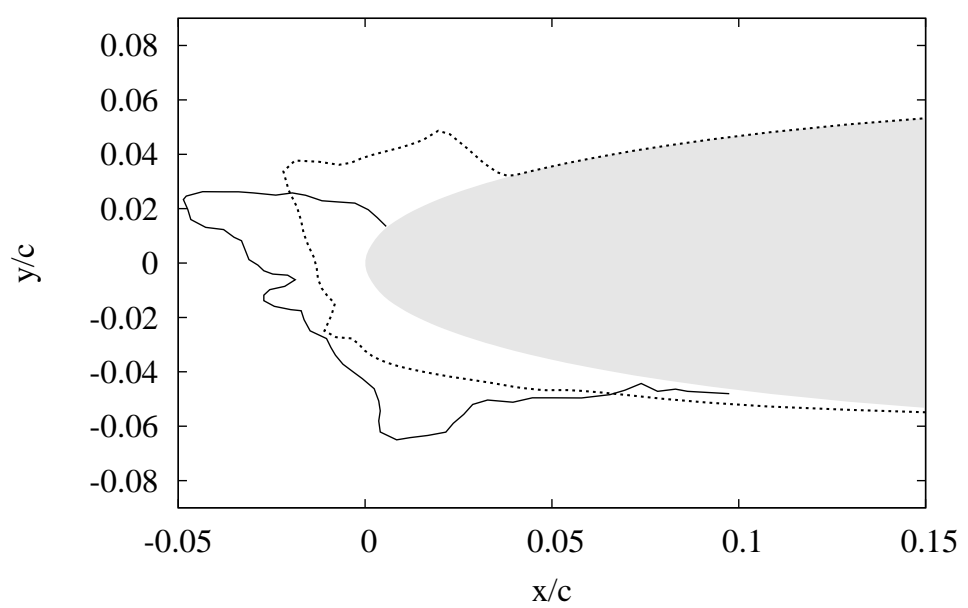

Experimental — Presente Trabalho

(b) $T_{\infty}=269,3 \mathrm{~K}$

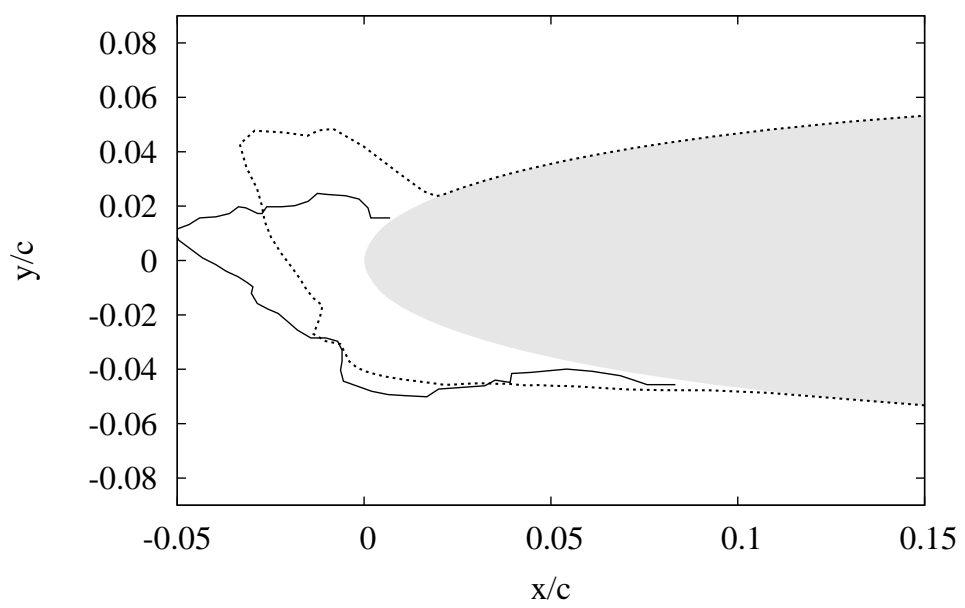

Experimental — Presente Trabalho

(c) $T_{\infty}=267,6 \mathrm{~K}$

Figura 5.10: Formas de gelo simuladas para o caso F03 da Tabela 5.3 


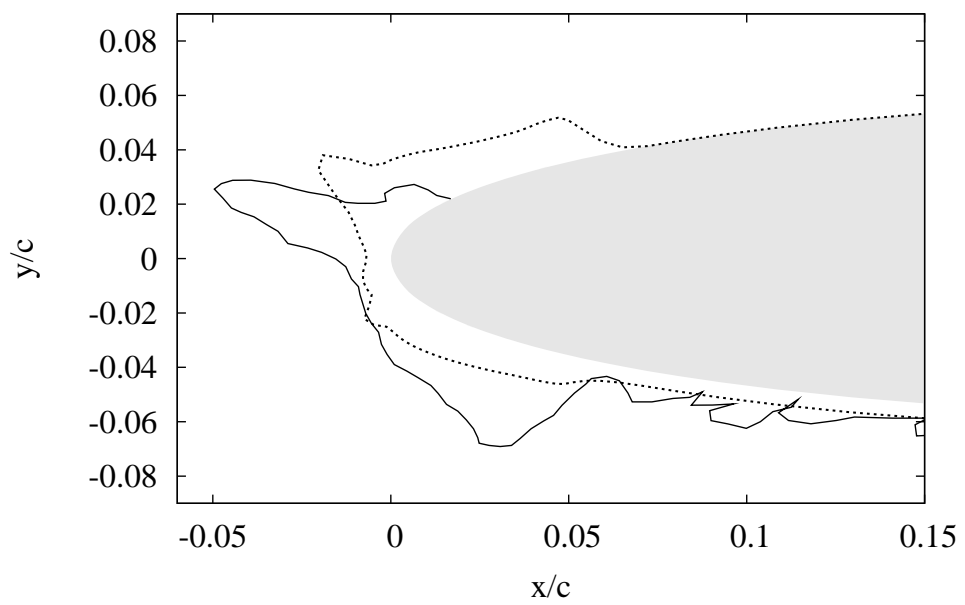

Experimental — Presente Trabalho

(a) $\mathrm{LWC}=1,0 \times 10^{-3} \mathrm{~kg} / \mathrm{m}^{3}$

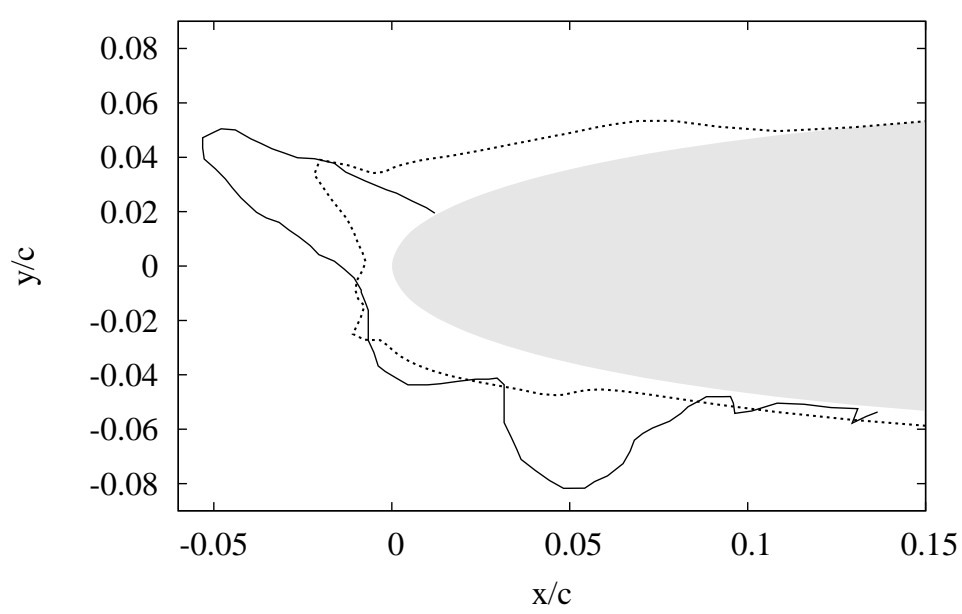

Experimental — Presente Trabalho

(b) $\mathrm{LWC}=1,3 \times 10^{-3} \mathrm{~kg} / \mathrm{m}^{3}$

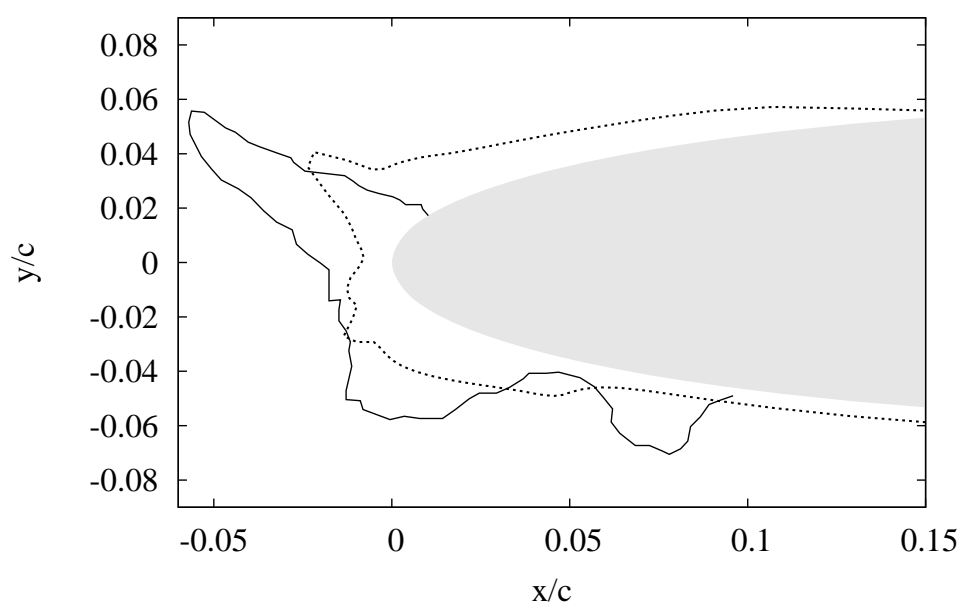

Experimental — Presente Trabalho

(c) $\mathrm{LWC}=1,6 \times 10^{-3} \mathrm{~kg} / \mathrm{m}^{3}$

Figura 5.11: Formas de gelo simuladas para o caso F04 da Tabela 5.3 


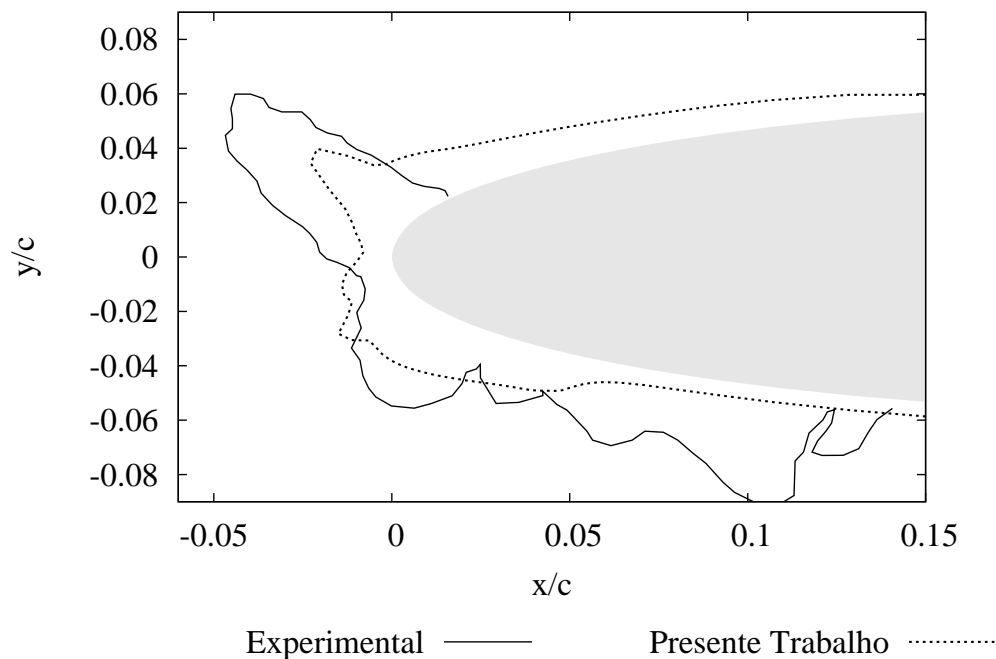

(d) $\mathrm{LWC}=1,8 \times 10^{-3} \mathrm{~kg} / \mathrm{m}^{3}$

Figura 5.11: Formas de gelo simuladas para o caso F04 da Tabela 5.3 (Continuação)

A Tabela 5.4 mostra os parâmetros da camada limite das simulações dos casos F01 a F04. Todos as simulações mostraram que a transição entre o regime laminar e turbulento ocorreram nos primeiros elementos da malha computacional, ou seja, muito próximo ao ponto de estagnação do escoamento. Os valores das rugosidades equivalentes foram semelhantes aos valores apresentados na Tabela 5.2 e estão, na maioria dos casos, dentro dos valores esperados, que variam de 0,1 a 2,0mm (OLSEN; SHAW; NEWTON, 1984).

A camada limite térmica e por consequência, o coeficiente de transferência de calor, são variáveis que podem afetar de forma significativa as formas de gelo. O valor do coeficiente é dependente de uma boa definição da rugosidade equivalente e hoje, os melhores modelos são ajustados empiricamente. A transição entre o regime laminar e turbulento aumenta muito o coeficiente de transferência de calor e afeta diretamente a geração de formas de chifres.

\subsection{Efeito Aerodinâmico da Formação de Gelo em Ae- rofólios de Uso Aeronáutico}

Bragg (1986) realizou uma série de experimentos com o objetivo de obter dados de degradação aerodinâmica do aerofólio NACA0012. O autor utilizou, para os testes, um aerofólio com um gelo artificial fixado ao seu bordo de ataque. A forma do gelo artificial, mostrada na figura 5.12 , é idêntica à forma de gelo gerada experimentalmente no túnel IRT para as condições da Tabela 5.5. Bragg realizou um trabalho abrangente da caracterização dos efeitos aerodinâmicos da formação de gelo. Ele mediu, para o aerofólio liso e para o aerofólio com a forma artificial, os coeficientes de sustentação $C_{l}$, de arraste $C_{d}$, de momento $C_{m}$, espessura da camada limite $\delta$, espessura de quantidade de movimento $\delta_{2}$ e os pontos de estagnação. As medições foram 
Tabela 5.4: Parâmetros da camada limite para os casos simulados da Tabela 5.3

\begin{tabular}{lcccccc}
\hline Caso & $k_{s}$ & \multicolumn{2}{c}{$(s / c)_{t r}\left[\mathrm{x} 10^{-3}\right]$} & $i_{\text {stag }}$ & \multicolumn{2}{c}{$i_{\text {trans }}$} \\
& $(\mathrm{mm})$ & intradorso & extradorso & & intradorso & extradorso \\
\hline F01(a) & 1,39 & $-3,07$ & 3,12 & 58 & 56 & 59 \\
\hline F01(b) & 1,32 & $-5,17$ & 3,08 & 59 & 56 & 60 \\
\hline F01(c) & 1,24 & $-7,25$ & 3,11 & 60 & 56 & 61 \\
\hline F01(d) & 1,01 & $-5,26$ & 3,16 & 62 & 59 & 63 \\
\hline F01(e) & 3,56 & $-5,29$ & 5,34 & 57 & 54 & 59 \\
\hline F02(a) & 0,89 & $-3,09$ & 3,11 & 58 & 56 & 59 \\
\hline F02(b) & 0,84 & $-5,20$ & 3,09 & 60 & 57 & 61 \\
\hline F02(c) & 0,80 & $-9,29$ & 5,17 & 62 & 57 & 64 \\
\hline F02(d) & 0,65 & $-3,18$ & 3,18 & 63 & 61 & 64 \\
\hline F02(e) & 0,23 & $-5,31$ & 5,30 & 57 & 54 & 59 \\
\hline F03(a) & 1,39 & $-3,11$ & 7,43 & 56 & 54 & 59 \\
\hline F03(b) & 1,32 & $-7,33$ & 5,23 & 59 & 55 & 61 \\
\hline F03(c) & 1,24 & $-3,17$ & 5,27 & 61 & 59 & 63 \\
\hline F04(a) & 1,52 & $-5,19$ & 3,17 & 59 & 56 & 60 \\
\hline F04(b) & 2,21 & $-5,35$ & 3,11 & 58 & 55 & 59 \\
\hline F04(c) & 3,08 & $-3,37$ & 5,17 & 56 & 54 & 58 \\
\hline F04(d) & 3,74 & $-3,37$ & 3,03 & 56 & 54 & 57 \\
\hline
\end{tabular}

Tabela 5.5: Caso de Teste de Bragg (1986) simulado no presente trabalho

\begin{tabular}{cccccc}
\hline $\begin{array}{c}u_{\infty} \\
(\mathrm{m} / \mathrm{s})\end{array}$ & $\begin{array}{c}\alpha \\
\text { (graus) }\end{array}$ & $\begin{array}{c}T_{\infty} \\
(\mathrm{K})\end{array}$ & $\begin{array}{c}\text { LWC } \\
\left(\mathrm{g} / \mathrm{m}^{3}\right)\end{array}$ & $\begin{array}{c}\text { MVD } \\
(\mu \mathrm{m})\end{array}$ & $\begin{array}{c}\mathrm{t} \\
(\mathrm{s})\end{array}$ \\
\hline 58,1 & 4,0 & 265,4 & 2,10 & 20,0 & 300,0 \\
\hline
\end{tabular}

realizadas para o intervalo de ângulos de ataque $\alpha$ variando de $-13,5^{0}$ a $13,5^{0}$.

O código implementado neste trabalho foi utilizado para prever as formas do gelo nas as mesmas condições em que foi obtido o gelo no IRT, ou seja, nas condições da Tabela 5.5. A forma de gelo simulado no presente trabalho é mostrada na Figura 5.12 junto com a forma de gelo artificial utilizada por Bragg.

Os dados do coeficiente de sustentação $C_{l}$ avaliam a degradação que as formas de gelo causam ao desempenho do aerofólio. No presente trabalho, o $C_{l}$ foi estimado para alguns casos de Bragg (1986) e os resultados foram comparados com os dados experimentais. O coeficiente de sustentação foi calculado, no presente trabalho, por meio da integral do coeficiente de pressão $C_{p}$ ao longo da superfície do aerofólio. Os dados de $C_{p}$ foram obtidos da solução do escoamento potencial do código ONERA e foram selecionados casos com ângulos de ataque no intervalo de $0^{\circ}<\alpha<4^{\circ}$. 


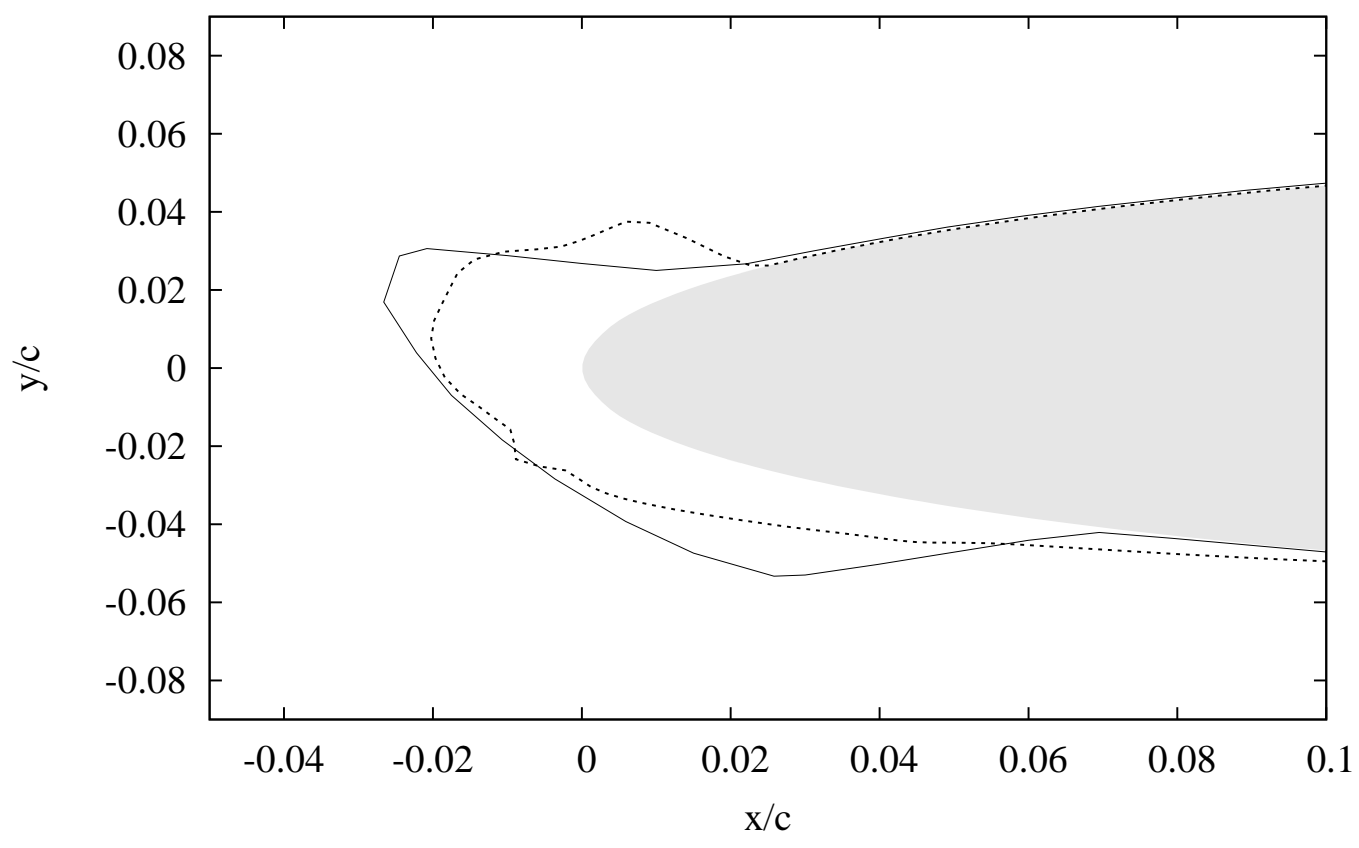

Gelo Artificial Simulado-Presente Trabalho

Figura 5.12: Forma do gelo artificial utilizado por Bragg (1986) e do gelo simulado no presente trabalho para o caso da Tabela 5.5

Tabela 5.6: Coeficiente de sustentação $C_{l}$ do aerofólio NACA0012 liso

\begin{tabular}{|c|c|c|c|c|}
\hline & \multicolumn{2}{|c|}{$M_{\infty}=0,125$} & \multicolumn{2}{c|}{$M_{\infty}=0,165$} \\
\hline$\alpha$ & Experimental & Estimado & Experimental & Estimado \\
\hline 0,0 & $-0,005$ & 0,000 & $-0,009$ & 0,000 \\
\hline 1,0 & 0,096 & 0,066 & 0,093 & 0,067 \\
\hline 2,0 & 0,198 & 0,135 & 0,194 & 0,136 \\
\hline 3,0 & 0,303 & 0,202 & 0,287 & 0,203 \\
\hline 4,0 & 0,409 & 0,272 & 0,388 & 0,274 \\
\hline
\end{tabular}

A Tabela 5.6 apresenta alguns dados experimentais de $C_{l}$ obtidos por Bragg para o aerofólio NACA0012 sem formação de gelo (liso) e os valores estimados de $C_{l}$, no presente trabalho, para as mesmas condições. As Figuras 5.13 e 5.14 representam os dados da Tabela 5.6.

Da análise das Figuras, nota-se que o valor da diferença entre os dados calculados aumenta com o ângulo de ataque. Esta tendência era esperada devido aos desvios da solução do escoamento potencial para $\alpha>2^{\circ}$.

A Tabela 5.7 mostra o $C_{l}$ medido para a forma de gelo artificial, o $C_{l}$ estimado no presente trabalho para a forma de gelo artificial e o $C_{l}$ estimado no presente trabalho para a forma de gelo simulado.

Tanto os dados experimentais como os resultados dos cálculos mostram que houve uma 


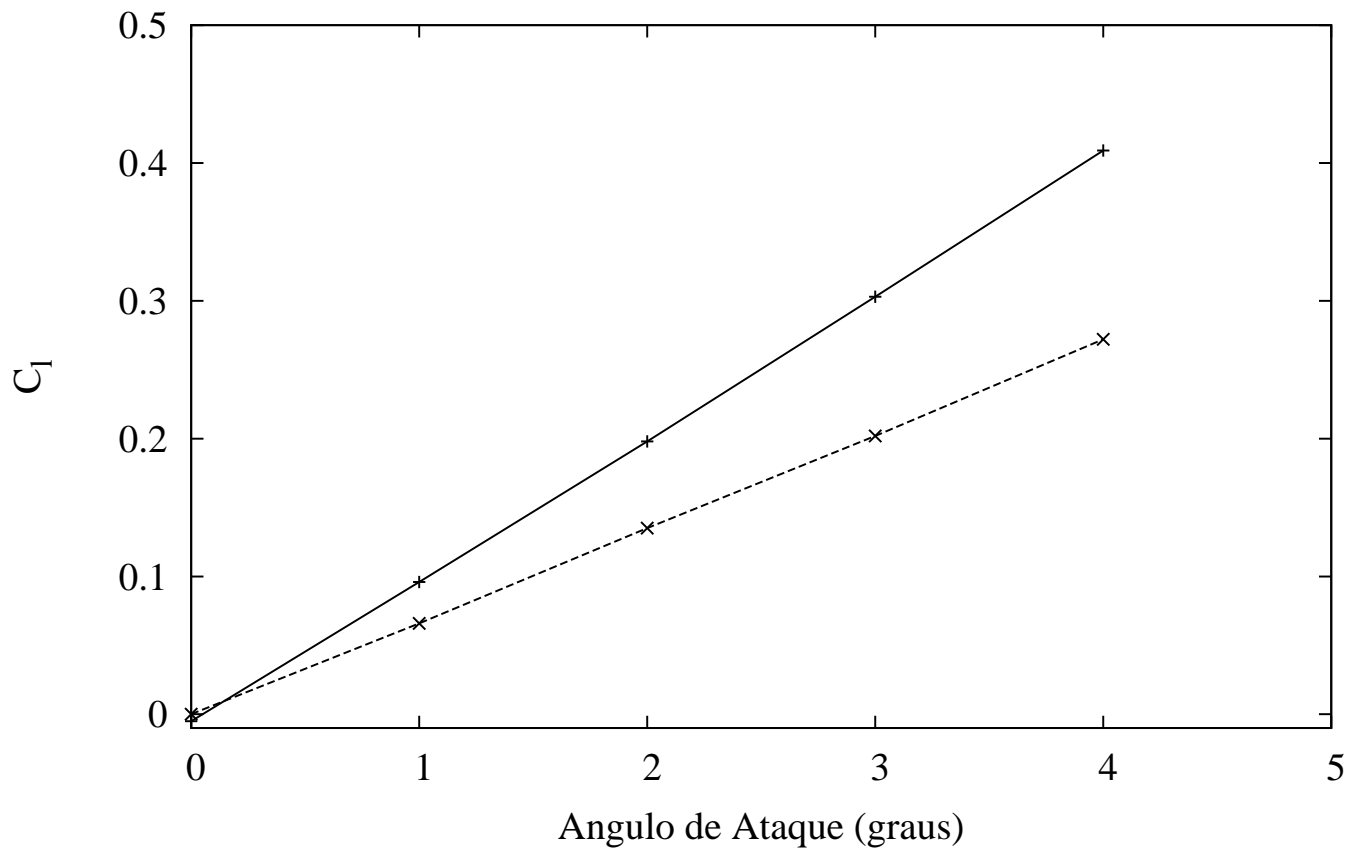

Experimental

Estimado-Presente Trabalho

Figura 5.13: Coeficiente de Sustentação do Aerofólio Liso $-M_{\infty}=0,125$

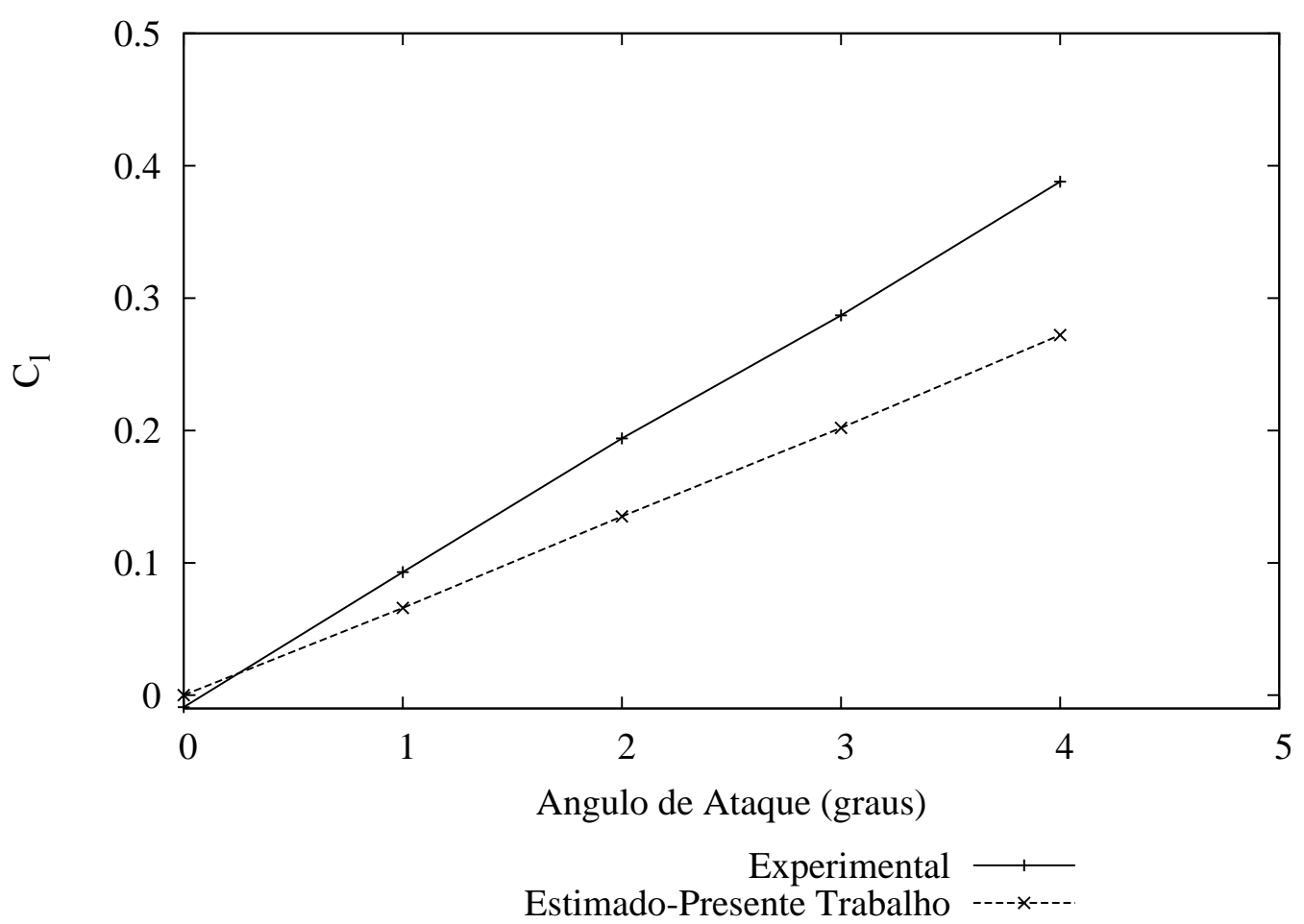

Figura 5.14: Coeficiente de Sustentação do Aerofólio Liso $-M_{\infty}=0,165$ 
Tabela 5.7: Coeficiente de Sustentação $C_{l}$ do Aerofólio NACA 0012 com Formas de Gelo

\begin{tabular}{|c|c|c|c|c|c|c|}
\hline & \multicolumn{3}{|c|}{$M_{\infty}=0,125$} & \multicolumn{3}{c|}{$M_{\infty}=0,165$} \\
\hline & \multicolumn{2}{|c|}{ Artificial } & Simulado & \multicolumn{2}{c|}{ Artificial } & Simulado \\
\hline$\alpha$ & Experimental & Estimado & Estimado & Experimental & Estimado & Estimado \\
\hline 0,0 & -0.038 & -0.001 & -0.007 & -0.034 & -0.007 & -0.001 \\
\hline 1,0 & 0.066 & 0.068 & 0.062 & \multicolumn{3}{|c|}{-} \\
\hline 2,0 & 0.167 & 0.142 & 0.130 & 0.159 & 0.143 & 0.133 \\
\hline 3,0 & 0.26 & 0.212 & 0.202 & \multicolumn{3}{|c|}{-} \\
\hline 4,0 & 0.361 & 0.285 & 0.273 & 0.345 & 0.286 & 0.281 \\
\hline
\end{tabular}

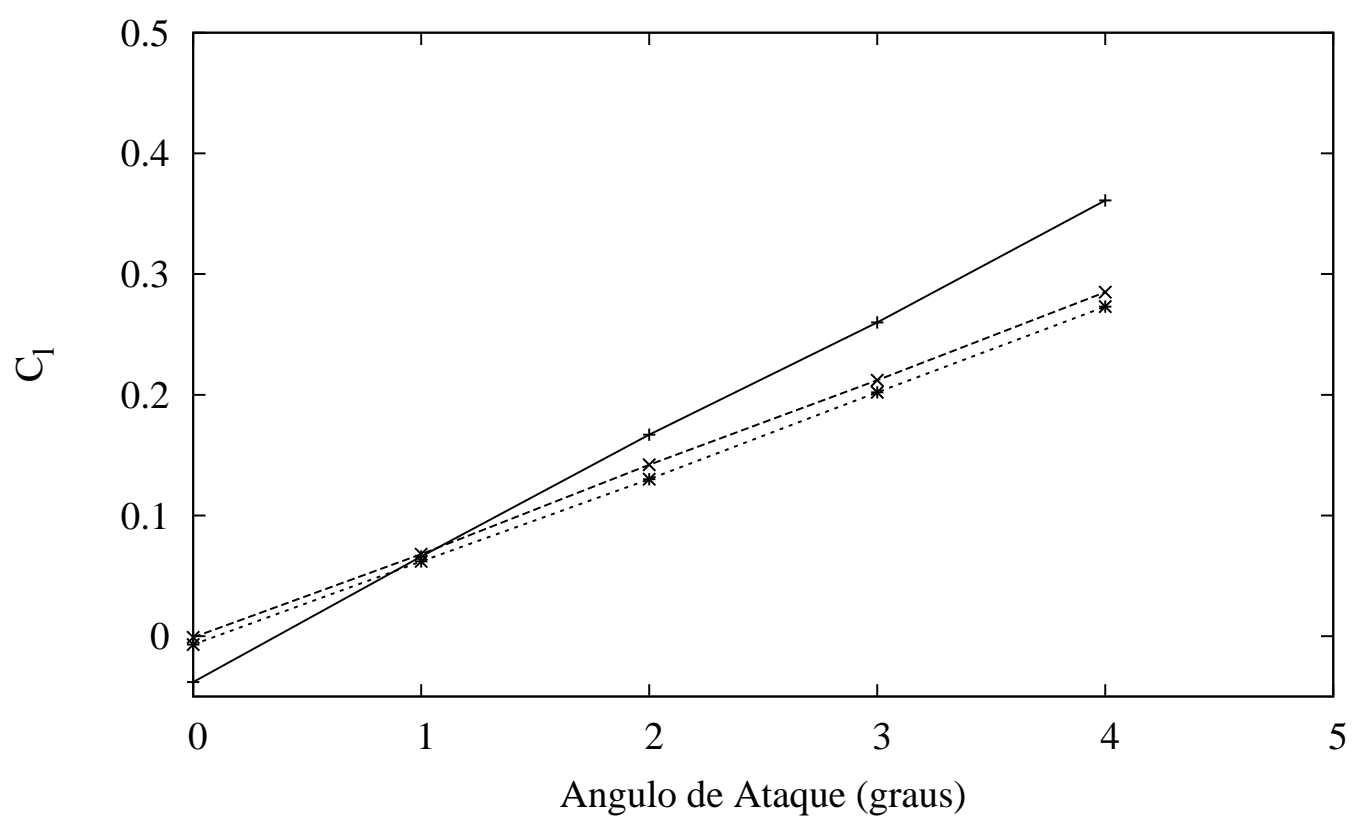

Experimental-Gelo Artificial

Estimado-Presente Trabalho-Gelo Artificial

Estimado-Presente Trabalho-Gelo Simulado

Figura 5.15: Coeficiente de Sustentação do Aerofólio com Formação de Gelo $-M_{\infty}=0,125$ 


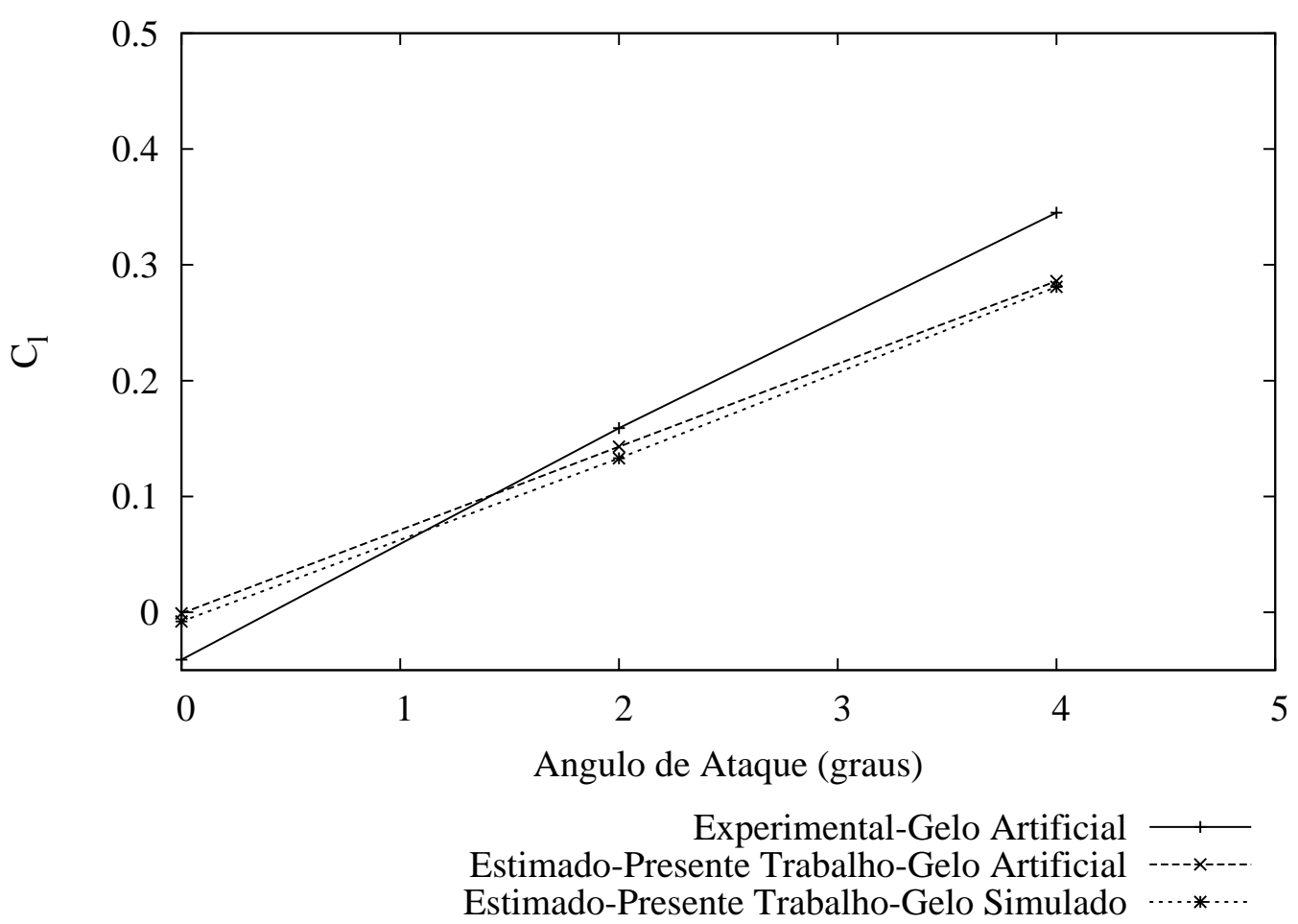

Figura 5.16: Coeficiente de Sustentação do Aerofólio com Formação de Gelo $-M_{\infty}=0,165$

degradação no coeficiente de sustentação da aeronave. Os coeficientes de sustentação estimados para a forma de gelo artificial e os estimados para a forma de gelo simulado ficaram próximos, e considerando que as formas eram também semelhantes, o método implementado neste trabalho mostrou-se adequado para avaliação da simulação de previsões de formas de gelo. 


\section{Discussão}

As simulações apresentadas neste trabalho têm o objetivo de avaliar a modelagem, implementação e os efeitos da camada limite nas formas de gelo dos aerofólios. Ao longo do trabalho foi verificado que parâmetros do escoamento, da malha computacional e métodos adotados para prever o crescimento de gelo influenciavam igualmente o formato do gelo obtido e, em alguns casos, estes parâmetros eram determinantes do resultado. O presente trabalho identificou os parâmetros que influenciam a previsão das formas de gelo e algumas discussões suscintas sobre eles foram apresentadas no Capítulo 5. Neste capítulo são apresentados estudos para suportar a discussão dos efeitos da camada limite nas formas de gelo. São discutidos métodos de avaliação da qualidade das formas de gelo simuladas e critérios para identificação as limitações do programa de simulação.

Foi feita uma análise das formas de gelo dos casos da Tabela 5.1, que correspondem às Figuras 5.1 a 5.7. As formas de gelo obtidas no presente trabalho se aproximam das formas experimentais, exceto o caso C04. Ao comparar as formas de gelo simuladas no presente trabalho com as formas de gelo obtidas pelos participantes dos testes propostos pela NATO (KIND, 2001), observa-se que as formas foram igualmente semelhantes, exceto para o caso C13. O caso C13 é uma caso particular, no qual a posição da transição entre o regime laminar e turbulento influi na forma do gelo. No caso C04 nenhum código gerou resultados de formas próximas a experimental. As condições do teste deste caso indicam uma limitação dos códigos de formação de gelo utilizados no teste promovido pela NATO.

A semelhança dos resultados apresentados neste trabalho com os dados experimentais e com resultados de outros códigos indica uma modelagem e uma implementação adequada do módulo de transferência de calor, considerando que os módulos de solução do escoamento, cálculo de trajetórias e crescimento do gelo não foram alterados e apresentaram comportamento previsível.

As análises até o presente momento ocorreram de uma forma subjetiva, pois as comparações entre formas de gelo utilizaram critérios de semelhança geométrica. Para uma análise objetiva das formas de gelo, foi utilizado neste trabalho o coeficiente de sustentação $C_{l}$. Parâmetros aerodinâmicos, tais como o coeficiente de sustentação $C_{l}$ e o coeficiente de 
arraste $C_{d}$, foram utilizados por pesquisadores desde os primeiros ensaios de formação de gelo em túnel. Com a utilização deste parâmetro avalia-se o efeito final, que é o desempenho do aerofólio. Neste trabalho optou-se por avaliar o coeficiente de sustentação devido à disponibilidade de dados de coeficiente de pressão $C_{p}$ para o cálculo deste parâmetro.

Para ensaios de formas de gelo, há uma grande quantidade de dados de coeficiente de arraste $C_{d}$. Foi implementado, ao longo deste trabalho, um método de avaliação deste coeficiente, porém os resultados obtidos tiveram uma grande diferença dos dados experimentais. O método avaliou a espessura de quantidade de movimento $\delta_{2}$ do bordo de fuga do aerofólio para o cálculo do do coeficiente de arraste. A avaliação integras da camada limite utilizando as Equações 3.3 e 3.12 fornecem resultados adequados de $\delta_{2}$ para gradientes de pressão favoráveis, porém para gradientes de pressão adversos, ela deve ser evitada (KAYS; CRAWFORD, 1993). Portanto, o uso destas equações deve ser restrita ao bordo de ataque dos aerofólios, que possuem gradiente de pressão favorável. Ao utilizar as equações ao longo de todo o aerofólio, para obter o $\delta_{2}$ no bordo de fuga, os erros são acumulados. Note que como o objetivo deste trabalho é a avaliação dos efeitos da camada limite em formas de gelo, que sempre formam-se em bordos de ataque, e portanto a utilização das equações integrais implementadas é adequada para este propósito.

A utilização do $C_{l}$ na avaliação comparativa das formas de gelo foi considerado satisfatória, apesar de serem encontrados erros nos cálculos com ângulos de ataque maiores que dois graus. Estes erros estão associados à solução do escoamento potencial em torno do aerofólio, que tem desvios para ângulos maiores que dois graus. Observa-se que é possível associar as diferenças geométricas observadas nas formas de gelo com os valores obtidos para o coeficiente de sustentação, e portanto, com a utilização deste parâmetro é possível avaliar a qualidade de uma forma de gelo simulada numericamente em comparação com a forma obtida experimentalmente.

Como objetivo deste trabalho não foi obter dados precisos do coeficiente $C_{l}$, mas utilizá-lo como um parâmetro de avaliação comparativa das formas de gelo, não foram geradas curvas $C_{l}$ x $\alpha$, nem calculados os ângulos de ataque $\alpha$ nos quais o coeficiente de sustentação é máximo $\left(C_{l}, \max \right)$.

Os casos apresentados na Tabela 5.3 tiveram, como objetivo, avaliar os efeitos da temperatura $T_{\infty}$ e da quantidade de água $L W C$ nas formas de gelo. Estes parâmetros foram selecionados pois são importantes no cálculo da transferência de calor e havia dados confiáveis disponíveis na literatura. Da análise dos casos F01, F02 e F03, que são apresentados nas Figuras 5.8, 5.9 e 5.10 respectivamente, pode-se concluir que em temperaturas inferiores a $-10^{\circ} \mathrm{C}$ os códigos fornecem resultados de formas de gelo com maior semelhança às formas 
experimentais de gelo. Esta análise é válida, porém deve ser estendida a todos os parâmetros que afetam o crescimento de gelo, tais como velocidade $V_{\infty}$ e quantidade de água $L W C$.

Para a avaliação dos parâmetros que influenciam a formação do gelo, foram selecionados parâmetros de similaridade que são utilizados quando há a necessidade de garantir que as condições de ensaio representem as condições de voo. Os parâmetros utilizados são descritos na Seção 4.3.

A Figura 6.1 apresenta os valores dos parâmetros de similaridade da Tabela 6.1. Da comparação da Figura 6.1 com as formas de gelo apresentadas na Figura 5.8 é possível verificar que para um mesmo número de Reynolds $R e_{a}$, definido na Seção 4.5, é possível se obter várias formas de gelo, que terão coeficientes aerodinâmicos $C_{l}$ e $C_{d}$ diferentes. Esta é uma constatação confirma as conclusões de diversos pesquisadores que, como foi descrito na Seção 2.3, verificaram que o número de Reynolds não tem grande influência no desempenho aerodinâmicos do aerofólio com formação de gelo. O parâmetro adimensional $A_{c}$, definido na Seção 4.3.2, está relacionado coleta de água do aerofólio e não teve variações signicativas.

O parâmetro $\phi$, definido na Seção 4.3.3, está relacionado com a transferência de calor na superfície do aerofólio e variou com a temperatura $T_{\infty}$. Nota-se que para $\phi>10$, as formas de gelo aproximam-se dos valores experimentais, que correspondem às formas de gelo das Figuras $5.8(\mathrm{~d})$ e $5.8(\mathrm{e})$.

O parâmetro $\phi$ é dimensional e representa a diferença entre a temperatura de fusão da água $T_{f}$ e a temperatura total do escoamento na superfície do aerofólio. Para pequenas valores de $\phi$ os códigos tiveram deficiências em prever a formação de gelo. Os casos mostrados nas Figuras 5.1, 5.8(a) e 5.9(a) são exemplos desta condição. Esta constatação confirma as conclusões de Wright, Gent e Guffond (1997) sobre a necessidade de mais pesquisas na simulação de formas de gelo do tipo Glaze. Esta forma de gelo, como foi descrito na seção 1.1, ocorre com temperaturas e velocidades altas. Nestas condições a determinação da fração de água congelada é muito sensível às taxas de transferência de calor. O estado termodinâmico da água está próximo da curva de saturação formada entre o estado sólido e líquido e, variações do coeficiente de transferência de calor afetam a fração de congelamento $n_{f}$. Esta constatação está de acordo com as conclusões de Gent, Dart e Cansdale (2000), que indicaram que o coeficiente de transferência de calor é o parâmetro mais importante para o cálculo preciso das formas do gelo do tipo Glaze.

A Figura 6.2 apresenta os valores dos parâmetros de similaridade da Tabela 6.2. Através da comparação desta figura com as formas de gelo da Figura 5.9 constata-se que a discussão do parágrafo anterior, é igualmente aplicável ao caso F02, ou seja, o parâmetro $\phi$ pode representar as condições nas quais o código tenderá a fornecer formas dissimilares aos casos experimentais. 
Tabela 6.1: Parâmetros de similaridade dos casos da Figura 5.8

\begin{tabular}{cccc}
\hline Caso & $R e_{d} \cdot 10^{-4}$ & $A_{c}$ & $\phi(\mathrm{K})$ \\
\hline F01(a) & 8,29 & 1,56 & 2,25 \\
\hline F01(b) & 8,40 & 1,56 & 3,85 \\
\hline F01(c) & 8,47 & 1,56 & 5,55 \\
\hline F01(d) & 8,83 & 1,57 & 11,05 \\
\hline F01(e) & 9,80 & 1,57 & 25,85 \\
\hline
\end{tabular}

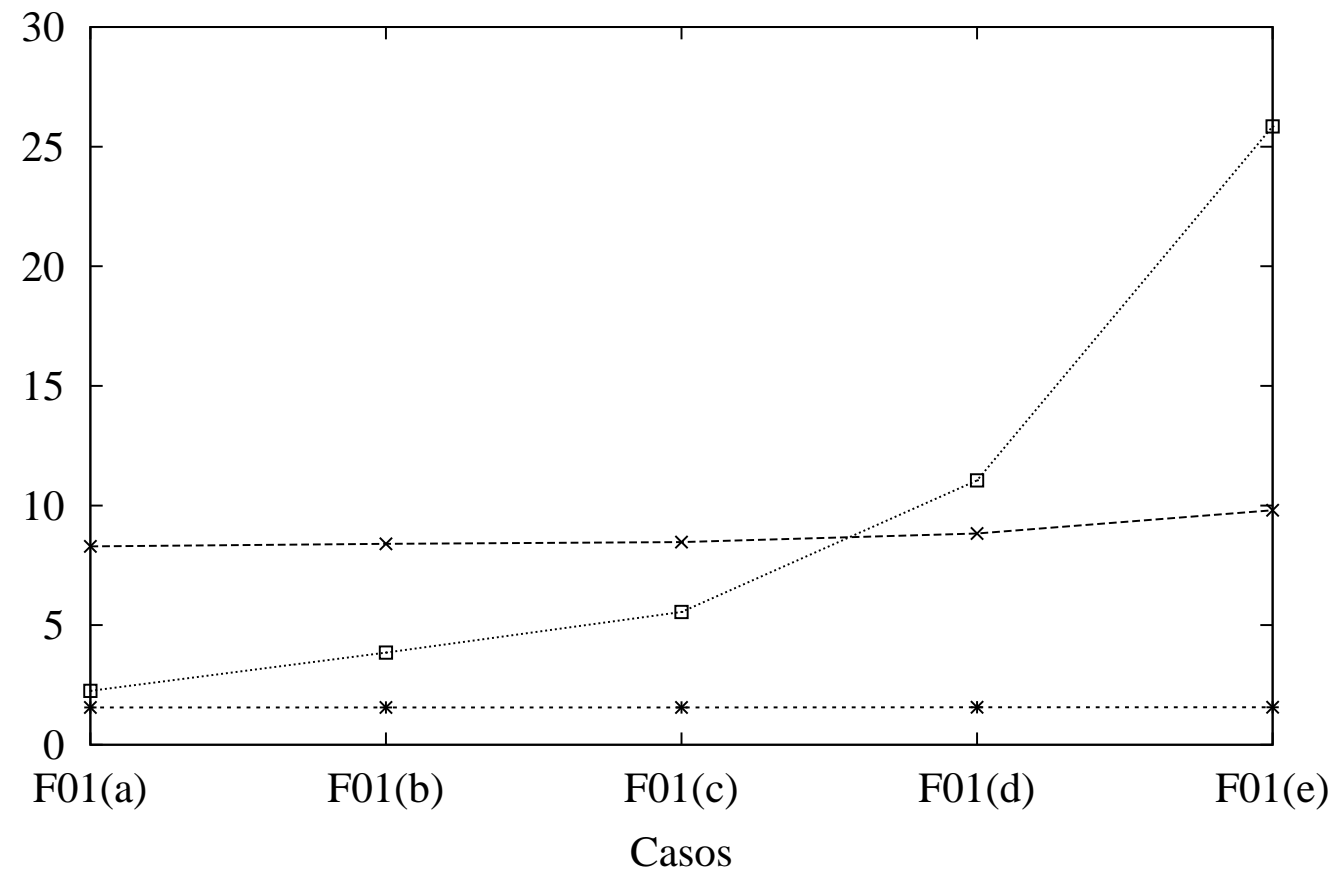

Red. $10^{-4}$---*--- Ac $\cdots \cdots * \cdots \cdot \quad$ fi $(\mathrm{K}) \quad \cdots \cdots \cdots \cdots \cdots$

Figura 6.1: Parâmetros de similaridade dos casos da Figura 5.8

As Figuras 6.3 e 6.4 apresentam os valores dos parâmetros de similaridade das Tabelas 6.3 e 6.4. As formas de gelo apresentadas nas Figuras 5.10 e 5.11 não foram consideradas similares às formas experimentais. Da análise dos parâmetros de similaridade não verificase uma tendência que possa justificar o uso de um parâmetro na análise das forma de gelo. Porém, pode-se constatar que os valores dos parâmetros $\phi$ estão fora das faixas que indicam previsões adequadas de formas de gelo.

Através da análise dos parâmetros de similaridade em simulações de formas de gelo constatou-se que eles poderiam ser utilizados para indicar as limitações dos códigos de previsão de gelo. Uma avaliação de uma maior quantidade formas de gelo e em condições não estudadas neste trabalho tem o potencial de trazer resultados para o desenvolvimento de métodos de avaliação de códigos de simulação numérica de formas de gelo.

Como foi exposto ao longo deste trabalho a transferência de calor é importante na deter- 
Tabela 6.2: Parâmetros de similaridade dos casos da Figura 5.9

\begin{tabular}{cccc}
\hline Caso & $R e_{d} \cdot 10^{-4}$ & $A_{c}$ & $\phi(\mathrm{K})$ \\
\hline F02(a) & 1,27 & 1,54 & 2,15 \\
\hline F02(b) & 1,29 & 1,54 & 3,85 \\
\hline F02(c) & 1,30 & 1,54 & 5,45 \\
\hline F02(d) & 1,35 & 1,54 & 10,85 \\
\hline F02(e) & 1,50 & 1,54 & 25,55 \\
\hline
\end{tabular}

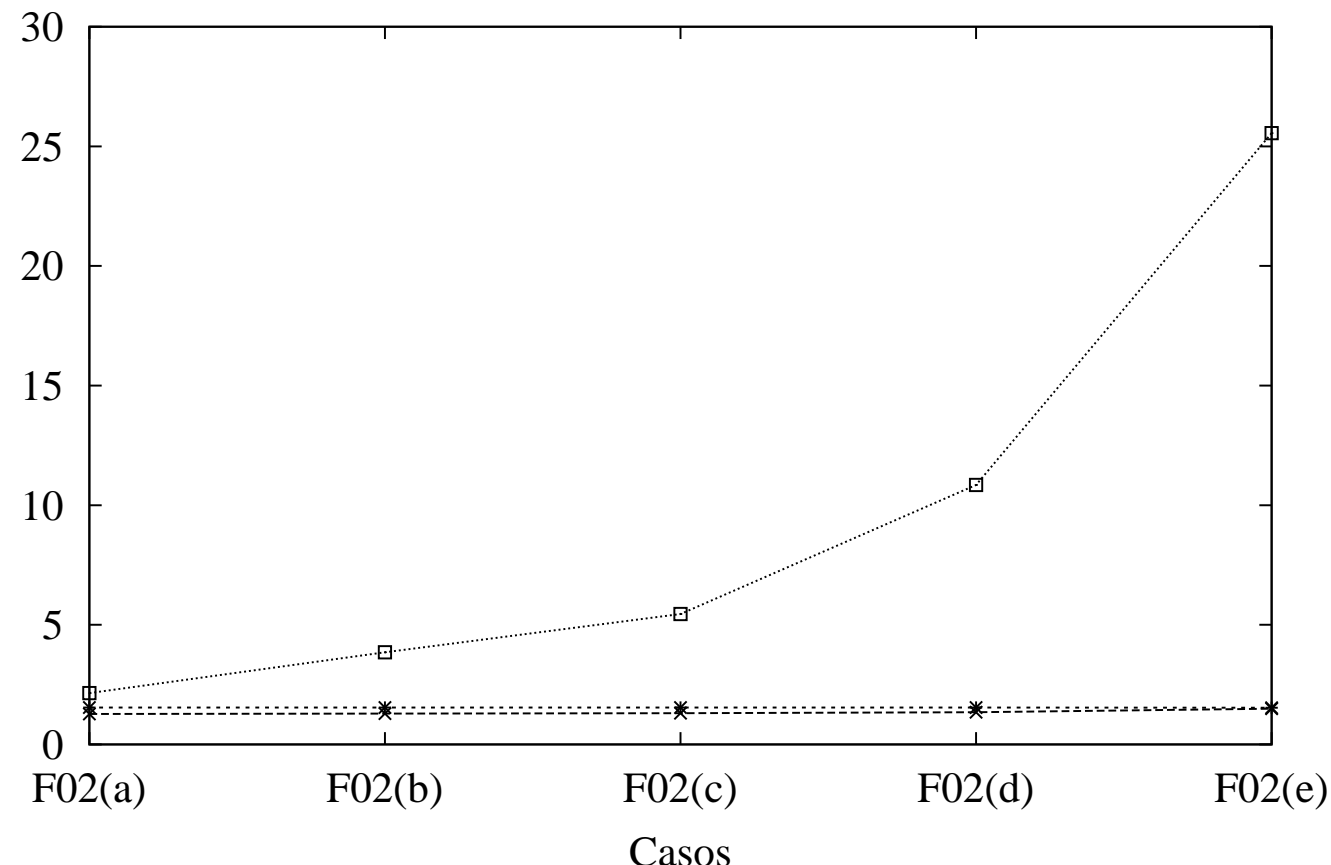

Red. $10^{-4}-\cdots *---\quad$ Ac $\cdots \cdots * \cdots \cdot \quad$ fi $(\mathrm{K}) \quad \cdots \cdots \cdots \cdots \cdots$

Figura 6.2: Parâmetros de similaridade dos casos da Figura 5.9

Tabela 6.3: Parâmetros de similaridade dos casos da Figura 5.10

\begin{tabular}{cccc}
\hline Caso & $R e_{d} \cdot 10^{-4}$ & $A_{c}$ & $\phi(\mathrm{K})$ \\
\hline F03(a) & 8,29 & 3,12 & 2,25 \\
\hline F03(b) & 8,40 & 3,13 & 3,85 \\
\hline F03(c) & 8,47 & 3,12 & 5,55
\end{tabular}

Tabela 6.4: Parâmetros de similaridade dos casos da Figura 5.11

\begin{tabular}{cccc}
\hline Caso & $R e_{d} \cdot 10^{-4}$ & $A_{c}$ & $\phi(\mathrm{K})$ \\
\hline F04(a) & 1,30 & 2,40 & 5,45 \\
\hline F04(b) & 1,30 & 3,12 & 5,45 \\
\hline F04(c) & 1,30 & 3,84 & 5,45 \\
\hline F04(d) & 1,30 & 4,32 & 5,45 \\
\hline
\end{tabular}




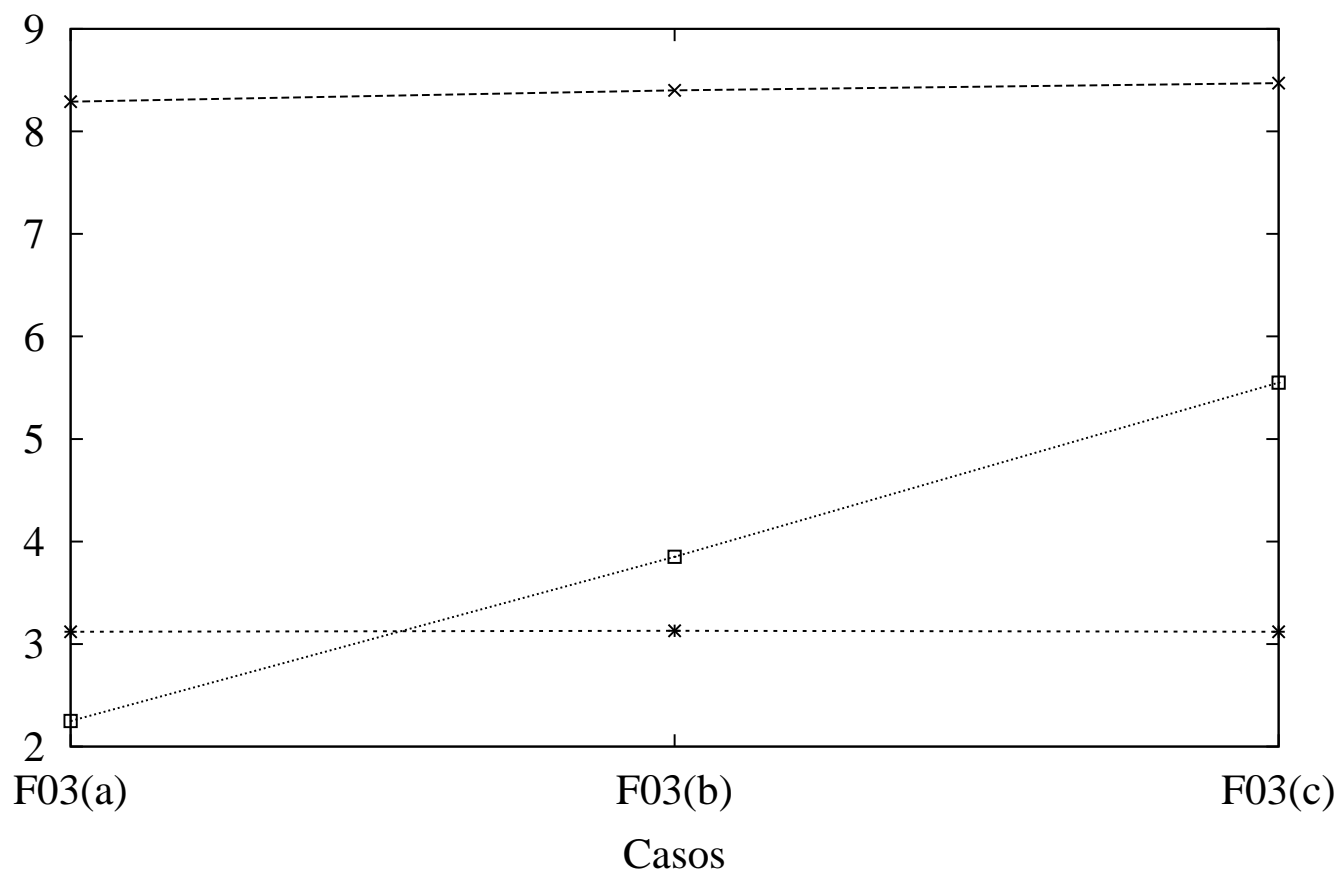

Red. $10^{-4}-\cdots *--\quad$ Ac $\cdots \cdots * \cdots \cdot \quad$ fi $(\mathrm{K}) \quad \cdots \cdots \cdots \cdots \cdots$

Figura 6.3: Parâmetros de similaridade dos casos da Figura 5.10

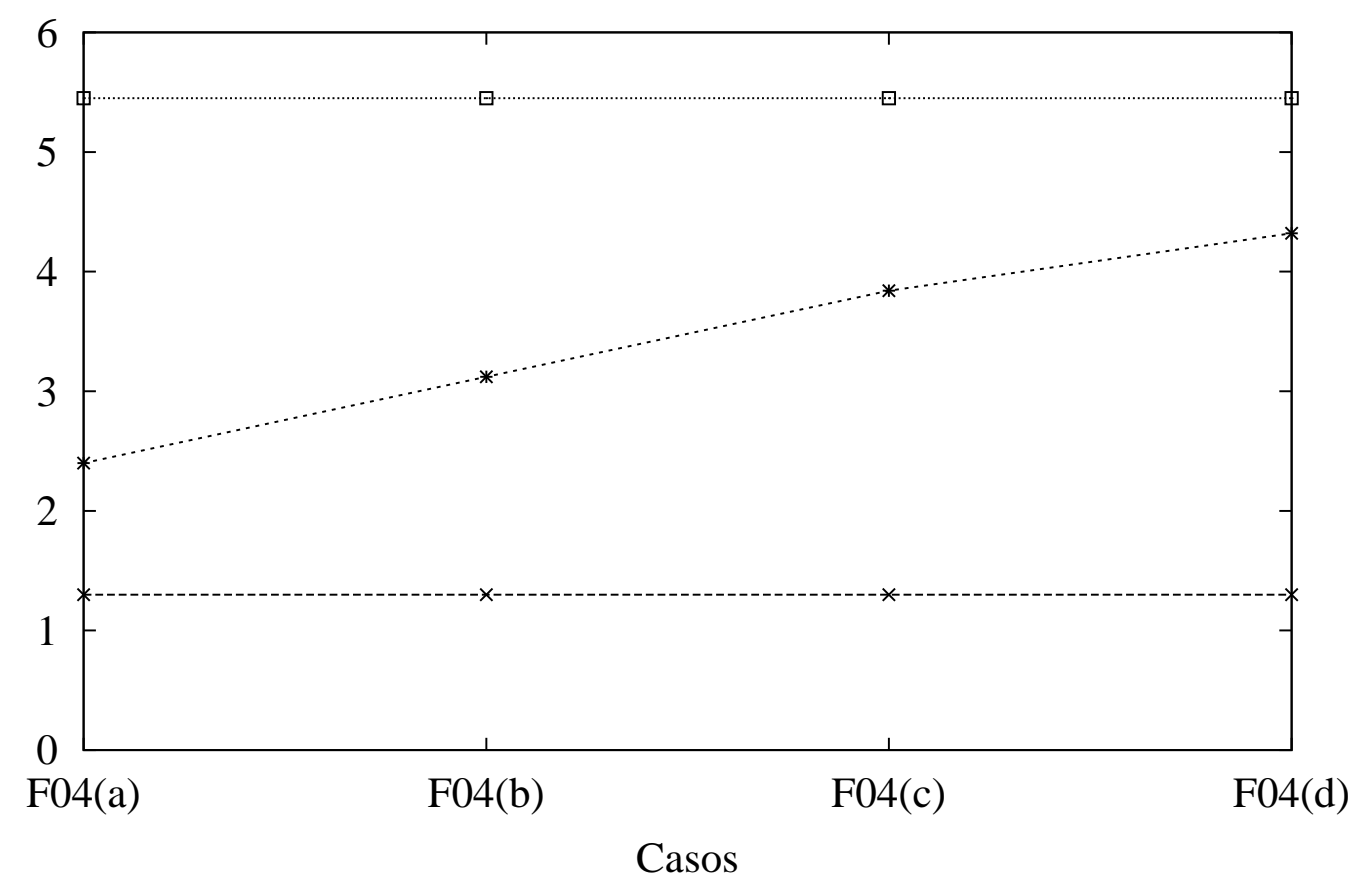
Red. $10^{-4}$
Ac $\cdots \cdots * \cdots \cdots \cdot \quad$ fi $(\mathrm{K}) \quad \cdots \cdots \cdots \cdots \cdots$

Figura 6.4: Parâmetros de similaridade dos casos da Figura 5.11 
minação das formas de gelo. A implementação, neste trabalho, da avaliação integral da camada limite térmica e a utilização deste módulo com o programa ONERA forneceu resultados que motivam a continuidade do desenvolvimento deste módulo. O cálculo da transferência de calor por métodos integrais é um procedimento ágil e que forneceu resultados satisfatórios, entretanto esta abordagem apresenta limitações e uma melhor avaliação do cálculo da transição entre o regime laminar e turbulento podem gerar resultados mais próximos dos dados experimentais.

O caso C13, apresentado na Figura 5.4 foi escolhido para apresentar as potencialidades do estudo da camada limite na transferência de calor sobre aerofólios com formas de gelo. No módulo de transferência de calor do presente trabalho foram implementadas opções que possibilitam a variação da rugosidade equivalente $k_{s}$, da posição de início da transição e do comprimento da transição. Para o último item foi implementado o modelo de intermitência mostrado na Equação 3.24. O estudo dos efeitos destes parâmetros nas formas de gelo é baseado em trabalhos recentemente publicados por Stefanini et al. (2007, 2008).

As simulações utilizam os modelos de transição abrupto e transição suavizada com a função intermitência $\gamma(s)$. Os dois tipos de transição foram testados e são apresentados resultados comparativos entre eles. O resultado do código ONERA é utilizado como base de comparação.

O valor da rugosidade equivalente do grão de areia $k_{s}$ é um parâmetro que influencia o cálculo do coeficiente de transferência de calor convectivo e que afeta a posição de início da transição laminar-turbulenta. Diversos valores de $k_{s}$ foram utilizados com o objetivo de avaliar o efeitos deste parâmetro no crescimento das formas de gelo. No estudo de sensibilidade, considerou-se que a transição ocorre abruptamente e segundo os critério da Equação 3.22. O estudo é apresentado na Figura 6.5.

Foi observado que para valores de $k_{s}$ inferiores a $0,1 \mathrm{~mm}$, as formas de gelo assemelham-se às formas apresentadas na Figura 6.5(a). $\mathrm{O}$ aumento do valor de $k_{s}$ implica na transição do regime para turbulento, que aumenta significativamente a transferência de calor e, por consequência, a altura da forma de gelo.

Nos resultados apresentados no Capítulo 5 foi apontado que as diferenças entre os resultados do código ONERA eo presente trabalho poderiam ser atribuidos a valores de rugosidade. O estudo de sensibilidade sustenta esta hipótese, pois as variações das formas de gelo foram significativas com pequenas variações do valor da rugosidade.

A irregularidade das formas de gelo implica em dificuldades para o cálculo da rugosidade equivalente. A maioria dos modelos de simulação de formação de gelo utiliza correlações empíricas para o cálculo da rugosidade equivalente. Para a definição destas correlações, diver- 


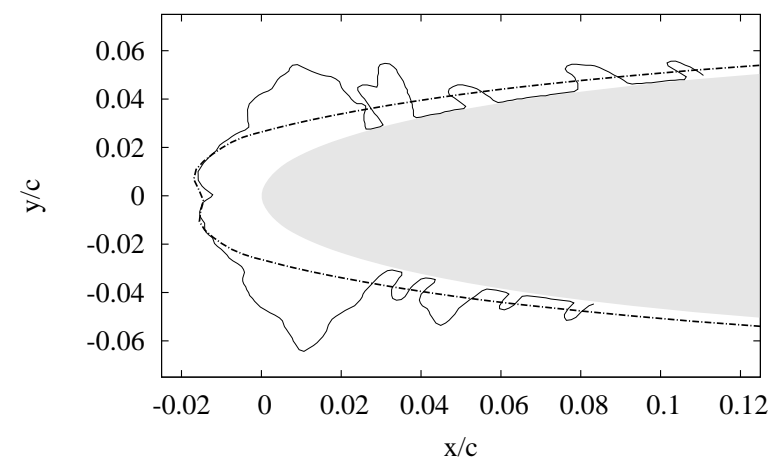

Experimental (Kind,2001, C13) Abrupta-Presente Trabalho

(a) $\mathrm{ks}=0,1(\mathrm{~mm})$

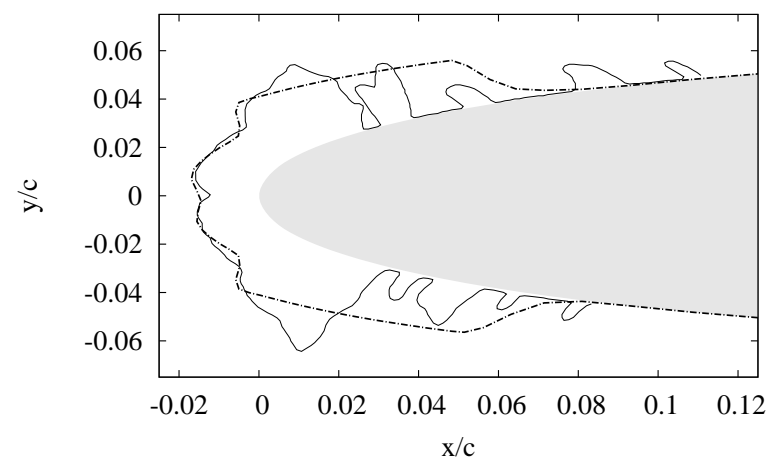

Experimental (Kind,2001, C13) Abrupta-Presente Trabalho

(b) $\mathrm{ks}=0,125(\mathrm{~mm})$

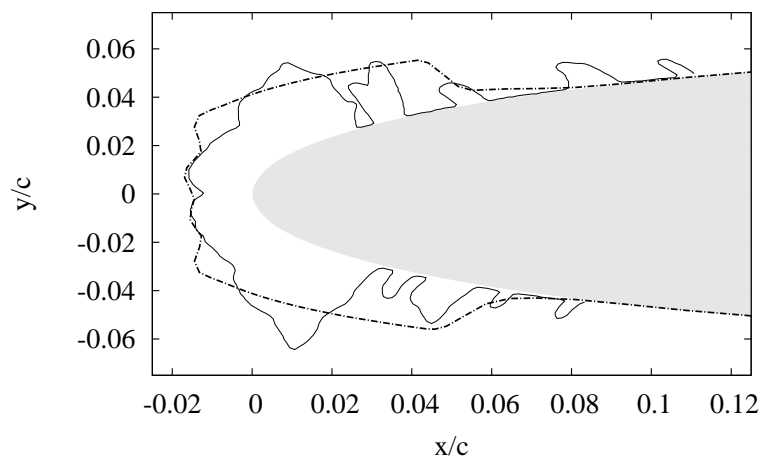

Experimental (Kind,2001, C13) Abrupta-Presente Trabalho

(c) $\mathrm{ks}=0,15(\mathrm{~mm})$

Figura 6.5: Efeito da rugosidade equivalente $k_{s}$ na forma de gelo do caso C13 da Tabela 5.1 


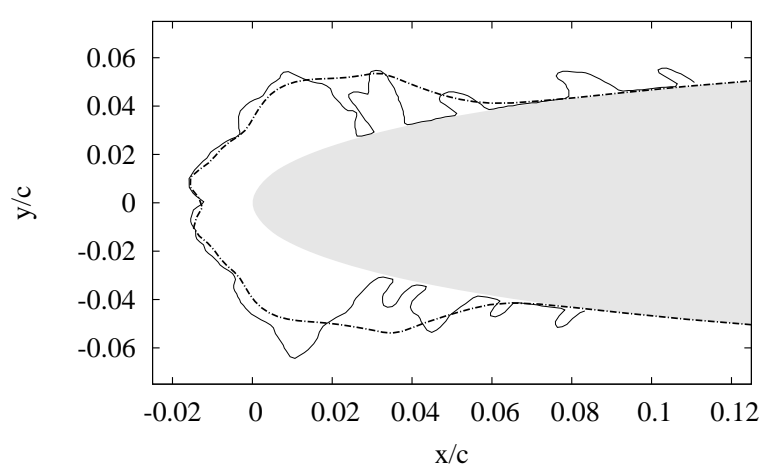

Experimental (Kind,2001, C13) Suave-Presente Trabalho

(a) $s_{t r} / c=0,003 /-0,001$

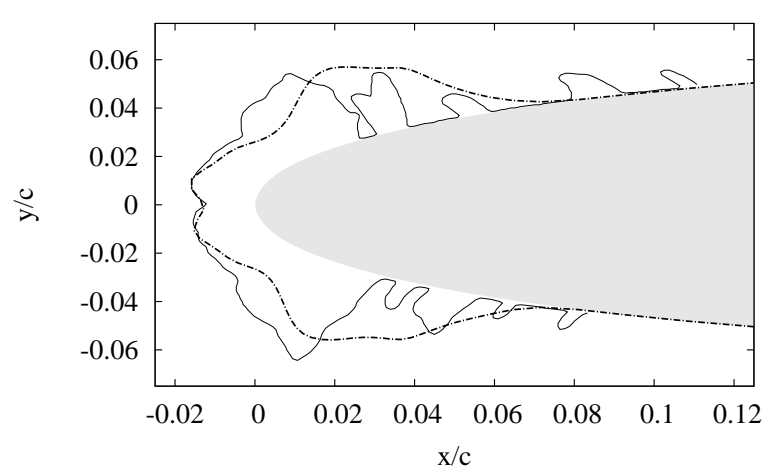

Experimental (Kind,2001, C13) Suave-Presente Trabalho

(b) $s_{t r} / c=0.013 /-0.011$

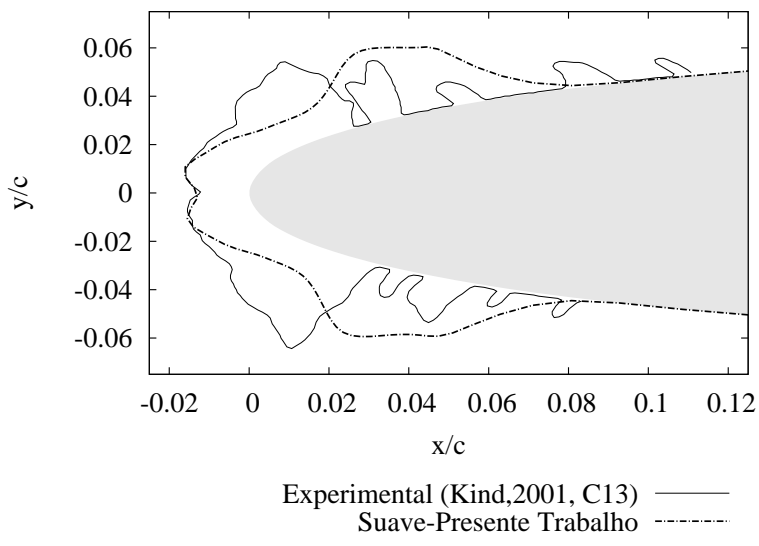

(c) $s_{t r} / c=0,023 /-0,021$

Figura 6.6: Efeito da posição de início da transição Laminar-Turbulenta na forma de gelo do caso C13 da Tabela 5.1

sos valores de $k_{s}$ são utilizados para ajustar a forma da gelo simulado. No presente trabalho foi utilizada a correlação ajustada para o código LEWICE (RUFF; BERKOWITZ, 1990). Uma correlação ajustada para o programa implementado neste trabalho traria melhores resultados.

Para o caso em que $k_{s}=0,125 \mathrm{~mm}$, a posição da transição entre o regime laminar e turbulento foi variada manualmente com o objetivo de estudar sua influência nas formas de gelo. O estudo é apresentado na Figura 6.6. Os valores positivos estão no extradorso do aerofólio e os valores negativos no intradorso.

Comparando-se as figuras percebe-se que a região de maior espessura move-se em direção ao bordo de fuga, ou seja, na mesma direção que a posição da transição é variada. Próximo à posição de transição, há um aumento no volume de gelo formado em consequência do aumento do coeficiente de transferência de calor devido à mudança do regime. Nos três casos apresentados o perfil de gelo é semelhante pois a transição ocorre de forma abrupta.

Apesar de ter sido mostrado os efeitos da transição nas formas de gelo, ela tem maior importância quando está afastada do ponto de estagnação. Em todos os casos apresentados 


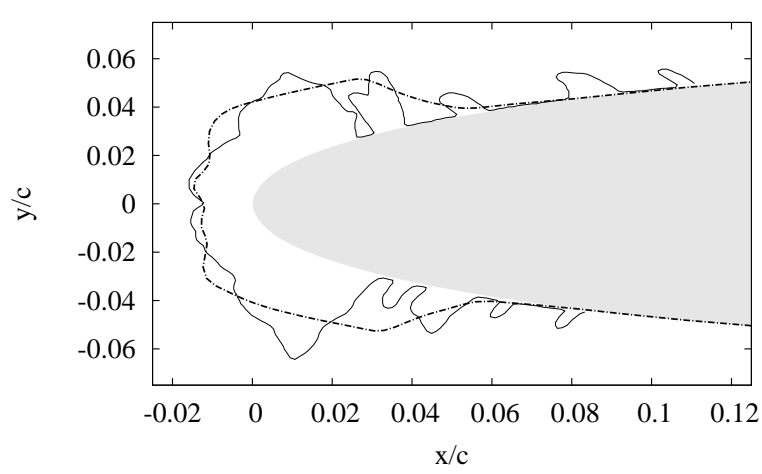

Experimental (Kind,2001, C13) Suave-Presente Trabalho

(a) $s_{f} / c=0,021 /-0,017$

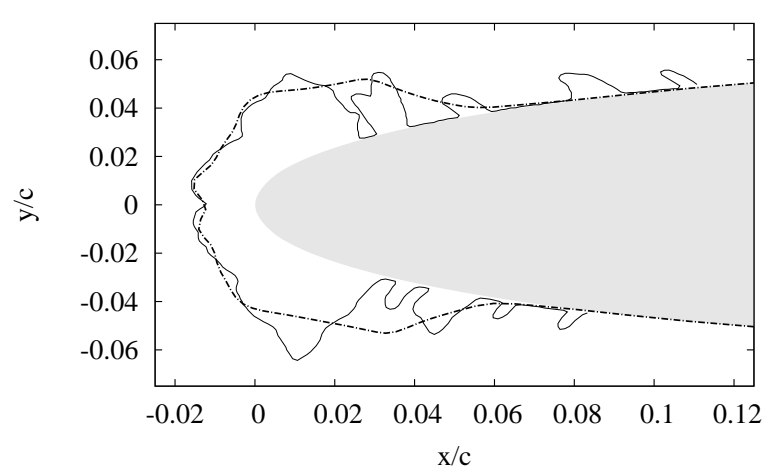

Experimental (Kind,2001, C13) Suave-Presente Trabalho

(b) $s_{f} / c=0.031 /-0.027$

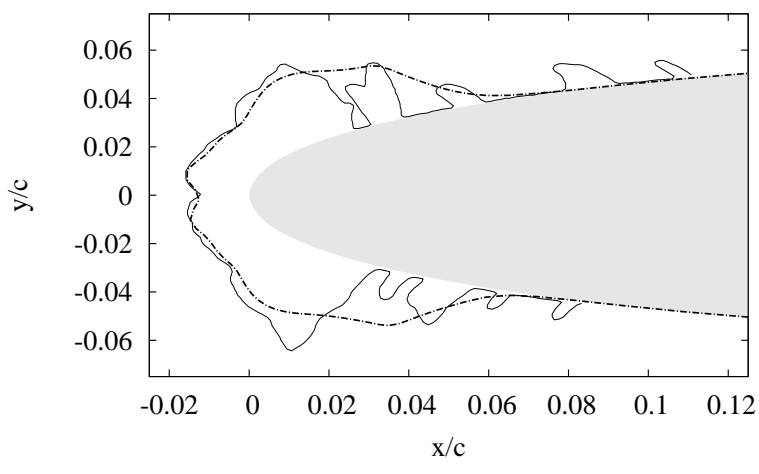

Experimental (Kind,2001, C13)

Suave-Presente Trabalho

(c) $s_{f} / c=0,041 /-0,037$

Figura 6.7: Efeito do Comprimento da Transição Laminar-Turbulenta na forma de gelo do caso C13 da Tabela 5.1

no Capítulo 5, com exceção do C13 e C14, a transição entre o regime laminar e turbulento ocorreu muito próximo ao ponto de estagnação e nas primeiras células da malha computacional. As transições foram previstas com Equação 3.22 e representa um modelo adequado para aerofólios com formação de gelo. Em uma situação com sistemas de proteção ou no início do congelamento, onde a superfície é considerada lisa, a transição ocorrerá mais distante do ponto de estagnação e o estudo de modelos mais precisos de previsão podem trazer melhores resultados de transferência de calor convectiva.

Para o caso com $k_{s}=0,125 \mathrm{~mm}$ e admitindo que a posição da transição ocorre em $s_{t r} / c=0.003$ no extradorso e $s_{t r} / c=-0.001$ no intradorso, variou-se o comprimento da região de transição. A função intermitência $\gamma(s)$ da Equação 3.24 foi ativada para fornecer os valores do coeficiente de transferência de calor nesta região. O resultado na formação de gelo é apresentado na Figura 6.7.

A variação do comprimento da transição afeta a forma do gelo, pois transições mais longas tornam as formas mais suaves. Quando a transição é curta as formas de gelo assemelham-se 


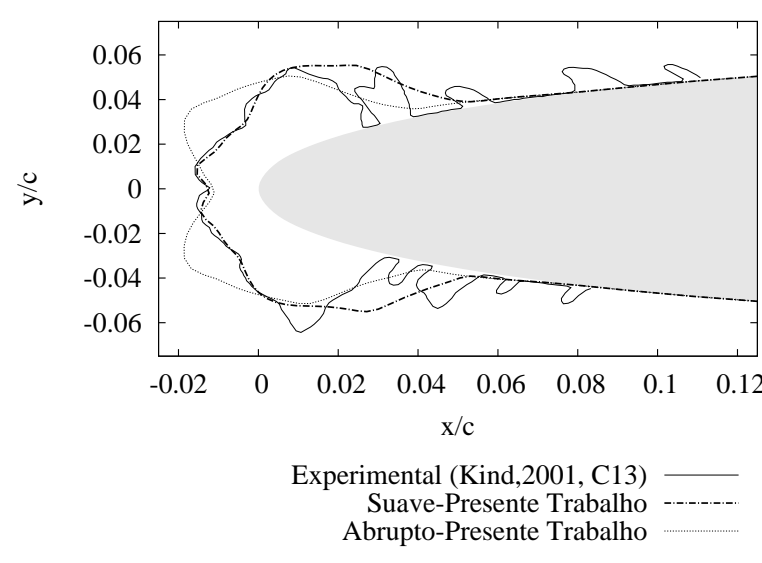

(a) Transição Abrupta

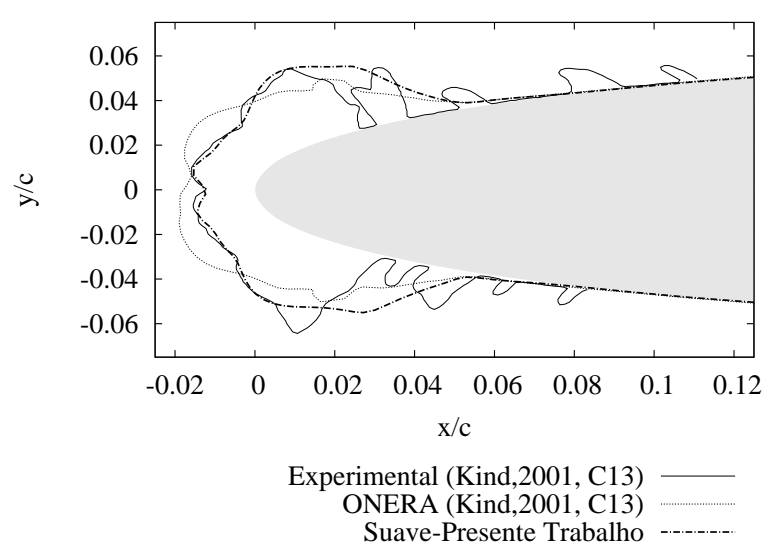

(b) Transição Suave

Figura 6.8: Comparação dos resultados experimentais e dos modelos implementados com o código ONERA (KIND, 2001)

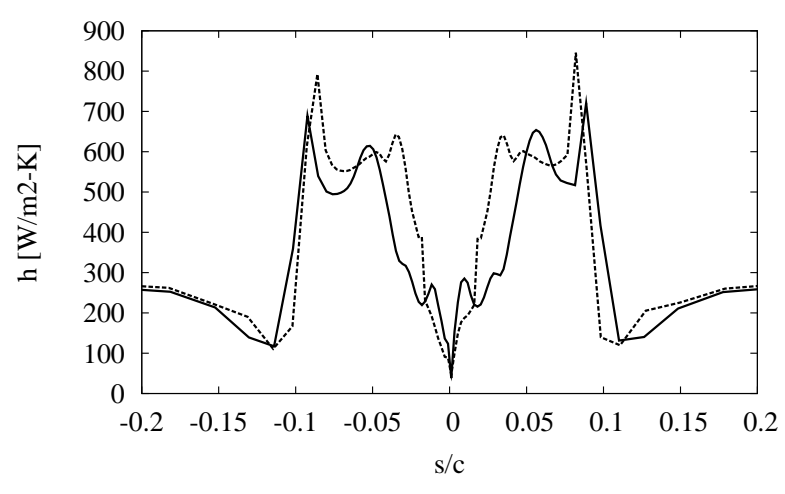

Suave-Presente Trabalho Abrupto-Presente Trabalho

(a) Coeficiente de Transferência de Calor Convectivo

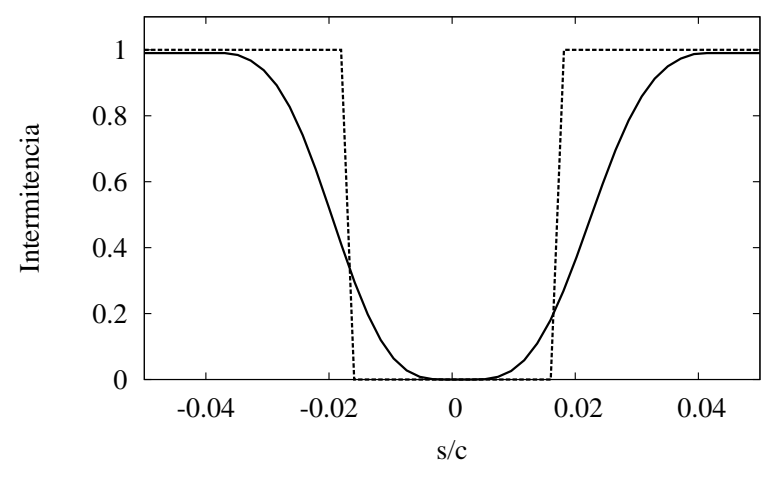

Suave-Presente Trabalho Abrupto-Presente Trabalho

(b) Função Intermitência

Figura 6.9: Comparação do coeficiente de transferência de calor e da função intermitência na transição suave e abrupta

às formas com transição abrupta.

A posição do início e do comprimento da transição, e o valor da rugosidade equivalente do grão de areia foram variados com o objetivo de obter uma forma de gelo similar as formas experimentais o caso C13 da Tabela 5.1. A Figura 6.8 apresenta o resultado destas simulações, com os modelos de intermitência abrupto e suavizado. Na Figura 6.8(a), os resultados do modelo implementado com a transição abrupta são comparados com os resultados do código ONERA.

A Figura 6.8(b) demonstra que uma adequada previsão da posição de início da transição combinado com um modelo adequado de desenvolvimento da transição pode melhorar significativamente as formas de gelo simuladas. A Figura 6.9 mostra a suavização da curva do coeficiente de transferência de calor devido à função intermitência. 
Os resultados apresentados neste trabalho e os estudos dos efeitos da camada limite nas formas de gelo, permitem concluir que a avaliação da integral da camada limite térmica é um método adequado para o cálculo da transferência de calor convectiva sobre aerofólios com formação de gelo. Para uma previsão adequada das formas é necessário, porém, que o módulo de solução do escoamento e de trajetória de partículas forneça resultados precisos. Por ser um método integral, pequenos erros no início do cálculo se acumulam ao longo de toda a integração. Mostrou-se também que algumas simulações apresentam deficiências na previsão de formas de gelo e acredita-se que estudos futuros na previsão do comprimento da transição e em modelos de rugosidade de gelo são necessários para a melhor compreensão dos fenômenos físicos e melhoria na previsão das formas de gelo sobre aerofólios. 


\section{Conclusões e Próximos Trabalhos}

\subsection{Conclusões}

Um módulo dedicado à avaliação da camada limite dinâmica e térmica foi implementado, no presente trabalho, para o cálculo do coeficiente de transferência de calor convectivo sobre aerofólios de uso aeronáutico e com formação de gelo. Foram considerados os efeitos da rugosidade e a região de transição foi avaliada de dois modos distintos, com modelo abrupto e com modelo de intermitência. O código implementado neste trabalho foi acoplado aos módulos do código ONERA para a simulação de previsão das formas de gelo em aerofólios aerofólios para diversas condições físicas do escoamento do ar com a presença de gotas de água subresfriadas.

O módulo proposto foi implementado com sucesso e os resultados obtidos foram considerados satisfatórios, tendo sido atingidos os objetivos pretendidos, conforme descrito na Seção 1.3.

O modelo de intermitência foi implementado no módulo de avaliação da camada limite e avaliou-se os efeitos dos parâmetros da transição na previsão da formação do gelo. O comprimento da transição afetou a forma do gelo prevista pela simulação, que teve curvas mais suaves e semelhantes às formas de gelo obtidas experimentalmente. A posição do início da transição afetou a localização da formação de gelo em forma de "chifres" e das regiões que possuem maior espessura de gelo. A posição de início da transição e o comprimento da transição tem maior importância em aerofólios lisos e no início do processo de congelamento. Através dos resultados das avaliações nota-se que os parâmetros podem ser utilizados em ajustes dos modelos de camada limite para melhores previsões de formas de gelo do tipo Glaze.

O valor da rugosidade equivalente $k_{s}$ foi variado e mostrou-se que este parâmetro afeta a previsão das formas de gelo quanto ao volume e ao formato do gelo. Os efeitos da variação deste parâmetro são justificáveis porque a rugosidade equivalente é importante na avaliação das camadas limites e no disparo da transição. A pesquisa bibliográfica indica que o cálculo de rugosidade equivalente utilizado pelos códigos utiliza correlações empíricas. Acredita-se que modelos que consigam prever as rugosidades ao longo da coordenada $s$ do aerofólio e nos vários 
intervalos de tempo do crescimento de gelo poderão resultar em cálculos de transferência de calor mais precisos e previsões de formas de gelo mais próximas das experimentais.

Foram avaliados os coeficientes de sustentação $C_{l}$ de aerofólios com e sem formas de gelo e constatou-se que, é possível utilizar este parâmetro na avaliação comparativa das formas de gelo simuladas. Os resultados dos cálculos mostraram uma degradação no coeficiente de sustentação equivalente aos dados experimentais.

Foram utilizados parâmetros de similaridade para a avaliação das simulações de previsão de formas de gelo. Constatou-se que é possível definir faixas de ordens de grandeza para o parâmetro $\phi$ nas quais as previsões da forma de gelo tem uma tendência em apresentar resultados pouco semelhantes aos dados experimentais, e maiores diferenças nos valores dos coeficientes aerodinâmicos.

Simulou-se casos de gelo do tipo Rime e Glaze. As simulações de formas de gelo do tipo 'Rime', do presente trabalho, apresentaram resultados próximos aos experimentais. As simulações de gelo do tipo Glaze apresentaram resultados com menor similaridade em relação aos dados experimentais. Os resultados obtidos por outros códigos apresentaram uma tendência semelhante.

As simulações de gelo do tipo Glaze apresentaram valores do parâmetro $\phi$ com uma ordem de grandeza maior que as simulações de gelo do tipo Rime. Em simulações de previsão de formas de gelo do tipo Rime, o congelamento ocorre quase instantaneamente. Para este tipo de gelo pequenas diferenças no valor do coeficiente de transferência de calor não afetam significativamente o processo de congelamento da água. Os métodos de avaliação do coeficiente de transferência de calor implementados neste trabalho foram considerados adequados para a simulação de previsões deste tipo de gelo.

Nas simulações de formas de gelo do tipo Glaze nem toda gotícula de água congela no impacto com o aerofólio, e pode escorrer em direção ao bordo de fuga. Como o congelamento ocorre mais lentamente, um módulo de crescimento de gelo que calcule as formas em intervalos de tempo, pode gerar melhores resultados. O módulo de crescimento de gelo do código ONERAé baseado em um método de predição-correção que utiliza um intervalo de tempo longo. Nesta condição, não foi possível estudar o efeito das variações temporais da distribuição do coeficiente de transferência de calor no processo de crescimento do gelo aderido ao aerofólio.

Para simulações de gelo do tipo Glaze uma previsão adequada do início e do comprimento transição laminar-turbulenta nos intervalos iniciais da simulação podem melhorar a previsão dos locais e das formas de gelo finais. O estudo de modelos de rugosidade equivalente que 
considerem as diferenças dos tipos de gelo formados ao longo do aerofólio e as diferentes rugosidades ao longo do tempo podem também contribuir para o aperfeiçoamento do modelo. Para a solução da transferência de calor ao redor de formas de gelo, ou seja, nos últimos intervalos de tempo da simulação, os modelos integrais de avaliação da camada limite e os critério de disparo e desenvolvimento abrupto da transição implementados neste trabalho, fornecem resultados adequados para o cálculo das formas de gelo.

A implementação de um código refinado para a solução do escoamento viscoso na região adjacente ao aerofólio poderá melhorar a avaliação da transferência de calor sobre formas complexas de gelo.

\subsection{Próximos Trabalhos}

Recomenda-se que no desenvolvimento de novos trabalhos em previsão de formas de gelo em aerofólios sejam considerados os seguintes assuntos:

- Estudo para melhorar o cálculo do coeficiente de transferência de calor na região de estagnação do escoamento;

- Incorporação do efeito do raio de curvatura e do fluxo de evaporação na avaliação dos parâmetros da camada limite;

- Implementação do coeficiente de arraste $C_{d}$ como método de avaliação das formas de gelo;

- Implementação de outros métodos de previsão do início e do desenvolvimento da transição laminar-turbulento sobre superfícies rugosas;

- Implementação de modelos de cálculo de rugosidade equivalente que considerem as diferentes rugosidades ao longo do aerofólio e que considerem os tipos de rugosidade durante crescimento do gelo;

- Utilização de programas diferenciais para a solução do escoamento;

- Utilização de outros módulos de crescimento de gelo, tais como o módulo do código LEWICE;

- Desenvolvimento de um módulo de crescimento de gelo, adequado aos intervalos de tempo utilizados na simulação do processo, e que considere os diferentes processos que ocorrem na formação e crescimento do gelo formado na superfície do aerofólio. 


\section{Referências}

ABU-GHANNAM, B.; SHAW, R. Natural transition of boundary layers - the effects of turbulence, pressure gradient and flow history. Journal of Mechanical Engineering Science, v. 22, n. 5, p. 213-228, 1980.

ACHENBACH, E. The effect of surface roughness on the heat transfer from a circular cylinder to the cross flow of air. Int. J. Heat and Mass Transfer, v. 20, p. 359-69, 1977.

ADDY, H. Ice Accretions and Icing Effects for Modern Airfoils. NASA TP-2000-210031, April 2000.

ADDY, H. et al. A Wind Tunnel Study of Icing Effects on a Business Jet Airfoil. NASA TM-2003-212124, 2003.

ANDERSON, D. N. Manual of Scaling Methods. NASA/CR 2004-212875, Março 2004.

BEAUGENDRE, H.; MORENCY, F.; HABASHI, W. G. Fensap-ice three-dimensional in-flight ice accretion module: Ice3d. J. Aircraft, v. 40, n. 2, p. 239-47, March-April 2003.

BRAGG, M.; HEINRICH, D.; VALAREZO, W. Effect of underwing frost on a transport aircraft airfoil at flight reynolds number. Journal of Aircraft, n. 31 (6), p. 1372-1379, 1994.

BRAGG, M.; KERHO, M.; CUMMINGS, M. Airfoil boundary layer due to large leading-edge roughness. In: . . [s.n.], 1995. (Special Course on Progress in Transition Modelling), p. .

BRAGG, M. B. Rime Ice Accretion and Its Effect on Airfoil Performance. Tese (Doutorado) - The Ohio State University, 1981.

BRAGG, M. B. An experimental study of the aerodynamics of a NACA 0012 airfoil with a simulated glaze ice accretion. Urbana, Ohio, 1986.

BRAGG, M. B.; BROEREN, A. P.; BLUMENTHAL, L. A. Iced-airfoil aerodynamics. Progress in Aerospace Sciences, v. 41, p. 323-362, jul 2005.

BRAGG, M. B.; CUMMINGS, S. L.; HENZE, C. M. Boundary-layer and heat transfer measurements on an airfoil with simulated ice roughness. In: AEROSPACE SCIENCES And MEEting, 34., 1996, Reno. M. B. Bragg and A. P. Broeren and L. A. Blumenthal. Reston: America Institute of Aeronautics and Astronautics, 1996. p. 1-16.

BREDIF, M. A fast finite element method for transonic potential flow calculations. In: AEROSPACE SCIENCES MEETING AND EXHIBIT, 21., 1983, Reno. AIAA Paper 83-16755. Reston: America Institute of Aeronautics and Astronautics, 1983.

BREDIF, M. Finite element calculation of potential flow around wings. Lecture Notes on Physics, v. 218, 1985. 
BROEREN, A.; ADDY, H.; BRAGG, M. Effect of intercycle ice accretions on airfoil performance. In: AMERICAN INSTITUTE OF AERONAUTICS AND ASTRONAUTICS. AIAA Paper 2002-0240. Reno, Nevada, EUA, 2002.

BRUMBY, R. Wing surface roughness - cause \& effect. In: D.C. Flight Approach,. -: [s.n.], 1979 .

CANSDALE, J. T.; GENT, R. Ice Accretion on Aerofoils in Two-dimensional Compressible Flow - A Theoretical Model. Farnborough: Royal Aircraft Establishment, 1983. (Technical Report, 82128).

CEBECI, T. Calculation of compressible turbulent boundary layers with heat and mass transfer. AIAA Journal, v. 9, n. 6, p. 1091-7, 1971.

CEBECI, T. Effects of environmentally imposed roughness on airfoil performance. In: Influence of environmetal on aircraft wing performance. .: Von Karman Institute for Fluid Dynamics, 1987, (Lecture Series 1987-03).

CEBECI, T. Calculation of flow over iced airfoils. Journal of Aircraft, v. 27, n. 7, p. 853-61, Junho 1989.

CEBECI, T.; CHEN, H. H.; ALEMDAROGLU, N. Fortified lewice with viscous effects. Journal of Aircraft, v. 28, n. 9, p. 564-71, Setembro 1991.

CEBECI, T.; KAFYEKE, F. Aircraft icing. Annu. Rev. Fluid Mech., v. 35, p. 11-21, 2003.

COLLYER, M.; LOCK, R. Prediction of viscous effects in steady transonic flow past an airfoil. Aeronaultical Quarterly, v. 30, p. 485-505, 1979.

CRAWFORD, M. E.; KAYS, M. E. STAN5 - A Program for Numerical Computation of Two-Dimensional Internal and External Boundary Layer Flows. Washington: National Aeronautics and Space Administration, 1976. 140 p. (Contractor Report, 2742).

DIPPREY, D. F.; SABERSKY, R. H. Heat and momentum transfer in smooth and rough tubes at various prandtl numbers. Int. Heat and Mass Transfer, n. 6, p. 329-353, 1963.

DOENHOFF, A. E. V.; HORTON, E. A. Low-Speed Experimental Investigation of the Effect of Sandpaper Type Roughness on Boundary-Layer Transition. NACA TN 3858. [S.1.], 1956.

DUKHAN, N.; MASIULANIEC, K. C.; DE WITT, K. J. Experimental heat transfer coeficients from ice-roughened surfaces for aircraft deicing design. Journal of Aircraft, v. 36, n. 6, p. 948-56, November-December 1999.

FLEMMING, R.; LEDNICER, D. High Speed Ice Accretion on Rotorcraft Airfoils. CR 3910, 1985 .

GENT, R. TRAJICE2 - A Combined Water Droplet Trajectory and Ice Accretion Prediction Program For Aerofoils. Farnborough: Royal Aerospace Establishment, 1990. (Technical Report, 90054).

GENT, R. W.; DART, N. P.; CANSDAlE, J. Aircraft icing. Phil. Trans. Royal Society London A, n. 358, p. 2873-2911, 2000. 
GILE-LAFLIN, B.; PAPADAKIS, M. Experimental investigation of simulated ice accretions on a natural laminar flow airfoil. In: AMERICAN INSTITUTE OF AERONAUTICS AND ASTRONAUTICS. AIAA Paper 2001-0088. Reno, Nevada, EUA, 2001.

GRAY, V. H. Correlations Among Ice Measurements, Impingement Rates, Icing Conditions, and Drag Coefficients for Unswept NACA 65A004 Airfoil. ., February 1958.

GRAY, V. H. Prediction of aerodynamic penalties caused by ice formations on various airfoils. NASA-TN-D-2166, February 1964.

GRAY, V. H.; GLAHN, U. H. von. Aerodynamics effects caused by icing of an unswept NACA 65A004 airfoil. Cleveland, Ohio, 1958.

GUFFOND, D.; BRUNET, L. Validation du programme bidimensionnel de capitation. Chátillon Cedex, France: Office National D'Études et de Recherches Aérospatiales, 1988. (Rapport Technique, RP 20/5146 SY).

HAVUGIMANA, P. et al. A comparison of skin friction and heat transfer prediction by various roughness models. Reston: American Institute of Aeronautics and Astronautics, 2002.

HEINRICH, A. et al. Aircraft icing handbook. In: . Atlantic City, NJ: Federal Aviation Administration, U.S. Department of Transportation, 1991. v. 2. (FAA Technical Center Report, DOT/FAA/CT-88/8-2).

HENGST, J. V.; BOER, J. The Effect of Hoar-Frosted Wings on the Fokker $50 m$ Take-Off Characteristics. CP 496, 1991.

HESS, J.; SMITH, A. Calculation of potencial flow about arbitrary bodies. Progress in Aeronautical Sciences, v. 8, p. 1-138, 1967.

INGELMAN, S. M.; TRUNOV, O.; IVANIKO, A. Methods for Prediction of the Influence of Ice on Aircraft Flying Characteristics. Sweden, 1977.

JACKSON, D.; BRAGG, M. Aerodynamic performance of an nlf airfoil with simulated ice. In: AMERICAN INSTITUTE OF AERONAUTICS AND ASTRONAUTICS. AIAA Paper 99-0373. Reno, Nevada, EUA, 1999.

KAYS, W. M.; CRAWFORD, M. E. Convective heat and mass transfer. New York: McGraw-Hill, 1993.

KENNEDY, J.; MARSDEN, D. Potencial flow velocity distributions on multi-component airfoils sections. Canadian Aeronautics and Space Journal, v. 22, n. 5, p. 243-56, 1976.

KERHO, M. F.; BRAGG, M. B. Airfoil boundary-layer development and transition with large leading-edge roughness. AIAA Journal, v. 35, n. 1, p. 75-84, January 1997.

KIM, H.; BRAGG, M. Effects of leading-edge ice accretion geometry on airfoil aerodynamics. In: AMERICAN INSTITUTE OF AERONAUTICS AND ASTRONAUTICS. AIAA Paper 99-3150. Reno, Nevada, EUA, 1999.

KIND, R. (Ed.). Ice Accretion Simulation Evaluation Test. Neuilly-Sur-Seine Cedex: North Atlantic Treaty Organization - Research and Technology Organisation - NATO-RTO, 2001. 32 p. (Technical Report, 038). 
KORKAN, K.; JR., E. C.; CORNELL, C. Experimental aerodynamic characteristics of an naca 0012 airfoil with simulated ice. Journal of Aircraft, v. 2, n. 22, p. 130-134, February 1985.

LANGMUIR, I. Supercooled water droplets in rising of cold saturated air. In: SUITS, C. G.; WAY, H. E. (Ed.). The Collected Works Of Irving Langmuir. The Atmospheric Phenomena. New York: Pregamon Press Reprints, 1961, (10). p. 199-334. (Report n. RL-223, October-August 1944).

LANGMUIR, I.; BLODGETT, K. B. A mathematical investigation of water droplets trajectories. In: SUITS, C. G.; WAY, H. E. (Ed.). The Collected Works Of Irving Langmuir. The Atmospheric Phenomena. New York: Pregamon Press Reprints, 1961, (10). p. 349-93. (Report n. RL-224, December 1944 - July 1945).

LEARY, W. M. "We Freeze to Please"A History of NASA's Icing Research Tunnel and the Quest for Flight Safety. .: National Aeronautics and Space Administration, 2002. (The NASA History Series, NASA SP-2002-4226).

LUDLAM, F. H. The heat economy of a rimed cylinder. Quarterly Journal of the Royal Meteorological Society, v. 77, n. 334, p. 663-666, 1951.

MACARTHUR, C.; KELLER, J.; LUERS, J. Mathematical modeling of airfoil ice accretion on airfoils. In: AEROSPACE SCIENCES MEETING AND EXHIBIT, 20., 1987, Reno. AIAA Paper 82-36042. Reston: America Institute of Aeronautics and Astronautics, 1982.

MAKKONEN, L. Models for the growth of rime, glaze, icicles and wet snow on structures. Philosophical Transactions of the Royal Society, v. 358, n. 1776, p. 2913-2939, November 2000.

MAKKONNEN, L. Heat transfer and icing of a rough cylinder. Cold Regions and Technology, v. 10, p. 105-116, 1985.

MASON, B. The Physics of the Clouds. 2a. ed. London: Oxford University Press, 1971.

MESSINGER, B. L. Equilibrium temperature of an unheated icing surface as a function of air speed. Journal of Aeronautical Sciences, v. 20, n. 1, 1953.

NASA: Icing branch gallery. 2009. Disponível em: <http://iceboxesn.grc.nasa.gov/gallery/index.html>. Acesso em: 15 fev. 2009.

NEWTON, J. E. et al. Measurement of Local Convective Heat Transfer Coefficients from a Smooth and Roughened NACA 0012 Airfoil: Flight Test Data. Cleveland: National Aeronautics and Space Agency, 1988. 17 p. (Technical Memorandum, 1000284).

NIKURADSE, J. Stomungsgesetz in rahen rohren. Forschg. Arb. Ing.- Wes, v. 361, p. -, 1933. Trad. Inglês NACA TM 1292.

OLSEN, W.; SHAW, R.; NEWTON, J. Ice Shapes and the Resulting Drag Increase for a NACA 0012 Airfoil. ., 1984.

OWEN, P. R.; THOMSON, W. R. Heat transfer accross rough surfaces. J. Fluid Mech., n. 15 , p. $321-334,1963$. 
PAPADAKIS, M.; ALANSATAN, S.; SELTMANN, M. Experimental study of simulated ice shapes on a naca 0011. In: AMERICAN INSTITUTE OF AERONAUTICS AND ASTRONAUTICS. AIAA Paper 99-0096. Reno, Nevada, EUA, 1999.

PAPADAKIS, M.; ALANSATAN, S.; WONG, S. Aerodynamic characteristics of a symmetric naca section with simulated ice shapes. In: AMERICAN INSTITUTE OF AERONAUTICS AND ASTRONAUTICS. AIAA Paper 2000-0098. Reno, Nevada, EUA, 2000.

PIMENTA, M. M. The turbulent boundary layer: an experimental study of the transport of momentum and heat with the effects of roughness. Tese (Doutorado) - Stanford University, Stanford, May 1975.

PIMENTA, M. M.; MOFFAT, R.; KAYS, W. M. The turbulent boundary layer: an experimental study of the transport of momentum and heat with the effects of roughness. Stanford: Thermosciences Division, Mechanical Engineering Department, Stanford University, 1975. X p. (Report, HMT-21).

POINSATTE, P. E. Heat Transfer Measurements from a NACA 0012 Airfoil in Flight and in the NASA Lewis Icing Research Tunnel. Dissertação (Mestrado) - The University of Toledo, Toledo, Ohio, EUA, Junho 1989.

POINSATTE, P. E.; VAN FOSSEN, G. J.; DE WITT, K. J. Convective Heat Transfer Measurements from a NACA 0012 Airfoil in Flight and in the NASA Lewis Icing Research Tunnel. Cleveland: National Aeronautics and Space Agency, 1990. 17 p. (Technical Memorandum, 102448).

RUFF, G. A.; BERKOWITZ, B. M. Users Manual for the NASA Lewis Ice Accretion Prediction Code (LEWICE). Cleveland: National Aernautics and Space Administration, 1990. 240 p. (Contractor Report, 185129).

SCHLITING, H. Experimental Investigation of the Problem of Surface Roughness. Washington, D.C., April 1937. (Technical Memorandum n.823).

SHIN, J.; BOND, T. H. Repeatability of ice shapes in the nasa lewis icing research tunnel. Journal of Aircraft, v. 31, n. 5, p. 1057-63, Set-Out 1994.

SHIN, J.; CHEN, H. H.; CEBECI, T. A Turbulence Model for Iced Airfoils and Its Validation. Washington: National Aeronautics and Space Administration, 1992. 18 p. (Technical Memorandum, 105373).

SILVA, G. A. L. Modelagem e simulação da operação de sistema antigelo eletrotérmico de um aerofólio. Dissertação (Mestrado) — Escola Politécnica da Universidade de São Paulo, São Paulo, SP, Brazil, April 2002.

SMITH, A. G.; SPALDING, D. B. Heat transfer in a laminar boundary layer with constant fluid properties and constant wall temperature. Journal of the Royal Aeronautical Society, v. 62 , p. $60-64,1958$.

SPALDING, D. B. Heat transfer from surfaces of non-uniform temperature. Journal of Fluid Mechanics, n. 4, p. 22-32, 1958.

STEFANINI, L. M. et al. Convective heat transfer effects in airfoil icing. In: $19 \mathrm{TH}$ INTERNATIONAL CONGRESS OF MECHANICAL ENGINEERING. Procedings of $C O B E M$ 200\%. Rio de Janeiro: Brazilian Society of Mechanical Sciences and Engineering, 2007. 
STEFANINI, L. M. et al. Boundary-layers integral analysis - airfoil icing. In: AEROSPACE SCIENCES MEETING AND EXHIBIT, 46th, 2008, Reno. AIAA Paper 2008-0474. Reston: American Institute of Aeronautics and Astronautics, 2008.

THWAITES, B. (Ed.). Incompressible Aerodynamics: An account of the theory and observation of the steady flow of incompressible fluid past aerofoils, wings, and other bodies. 1. ed. New York: Dover Publications Inc., 1960.

WHITE, F. M. Viscous Fluid Flow. 2a. ed. New York: McGraw-Hill, 2000.

WRIGHT, W.; GENT, R.; GUFFOND, D. DRA/NASA/ONERA Collaboration on Icing Research Part II - Prediction of Airfoil Ice Accretion. Cleveland: National Aeronautics and Space Administration, 1997. 50 p. (Contractor Report,202349).

WRIGHT, W. B. NASA CR. User Manual for the Improved NASA Lewis Ice Accretion Code LEWICE 1.6. Cleveland: National Aeronautics and Space Administration, 1995. 95 p. (Contractor Report, 198355).

WRIGHT, W. B. User Manual for the NASA Glenn Ice Accretion Code LEWICE Version 2.0. Cleveland: National Aeronautics and Space Administration, 1999. 181 p. (Contractor Report, 209409).

WRIGHT, W. B.; CHUNG, J. Correlation between geometric similarity of ice shapes and the resulting aerodynamic performance degradation - a preliminary investigation using wind. In: AMERICAN INSTITUTE OF AERONAUTICS AND ASTRONAUTICS. AIAA 2000 0097. Reno, Nevada, EUA, 2000.

WRIGHT, W. B.; RUTKOWSKI, A. Validation Results for LEWICE 2.0. ., January 1999. ZIERTEN, T.; KHODADOUST, A. Effects of wing simulated ground frost on aircraft performance. In: . (Ed.). VKI Lecture Series. .: [s.n.], 1987. cap. . 